\title{
The 2014 Annual Report for the Hawailan Volcano Observatory
}

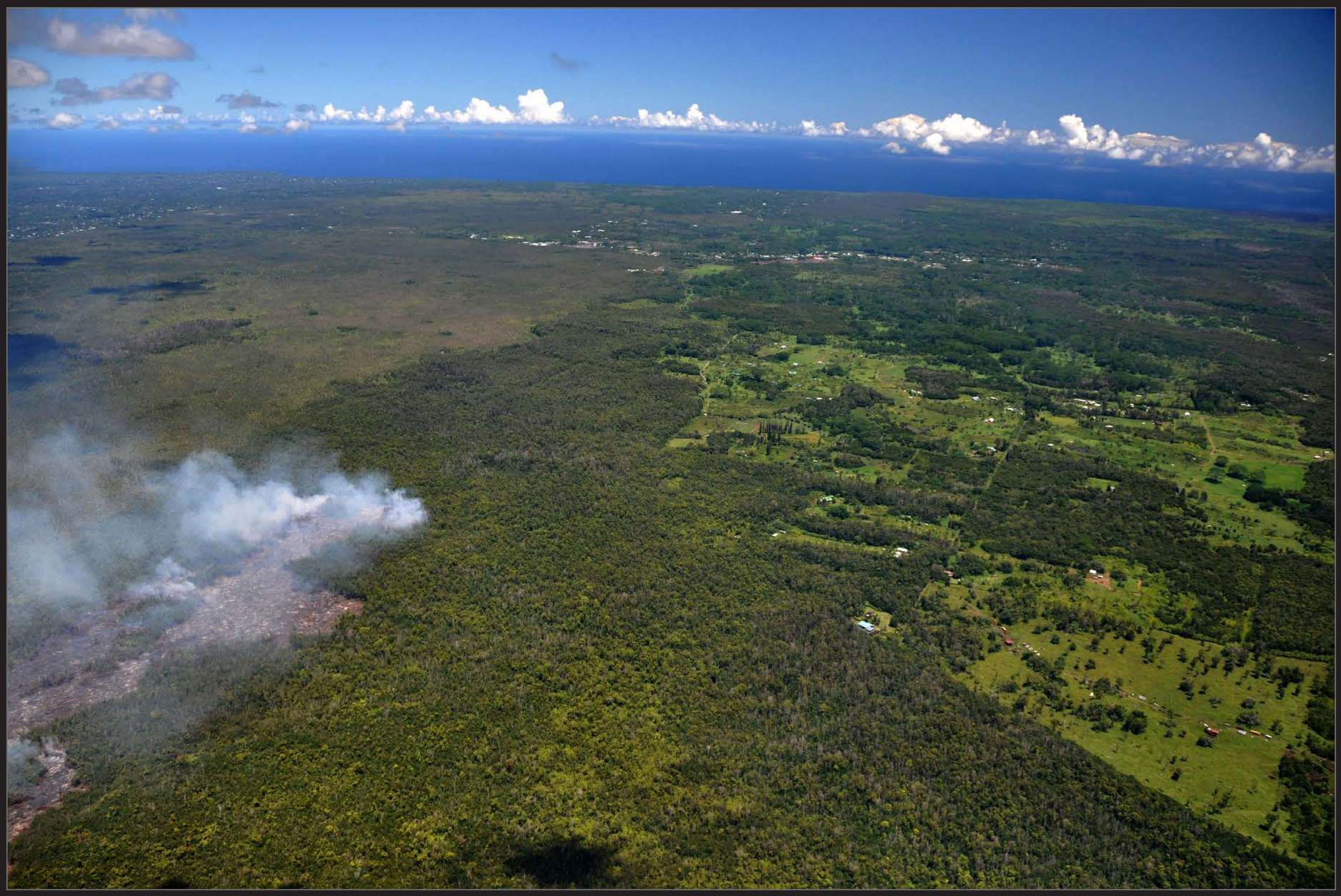

Scientific Investigations Report 2016-5059 
Cover. The June 27th lava flow advancing toward the town of Pāhoa (the cluster of structures straight ahead of the flow). Also shown are Kaohe Homesteads to the immediate right of the flow and the Paradise Park subdivision in the upper left. Photo taken on September 12,2014 by Mike Poland. 


\section{The 2014 Annual Report for the Hawailan Volcano Observatory}

Compiled by Jim Kauahikaua

Chapter A

Introduction to the 2014 Annual Report for the Hawaiian Volcano

Observatory

By Jim Kauahikaua

Chapter B

Kīlauea Geology

By Tim Orr and Matt Patrick

Chapter C

Seismology

By Wes Thelen and Matt Burgess

Chapter D

Deformation

By Asta Miklius, Michael Poland, Kyle Anderson, and Loren Antolik

Chapter E

Gas Geochemistry

By Tamar Elias, Jeff Sutton, Christoph Kern, and Cindy Werner

Scientific Investigations Report 2016-5059

U.S. Department of the Interior

U.S. Geological Survey 


\section{U.S. Department of the Interior SALLY JEWELL, Secretary}

\section{U.S. Geological Survey \\ Suzette M. Kimball, Director}

\section{U.S. Geological Survey, Reston, Virginia: 2016}

For more information on the USGS—-the Federal source for science about the Earth, its natural and living resources, natural hazards, and the environment-visit http://www.usgs.gov/ or call (1-888-275-8747).

For an overview of USGS information products, including maps, imagery, and publications, visit http://www.usgs.gov/pubprod/.

Any use of trade, firm, or product names is for descriptive purposes only and does not imply endorsement by the U.S. Government.

Although this information product, for the most part, is in the public domain, it also may contain copyrighted materials as noted in the text. Permission to reproduce copyrighted items must be secured from the copyright owner.

Suggested citation:

Hawaiian Volcano Observatory staff, and Jim Kauahikaua, compiler, 2016, The 2014 annual report for the Hawaiian Volcano Observatory: U.S. Geological Survey Scientific Investigations Report 2016-5059, 65 p., http://dx.doi.org/10.3133/sir20165059.

ISSN 2328-0328 (online) 


\section{Contents}

\section{Chapter A-Introduction to the 2014 Annual Report for the Hawaiian Volcano Observatory}

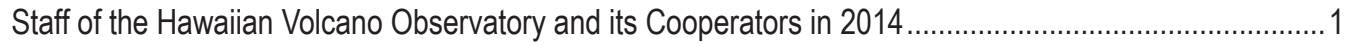

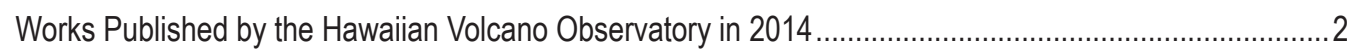

\section{Chapter B-Kīlauea Geology}

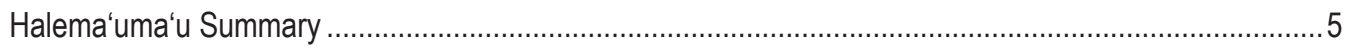

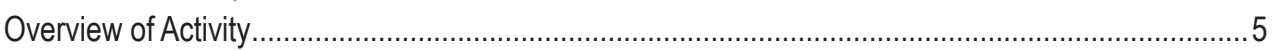

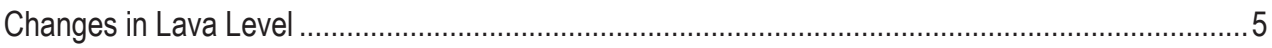

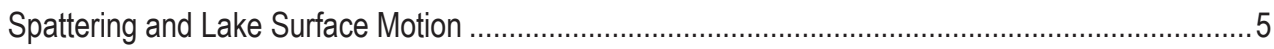

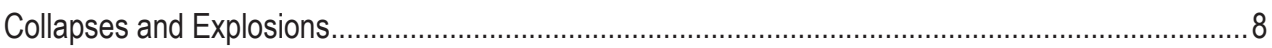

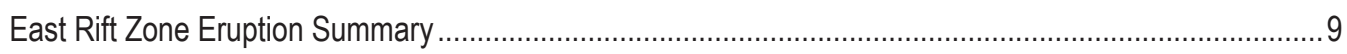

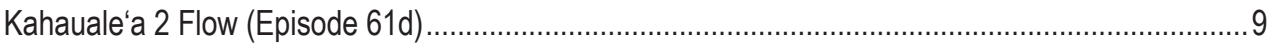

Pu'u 'Ō'ō Activity During the K2 Flow ........................................................................................

June 27th Breakout and Flow .............................................................................................. 10

Pu'u 'Ō'ō's 'Response to the June 27th Flow ........................................................................ 13

Appendix B-1. Kīlauea summit eruption statistics for 2008-2014 ..................................................................... 13

Dates of Important Events .............................................................................................. 13

Other Interesting Facts ................................................................................................... 13

Appendix B-2. Kīlauea East Rift Zone Eruption Statistics for 1983-2014 ................................................... 14

Miscellaneous statisitics and Fascinating Facts ................................................................ 14

\section{Chapter C-Seismology}

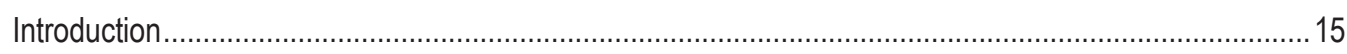

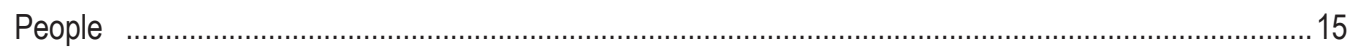

The Second Great Hawaii Shakeout ................................................................................................ 15

Earthquake Early Warning Assessment in Hawaii................................................................................ 15

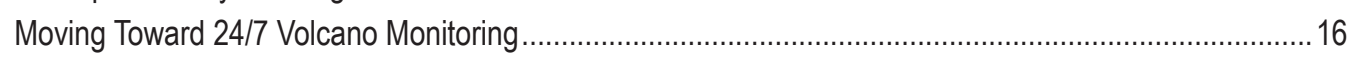

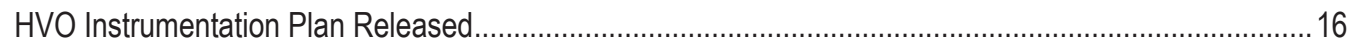

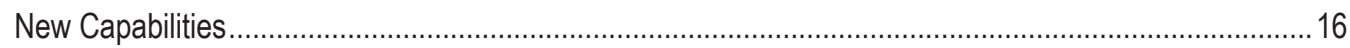

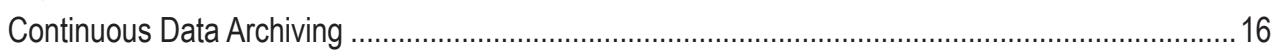

Firmware Upgrades Improve Data Continuity...................................................................... 16

Kīlauea Summit Broadband Upgrade Commences ................................................................ 16

Automated Tremor Detection and Location ....................................................................... 16

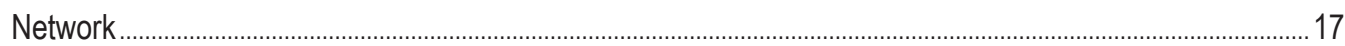

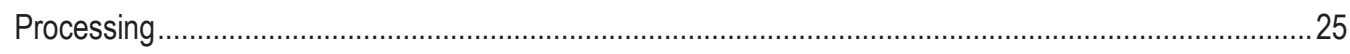

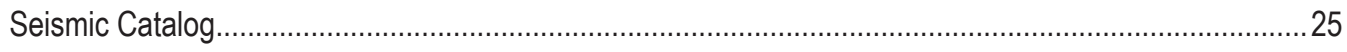

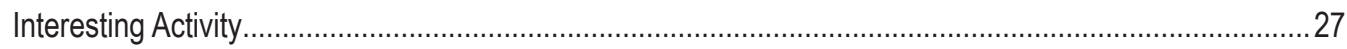




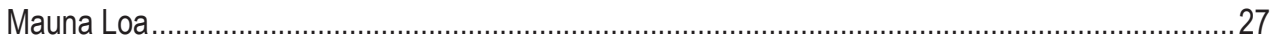

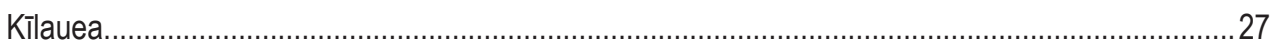

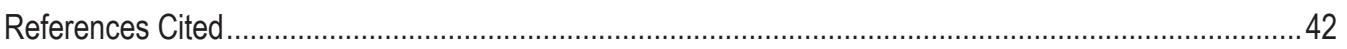

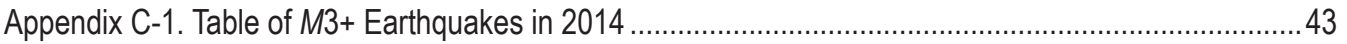

\section{Chapter D-Deformation}

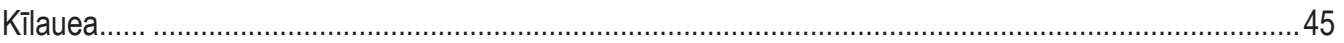

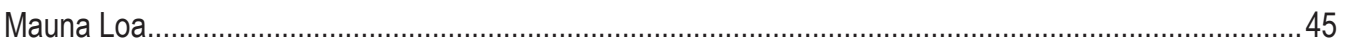

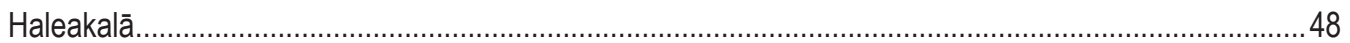

\section{Chapter E-Gas Geochemistry}

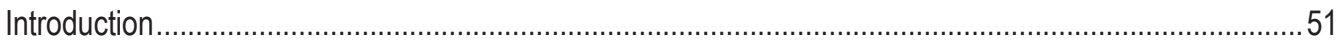

Kīlauea Summit Gas Emission Rate Measurements................................................................ 51

FLYSPEC Array: Measuring a More Dispersed and Optically Thin Plume .....................................51

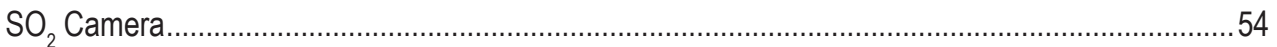

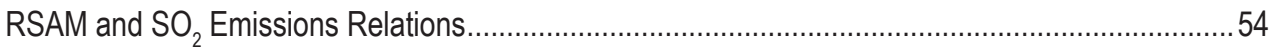

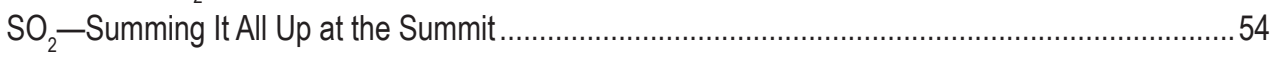

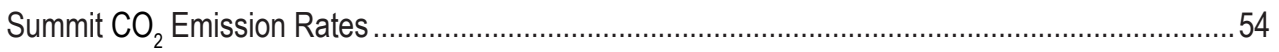

Quantifying Summit Plume Characteristics .....................................................................................59

East Rift Zone $\mathrm{SO}_{2}$ Emissions: Summit Pre-Eruptive Degassing Produces Lower Emissions from East

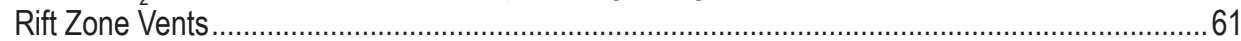

Gas-Derived East Rift Zone Lava Effusion Rates................................................................6 61

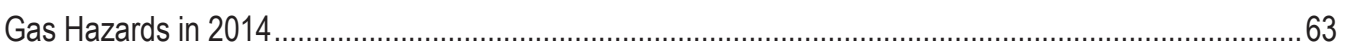

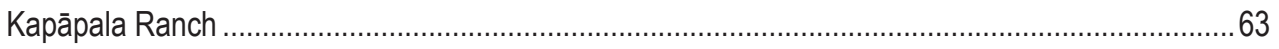

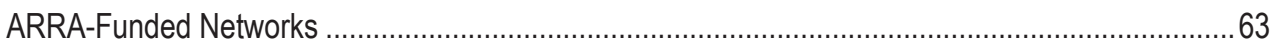

Highlights from Air-Quality-Related Activities in Hawai'i Volcanoes National Park ............................63

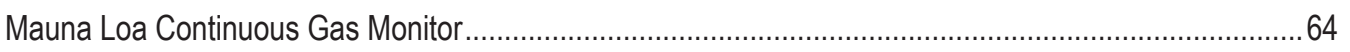

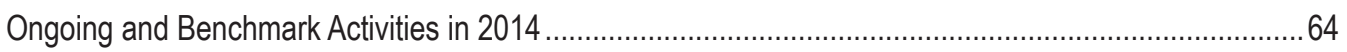

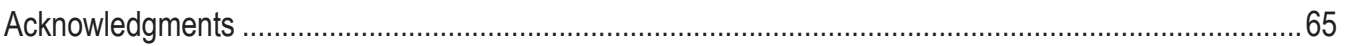

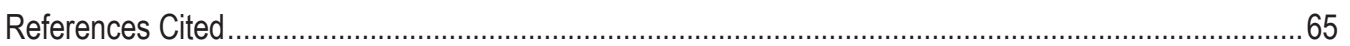




\section{Figures}

\section{Chapter B-Kïlauea Geology}

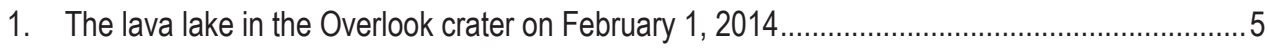

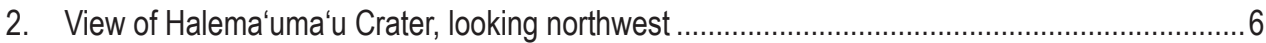

3. Selected thermal webcam (HTcam) images of the summit lava lake ....................................... 6

4. Comparison of summit lava lake level and radial tilt at station UWE for $2014 \ldots \ldots \ldots \ldots \ldots \ldots \ldots \ldots . . . . . .77$

5. View of the Overlook crater, looking east, showing spattering along the east lake margin .........8 8

6. The July 23,2014 , explosion in the Halema'uma'u lava lake .............................................. 8

7. Map showing changes to the Kahauale'a 2 flow field from December 26, 2013 until its

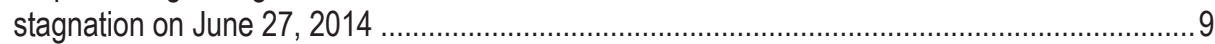

8. Oblique aerial photographs showing Pu'u 'Ō'ō before and after the June 27, 2014, eruption.....9

9. Oblique aerial photographs showing channelized flow at start of June 27 th eruption, and perched lava pond formed over fissure D of June 27th eruption ...........................................10

10. Oblique aerial photograph showing the ground cracks and lava pads near the True/Mid-Pacific geothermal well site on September 6, 2014.

11. Oblique aerial photograph showing the flow on October 31, after it stalled on Sugimoto's property, $155 \mathrm{~m}$ upslope from Pāhoa Village and before reaching Lee's property .................... 11

12. Oblique aerial photograph showing flow upslope from Pahoa Marketplace on December 30, 2014. 12

13. Four maps showing the progress of the June 27 th lava flow during the last 6 months of $2014 \ldots .12$

\section{Chapter C-Seismology}

1. Map of seismic stations operated by the Hawaiian Volcano Observatory .................................18

2. Map of seismic stations around Kīlauea Caldera …................................................... 19

3. Map showing infrasound arrays across the Island of Hawai' i ................................................19

4. Telemetry map of stations maintained by the Hawaiian Volcano Observatory .........................20

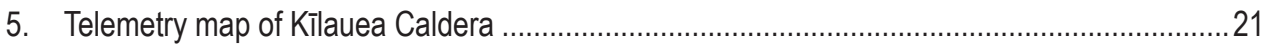

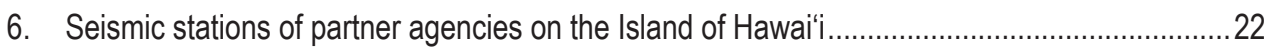

7. Map showing the seismic stations on the lower East Rift Zone ...........................................23

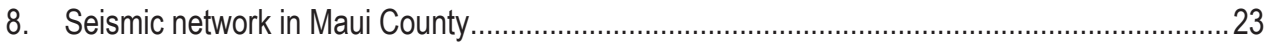

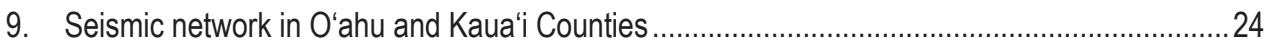

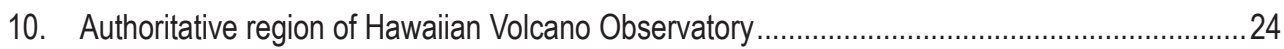

11. Chart of the percentage of earthquakes reviewed with respect to magnitude.........................25

12. Histogram of horizontal and depth positional errors of earthquakes above M0.1 during 2014.. 26

13. Map of earthquake locations in the Hawaiian Islands during 2014, showing earthquakes that were $0-60 \mathrm{~km}$ deep having $M>3.5$.

14. Map of earthquake locations on the Island of Hawaili during 2014, showing earthquakes that

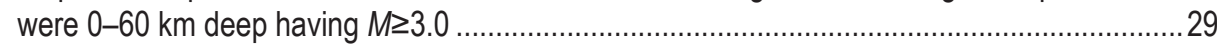

15. Map of earthquake locations on the Island of Hawai'i during 2014 showing shallow ( $0-5 \mathrm{~km}$ deep) earthquakes having $M \geq 2.0$...

16. Map of earthquake locations on the Island of Hawaili during 2014 showing earthquakes of intermediate depth $(5.1-13.0 \mathrm{~km})$ having $M \geq 2.0$.

17. Map of earthquake locations on the Island of Hawai'i during 2014 showing deep earthquakes (13.1-60.0 km) having $M \geq 2.0$. 
18. Map of earthquake locations at the Kïlauea summit during 2014 showing shallow earthquakes (0-5.0 km deep) having $M \geq 1.0$.

19. Map of earthquake locations at Killauea summit during 2014 showing earthquakes of intermediate depth (5.1-13.0 km) having $M \geq 1.0$. 34

20. Map of earthquake locations at Kīlauea summit during 2014 showing deep earthquakes (13.1-60.0 km) having $M \geq 1.0$ 35

21. Map of earthquake locations along Kïlauea's East Rift Zone and south flank during 2014 showing shallow earthquakes $(0-5.0 \mathrm{~km})$ having $M \geq 2.0$. 36

22. Map of earthquake locations along Kïlauea's East Rift Zone and south flank during 2014 showing earthquakes of intermediate depth (5.1-13.0 km) having $M \geq 2.0$..

23. Map of earthquake locations along Kïlauea's East Rift Zone and south flank during 2014 showing deep earthquakes (13.1-60.0 km) having $M \geq 2.0$.

24. Map of earthquake locations near the Mauna Loa summit during 2014 showing shallow earthquakes $(0-5.0 \mathrm{~km})$ having $M \geq 2.0$.

25. Map of earthquake locations near the Mauna Loa summit during 2014 showing earthquakes of intermediate depth (5.1-13.0 km) having $M \geq 2.0$...

26. Map of earthquake locations near the Mauna Loa summit during 2014 showing deep earthquakes (13.1-60.0 km) having $M \geq 2.0$.

\section{Chapter D-Deformation}

1. Radial tilt measured by borehole instruments at the summit (station code UWE) and at Pu'u 'Ō'ō (station code POC) during 2014

2. Changes in position of the GPS site near the north rim of Pu'u 'Ō'ō crater in 2014 ......

3. Changes in distance across Halema'uma'u and elevation of selected Kïlauea summit GPS stations in 2014

4. Changes in distance across Halema'uma'u and elevation of selected Kīlauea summit GPS stations from 2009 through 2014

5. GPS data from selected continuously recording GPS sites on Mauna Loa Volcano.

6. COSMO-SkyMed (COnstellation of small Satellites for the Mediterranean basin Observation) ascending-mode interferogram of Mauna Loa spanning January 26-December 28, 2014 ....... 48

7. COSMO-SkyMed ascending-mode interferograms of Mauna Loa's summit region showing two periods of inflation..

8. Preliminary modeling of deformation sources on Mauna Loa.

\section{Chapter E-Gas Geochemistry}

1. Daily average $\mathrm{SO}_{2}$ emissions from the summit of Kilauea, 2007-2014

2. Modeled $\mathrm{SO}_{2}$ emission-rate data (using the SRT-DOAS algorithm) versus FLYSPEC dual fit window (DFW) SO emission-rate data for the period 2008-2014 .....................................52

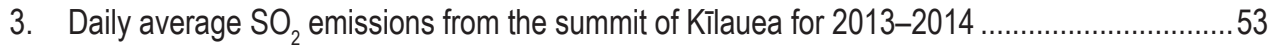

4. $\mathrm{SO}_{2}$ emissions from the summit of Kïlauea for October-December 2014 as measured by the $\mathrm{SO}_{2}$ camera and the FLYSPEC array

5. Kîlauea summit real-time seismic amplitude (RSAM) and $\mathrm{SO}_{2}$ during transitions in lava lake activity

6. The upper time-series plot shows summit $\mathrm{SO}_{2}$ emissions estimated using the FLYSPEC array and the real-time seismic amplitude measurement (RSAM) on May 12, 2014. The lower graph shows correlation between $\mathrm{SO}_{2}$ emission rate measurements and real-time seismic amplitude measurements (RSAM) 
7. The upper time-series plot shows summit $\mathrm{SO}_{2}$ emissions estimated using the FLYSPEC array and the real-time seismic amplitude measurement (RSAM) on December 11, 2014. The lower graph shows correlation between $\mathrm{SO}_{2}$ emission rate measurements and $\mathrm{RSAM}$....................57

8. $\mathrm{CO}_{2}$ emission rates in metric tonnes per day from the summit of Kīlauea for 2003 to 2014 ....58

9. Eddy correlation instrument in mobile mode.................................................................. 58

10. Jeff Sutton and Cindy Werner measuring ambient gas concentrations using the multi-gas system designed and fabricated at the Cascades Volcano Observatory

11. Preliminary FTIR (Fourier-transform infrared spectrometer) results for measurements of the summit gas plume at Kïlauea, June 22, 2014

12. An overview of eruptive gas composition (during 2008-2014, along with two earlier samples from 1968 and 1983) for rift and summit degassing sources......

13. Daily average $\mathrm{SO}_{2}$ emissions for the years 2013 and 2014 as measured along Chain of Craters Road under trade-wind conditions.

14. Lava effusion rates for 2011-2014 calculated using estimated $\mathrm{CO}_{2}$ weight fraction dissolved in melt, historical $\mathrm{C} / \mathrm{S}$ ratio data, and $\mathrm{SO}_{2}$ emission rates.

15. Lava effusion rate calculated using an estimated $\mathrm{CO}_{2}$ weight fraction of 0.017 percent dissolved in melt, a range of C/S ratio data, and $\mathrm{SO}_{2}$ emission rate for 2014

16. Ambient $\mathrm{SO}_{2}$ concentrations measured on the west edge of the Halema'uma'u parking lot during the final quarter of 2014

17. Number of days each year that the 24-hour ambient air quality standard was exceeded at the Jaggar Museum and Kïlauea Visitor Center monitoring stations, both located at the Kīlauea summit

\section{Tables}

\section{Chapter C-Seismology}

1. Number of stations in each network whose data are collected by the Hawaiian Volcano Observatory 17

2. Velocity model used for earthquake locations

\section{Chapter D-Deformation}

1. Carbon-Sulfur ratios from the summit and Pưu 'Ō'ō vent, Kīlauea Volcano 



\title{
Chapter A
}

\section{Introduction to the 2014 Annual Report for the Hawaiian Volcano Observatory}

\author{
By Jim Kauahikaua
}

This report summarizes team activities and findings of the Hawaiian Volcano Observatory during the year 2014 in geology, geodesy, seismicity, and gas geochemistry. The eruption of $\mathrm{Pu}^{\prime} \mathrm{u}^{\prime} \mathrm{C}^{\prime} \mathrm{o}$ continued into its 32 nd year with flows active to the northeast of the vent. One of them, the June 27th lava flow, named for the date in 2014 that the flow started, advanced far and fast enough to threaten the town of Pāhoa and Highway 130 in the Puna District of the Island of Hawai' $i$. In response, the alert level for Killauea was elevated from WATCH to WARNING on September 4, followed by the declaration of a State Disaster on September 5 and a National Disaster on November 3.

During 2014, renewed inflation and increased seismicity were detected beneath Mauna Loa. Although above background, the frequency and magnitude of the earthquakes remained at such low levels that, by year's end, the four-tier alert level code for Mauna Loa remained at its lowest level-NORMAL. These changes were discussed in several Volcano Watch articles.

Hualālai, Haleakalā, Mauna Kea, and Lo'îhi showed no signs of unrest during the year.

\section{Staff of the Hawaiian Volcano Observatory and its Cooperators in 2014}

Jim Kauahikaua, Scientist-in-Charge

Steve Brantley, Deputy Scientist-in-Charge

Jane Taeko Takahashi, archivist/librarian

Janet Babb, outreach, media

Pauline Fukunaga, administrative technician

Marian Kagimoto, administrative technician

Lopaka Lee, IT network manager

Bill Million, facilities manager

Kevan Kamibayashi, technical support manager

C.J. Moniz, physical science technician

Bruce Furukawa, electronics technician

Steven Fuke, electronics technician

Tim Orr, geologist

Matt Patrick, research geologist

Don Swanson, research geologist
Frank Trusdell, geologist

Jeff Sutton, research chemist

Tamar Elias, chemist

Asta Miklius, geodetic network manager

Mike Poland, research geodesist

Loren Antolik, physical science technician

Kyle Anderson, geodesy Mendenhall Fellow

Wes Thelen, seismic network manager

Matt Burgess, seismic analyst

Paul Okubo, research seismologist

Bill Tollett, University of Hawai' $i$ at Hilo software engineer

Kanani Pali, summer intern

Greg Javar, summer intern

Carolyn Parcheta, University of Hawai'i at Manoa student 


\section{Works Published by the Hawaiian Volcano Observatory in 2014}

Bagnardi, M., Poland, M.P., Carbone, D., Baker, S., Battaglia, M., and Amelung, F., 2014, Gravity changes and deformation at Kîlauea Volcano, Hawaii, associated with summit eruptive activity, 2009-2012: Journal of Geophysical Research Solid Earth, v. 119, p. 7,288-7,305.

Chen, J., Zebker, H.A., Segall, P., and Miklius, A., 2014, The 2010 slow slip event and secular motion at Kīlauea, Hawai' $i$, inferred from TerraSAR-X InSAR data: Journal of Geophysical Research Solid Earth, v. 119, p. 6,667-6,683.

Eychenne, J., Houghton, B.F., Swanson, D.A., Carey, R.J., and Swavely, L., 2014, Dynamics of an open basaltic magma system - The 2008 activity of the Halema'uma'u Overlook vent, Kîlauea Caldera: Earth and Planetary Science Letters, v. 409 , p. $49-60$.

Kauahikaua, J., and Tilling, R.I., 2014, Natural hazards and risk reduction in Hawai'i, chap. 10 of Poland, M.P., Takahashi, T.J., and Landowski, C.M., eds., Characteristics of Hawaiian volcanoes: U.S. Geological Survey Professional Paper 1801, p. 397-427. [Also available at http://pubs.usgs.gov/pp/1801/.]

Kauahikaua, J., and Orlando, C., 2014, Interagency collaboration on an active volcano; A case study at Hawai' $i$ Volcanoes National Park, in Santucci, V.L., ed., NPS-USGS collaboration to support science and resource management in the national parks: The George Wright Forum, v. 31, no. 2, p. 149-156, accessed Sept. 2, 2014, at http:/www.georgewright.org/ node/ 9643 .

Kern C., Sutton J., Elias T., Lee L., Kamibayashi K., Antolik L., Werner C., 2014, An automated $\mathrm{SO}_{2}$ camera system for continuous, real-time monitoring of gas emissions from Kīlauea Volcano's summit Overlook Crater: Journal of Volcanology and Geothermal Research, v. 300, p. 81-94, doi: 10.1016/j. jvolgeores.2014.12.004.

Klawonn, M., Houghton, B.F., Swanson, D.A., Fagents, S.A., Wessel, P., and Wolfe, C.J., 2014, Constraining explosive volcanism; subjective choices during estimates of eruption magnitude: Bulletin of Volcanology, v. 76, 793, 6 p.

Klawonn, M., Houghton, B.F., Swanson, D.A., Fagents, S.A., Wessel, P., and Wolfe, C.J., 2014, From field data to volumesconstraining uncertainties in pyroclastic eruption parameters: Bulletin of Volcanology, v. 76, 839, 16 p.

Lin, G., Amelung, F., Lavallée, Y., and Okubo, P.G., 2014, Seismic evidence for a crustal magma reservoir beneath the upper east rift zone of Kilauea volcano, Hawaii: Geology, v. 42, p. $187-190$.
Lin, G., Shearer, P.M., Matoza, R.S., Okubo, P.G., and Amelung, F., 2014, Three-dimensional seismic velocity structure of Mauna Loa and Kilauea volcanoes in Hawaii from local seismic tomography: Journal of Geophysical Research Solid Earth, v. 119, p. $4377-4392$.

Mangan, M.T., Cashman, K.V., and Swanson, D.A., 2014, The dynamics of Hawaiian-style eruptions - A century of study, chap. 8 of Poland, M.P., Takahashi, T.J., and Landowski, C.M., eds., Characteristics of Hawaiian volcanoes: U.S. Geological Survey Professional Paper 1801, p. 323-354. [Also available at http://pubs.usgs.gov/pp/1801/.]

Matoza, R.S., Shearer, P.M., and Okubo, P.G., 2014, Highprecision relocation of long-period events beneath the summit region of Kîlauea Volcano, Hawai' $i$, from 1986 to 2009: Geophysical Research Letters, v. 41, p. 3413-3421.

Okubo, P.G., Nakata, J.S., and Koyanagi, R.Y., 2014, The evolution of seismic monitoring systems at the Hawaiian Volcano Observatory, chap. 2 of Poland, M.P., Takahashi, T.J., and Landowski, C.M., eds., Characteristics of Hawaiian volcanoes: U.S. Geological Survey Professional Paper 1801, p. 67-94. [Also available at http://pubs.usgs.gov/pp/1801/.]

Orr, T.R., 2014, The June-July 2007 collapse and refilling of Pu'u 'Ō'ō Crater, Kīlauea Volcano, Hawai'i: U.S. Geological Survey Scientific Investigations Report 2014-5124, 15 p. [Available at http://pubs.usgs.gov/sir/2014/5124/.]

Patrick, M.R., and Delparte, D., 2014, Tracking dramatic changes at Hawaii's only alpine lake: Eos [Transactions of the American Geophysical Union], v. 95, no. 14, p. 117-118.

Patrick M.R., Orr T., Antolik L., Lee L., and Kamibayashi K., 2014, Continuous monitoring of Hawaiian volcanoes with thermal cameras: Journal of Applied Volcanology, v. 3, no. 1, $19 \mathrm{p}$.

Pinel, V., Poland, M.P., and Hooper, A., 2014, VolcanologyLessons learned from synthetic aperture radar imagery: Journal of Volcanology and Geothermal Research, v. 289, p. 81-113.

Poland, M.P., 2014a. Contrasting volcanism in Hawai'i and the Galápagos, in Harpp, K.S., Mittelstaedt, E., d'Ozouville, N., and Graham D.W., eds., The Galápagos - A Natural Laboratory for the Earth Sciences: American Geophysical Union, Geophysical Monograph, v. 204, p. 5-26.

Poland, M.P., and Orr, T.R., 2014, Identifying hazards associated with lava deltas: Bulletin of Volcanology, v. 76, 880, 10 p.

Poland, M.P., Miklius, A., and Montgomery-Brown, E.K., 2014, Magma supply, storage, and transport at shield-stage Hawaiian volcanoes, chap. 5 of Poland, M.P., Takahashi, T.J., and Landowski, C.M., eds., Characteristics of Hawaiian volcanoes: U.S. Geological Survey Professional Paper 1801, p. 179-234. [Also available at http://pubs.usgs.gov/pp/1801/.] 
Poland, M.P., Takahashi, T.J., and Landowski, C.M., eds., 2014, Characteristics of Hawaiian volcanoes: U.S. Geological Survey Professional Paper 1801, 429 p. [Also available at http://pubs. usgs.gov/pp/1801/.]

Poland, M.P., 2014b, Time-averaged discharge rate of subaerial lava at Kīlauea Volcano, Hawai'i, measured from TanDEM-X interferometry - Implications for magma supply and storage during 2011-2013: Journal of Geophysical Research Solid Earth, v. 119, p. 5464-5481.

Segall, P., and Anderson, K., 2014, Volcanology—Look up for magma insights: Nature Geoscience, v. 7, no. 3, p. 168-169, doi:10.1038/ngeo2064.

Sides, I., Edmonds, M., Maclennan, J., Houghton, B.F., Swanson, D.A., and Steele-MacInnis, M.J., 2014, Magma mixing and high fountaining during the 1959 Killauea Iki eruption, Hawai' $i$ : Earth and Planetary Science Letters, v. 400, p. 102-112.

Sides, I. R., Edmonds, M., Maclennan, J., Swanson, D.A., and Houghton, B. F., 2014, Eruption style at Kỉlauea Volcano in Hawai' $i$ linked to primary melt composition: Nature Geoscience, v. 7, p. 464-469.

Sutton, A.J., and Elias, T., 2014, One hundred volatile years of volcanic gas studies at the Hawaiian Volcano Observatory, chap. 7 of Poland, M.P., Takahashi, T.J., and Landowski, C.M., eds., Characteristics of Hawaiian volcanoes: U.S. Geological Survey Professional Paper 1801, p. 295-320. [Also available at http://pubs.usgs.gov/pp/1801/.]
Swanson, D.A., Rose, T.R., Mucek, A.E., Garcia, M.O., Fiske, R.S., and Mastin, L.G., 2014, Cycles of explosive and effusive eruptions at Kîlauea Volcano, Hawai'i: Geology, v. 42, p. 631-634.

Swanson, D.A., Weaver, S.J., and Houghton, B.F., 2014, Reconstructing the deadly eruptive events of $1790 \mathrm{CE}$ at Kīlauea Volcano, Hawai'i: Geological Society of America Bulletin, doi:10.1130/B31116.1.

Thelen, W.A., 2014, Seismic instrumentation plan for the Hawaiian Volcano Observatory: U.S. Geological Survey Scientific Investigations Report 2014-5179, 43 p. [Available at http://pubs.usgs.gov/sir/2014/5179/.]

Tilling, R.I., Kauahikaua, J., Brantley, S.R., and Neal, C.A., 2014, The Hawaiian Volcano Observatory-A natural laboratory for studying basaltic volcanism, chap. 1 of Poland, M.P., Takahashi, T.J., and Landowski, C.M., eds., Characteristics of Hawaiian volcanoes: U.S. Geological Survey Professional Paper 1801, p. 1-64. [Also available at http://pubs.usgs.gov/pp/1801/.]

Wauthier, C., Cayol, V., Poland, M., Kervyn, F., D’Oreye, N., Hooper, A., Samonsov, S., Tiampo, K., and Smets, B., 2014, Nyamulagira's magma plumbing system inferred from 15 years of InSAR, in Pyle, D.M., Mather, T.A., and Biggs, J., eds., Remote sensing of volcanoes and volcanic processesIntegrating observation and modelling: Geological Society of London Special Publication 380, 27 p. 



\title{
Chapter B
}

\section{Kïlauea Geology}

\author{
By Tim Orr and Matt Patrick
}

\section{Halema'uma‘u Summary}

\section{Overview of Activity}

Kîlauea's summit lava lake (figs. 1-3) was relatively steady throughout 2014, with no major changes in activity. The lava level ranged between 30 and $75 \mathrm{~m}$ below the floor of Halema'uma' $u$ Crater and tracked summit tilt (fig. 4). The lake surface consisted of black crustal plates separated by narrow incandescent cracks, and the plates normally moved from north to south.

Small collapses occasionally occurred in the crater, often involving sections of the lava veneer (sometimes building an inner ledge) that fell from the crater walls into the lake when the lake level dropped during large deflation-inflation (DI) events. Relatively small collapses of the Overlook crater rim and upper wall occurred sporadically throughout the year, producing minor enlargement of the Overlook crater dimensions. Based on a structure-from-motion model built from overflight images captured on December 18, 2014, the Overlook crater size was $220 \mathrm{~m}$ by $170 \mathrm{~m}$, which is only a minor enlargement (about 4 percent, in terms of linear distance) since the last lidar measurement on December 17, 2013 (when the Overlook crater was about $212 \mathrm{~m}$ by $164 \mathrm{~m}$ ). The $220 \mathrm{~m}$ dimension is measured from the northwest rim to the southeast rim, below the Halema'uma'u Overlook, where the rim is irregular and overhanging; thus the measurement is slightly subjective. Adding the extra span beneath the overhang increases the long axis of the crater to about $225 \mathrm{~m}$.

\section{Changes in Lava Level}

Fluctuations of the level of the lava lake spanned several timescales. Over minutes to hours, gas piston events (driving spattering and non-spattering transitions) caused the lake level to change by a few meters. Over days to weeks, the lava level followed summit tilt closely, and often exhibited changes related to DI events. During June and August, however, there was a DI event that was not expressed by the lava level (fig. 4). This lack of correspondence is unusual and deserves further study. We suspect that it was related to the possible small intrusion that occurred in early May into Kīlauea's upper Southwest Rift Zone, or perhaps an adjustment of the summit to the new East Rift Zone vent elevation for the June 27th flow.

At its lowest, the lava level was $75 \mathrm{~m}$ below the Overlook crater rim, and at its highest it was $30 \mathrm{~m}$ below the rim (fig. 3). Overall, there was no long-term trend to the lava level during 2014.

\section{Spattering and Lake Surface Motion}

Spattering was common in the summit lava lake but could abruptly terminate when the lake entered non-spattering phases. We previously called the non-spattering periods "inactive" phases, with the spattering periods called "active" phases, but "inactive" is a misleading characterization of the lake in this context. As usual, the non-spattering phases corresponded to greatly reduced tremor and a very weak, wispy plume, presumably due to a decrease in lake outgassing.

Observations from the Halema'uma'u Overlook found that rockfalls impacting the lava lake - even those too small to produce an obvious seismic signal — could initiate a transition from a non-spattering to a spattering phase. This shows that

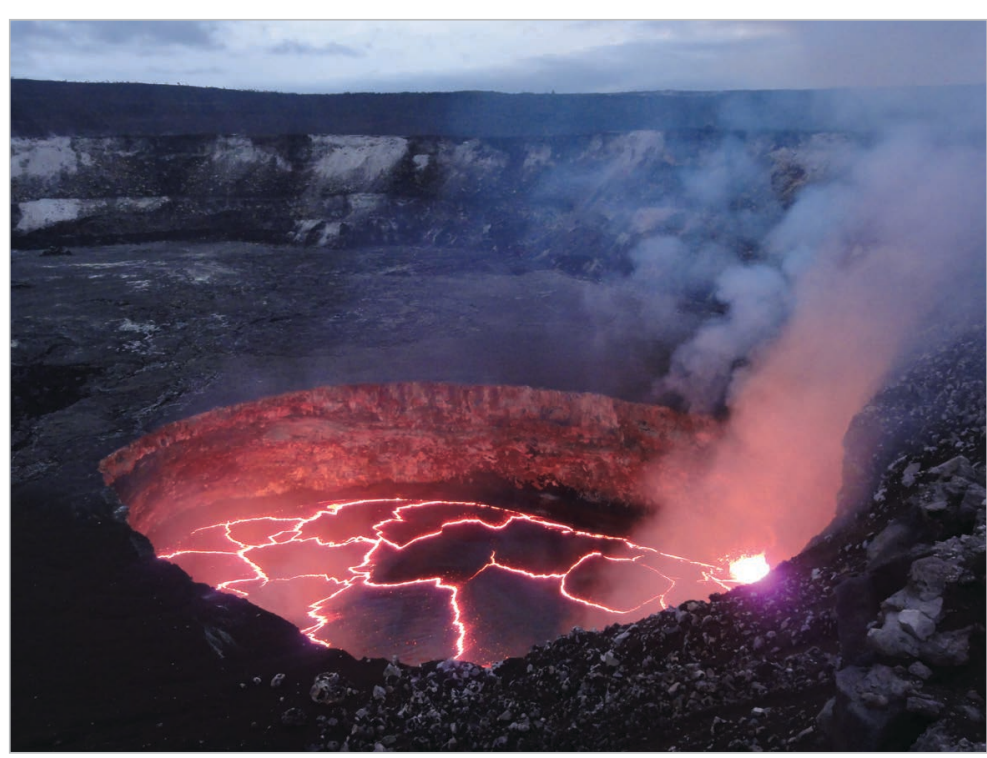

Figure 1. The lava lake in the Overlook crater on February 1, 2014. The lava level is about $50 \mathrm{~m}$ below the Overlook crater rim (that is, below the floor of Halema'uma'u Crater). The bright area shows the common spatter source along the southeast margin of the lake. View to the northwest. USGS photo by M. Patrick. 
Figure 2. View of Halema'uma'u Crater, looking northwest. The Halema'uma'u Overlook crater and lava lake are in the foreground. USGS photo by J. Kauahikaua, September 17, 2014.
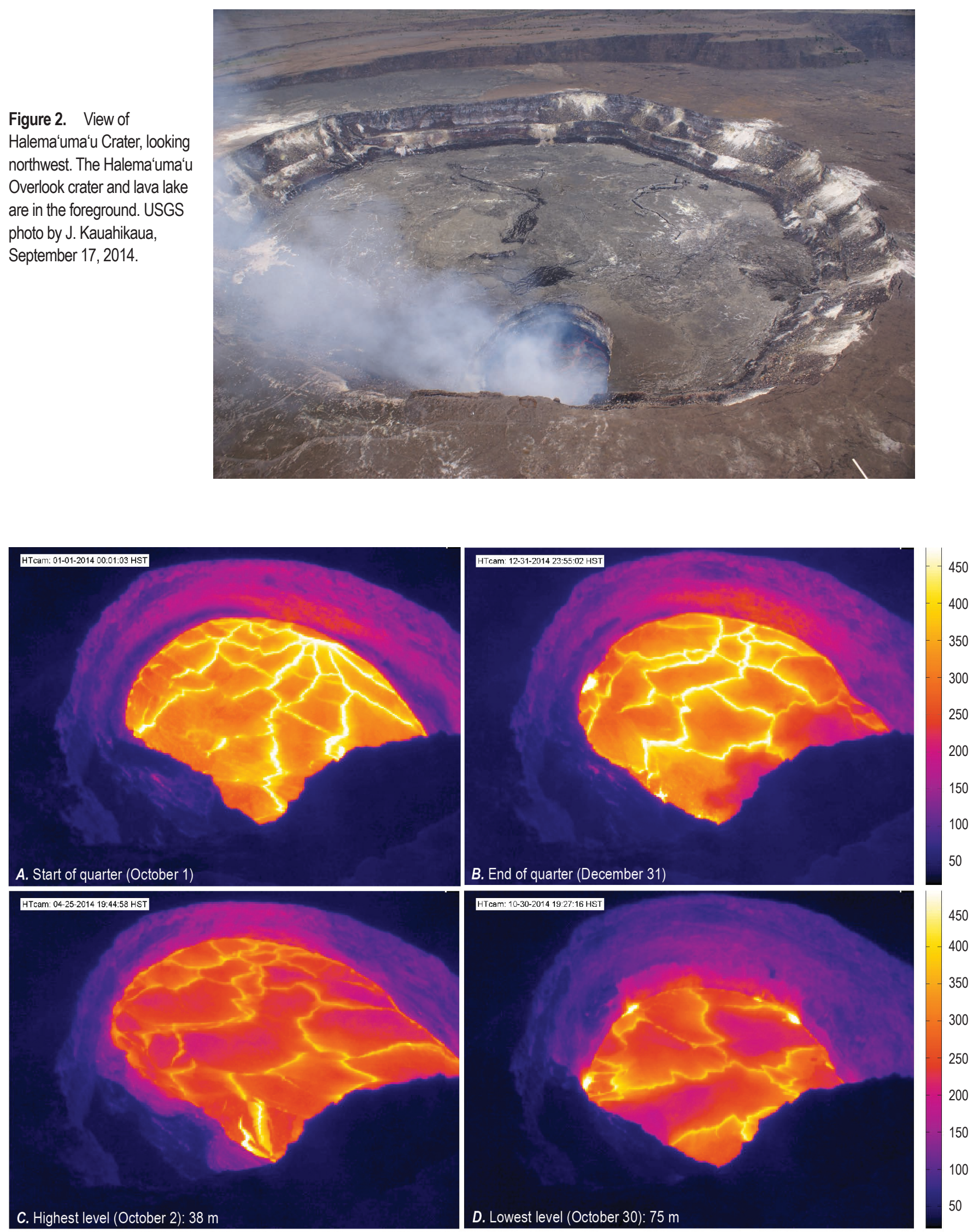

Figure 3. Selected thermal webcam (HTcam) images of the summit lava lake. Thermal scale shows apparent temperature in degrees Celsius. 


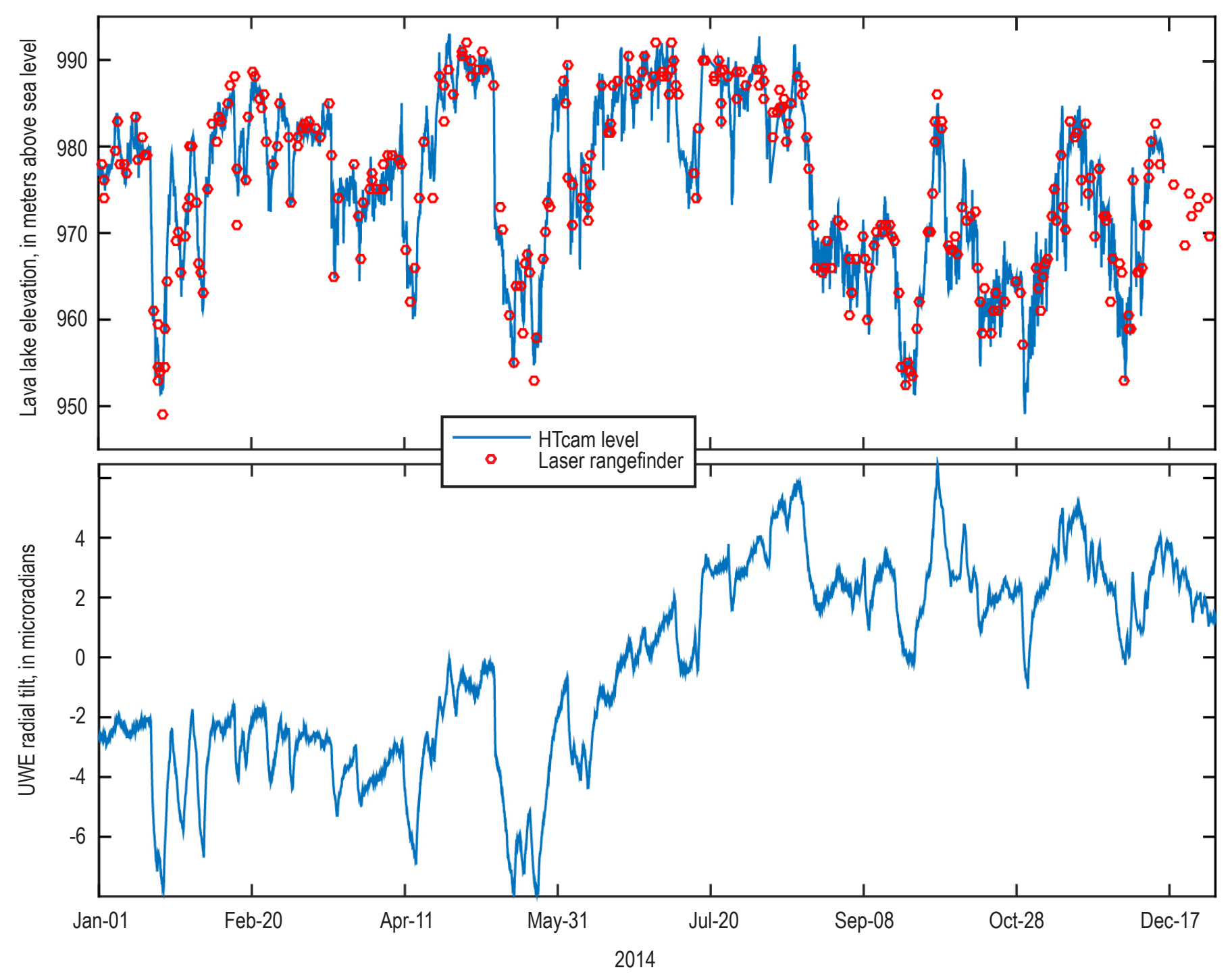

Figure 4. Comparison of summit lava lake level and radial tilt at station UWE for 2014. The blue lava level data represent hourly manual measurements from the HTcam images that have been converted to absolute elevation using laser rangefinder measurements (red dots).

rockfalls, even when too small to be observed or resolved from the seismic records, are nevertheless capable of influencing lava lake dynamics.

During spattering phases, the spatter source was most commonly located along the southeast margin of the lake (fig. 1), but spattering could also appear in other sections of the lake, particularly when lava veneer would collapse into the lake (which was common during dropping lava levels associated with deflation). In all cases, the surface crust in the area around the spattering tended to be drawn towards the spatter source, where it would be consumed and sink.

During 2014, the typical lake surface motion was roughly from north to south (fig. 5). The upwelling area is along the north margin of the lake, as shown by the velocity vectors in figure 5 .
The preponderance of gas slugs to burst through the crust in this general area, perhaps representing gas rising directly from the deeper conduit, also suggests that upwelling occurs mainly on the north margin of the lake. During typical behavior, the lake surface velocity, measured from the geometrically corrected webcam images, was around $0.3 \mathrm{~m} / \mathrm{s}$.

Lake motion sometimes changed, however, based on the location of spattering. For instance, when small collapses of the lava veneer triggered spattering along the north margin, the lake surface motion could completely reverse and could also slow down considerably in the process. The typical behavior was invariably reestablished within minutes to hours, suggesting that these divergences from the usual circulation direction were controlled shallowly. 

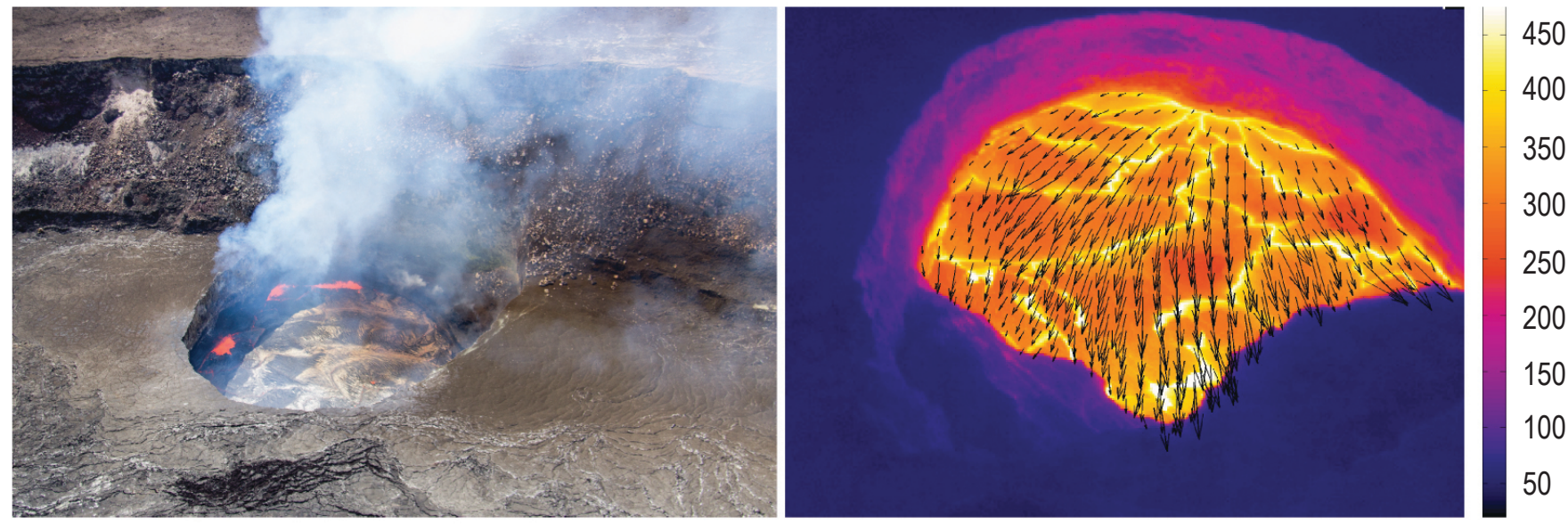

Figure 5. Left, View of the Overlook crater, looking east, showing spattering along the east lake margin. USGS photo by T. Orr, June 17, 2014. Right, Example output of the automated lava surface motion algorithm for 13:30 Hawaii Standard Time on October 2, 2014, showing typical lake surface motion from north (top of the image) to south (bottom of the image).

\section{Collapses and Explosions}

Small collapses occurred occasionally in the Overlook crater, most often associated with small sections of the juvenile lava veneer (sometimes forming an inner ledge around the lake margin) on the Overlook crater walls collapsing into the lake when the lake level dropped. When these sections impacted the lake they commonly triggered sloshing and agitation, and often a very-long-period seismic signal. They also sometimes triggered spattering that persisted for minutes to hours and temporarily changed the flow direction of the lake surface (the surface crust would tend to flow towards the areas of spattering).

Two larger collapses triggered small explosive events, and these involved collapses of the lithic walls of the Overlook crater. The first was at 10:11 HST (Hawaii Standard Time) on July 23, 2014 (fig. 6), when a slice of the east rim of the Overlook crater collapsed. The ejected spatter coated the nearby section of the Halema'uma' $u$ Crater floor, leaving a thick deposit on the Overlook crater rim. Ash-sized particles, ragged lapilli, and spatter bombs up to $70 \mathrm{~cm}$ in length blanketed the ground around the overlook immediately above the crater. Small bombs landed up to $1 \mathrm{~km}$ downwind from the vent, distributed along a narrow corridor. Similar to other explosive events, the juvenile tephra had small debris of lithic material incorporated into the lava. The second explosive event was at 01:15 HST on October 19, when a section of the south rim of the Overlook crater, which forms the wall of Halema'uma'u Crater immediately beneath the Halema'uma'u Overlook, collapsed into the lake. This triggered an explosion that was smaller than the July event - the spatter landed only around the immediate area of the Halema'uma'u Overlook.
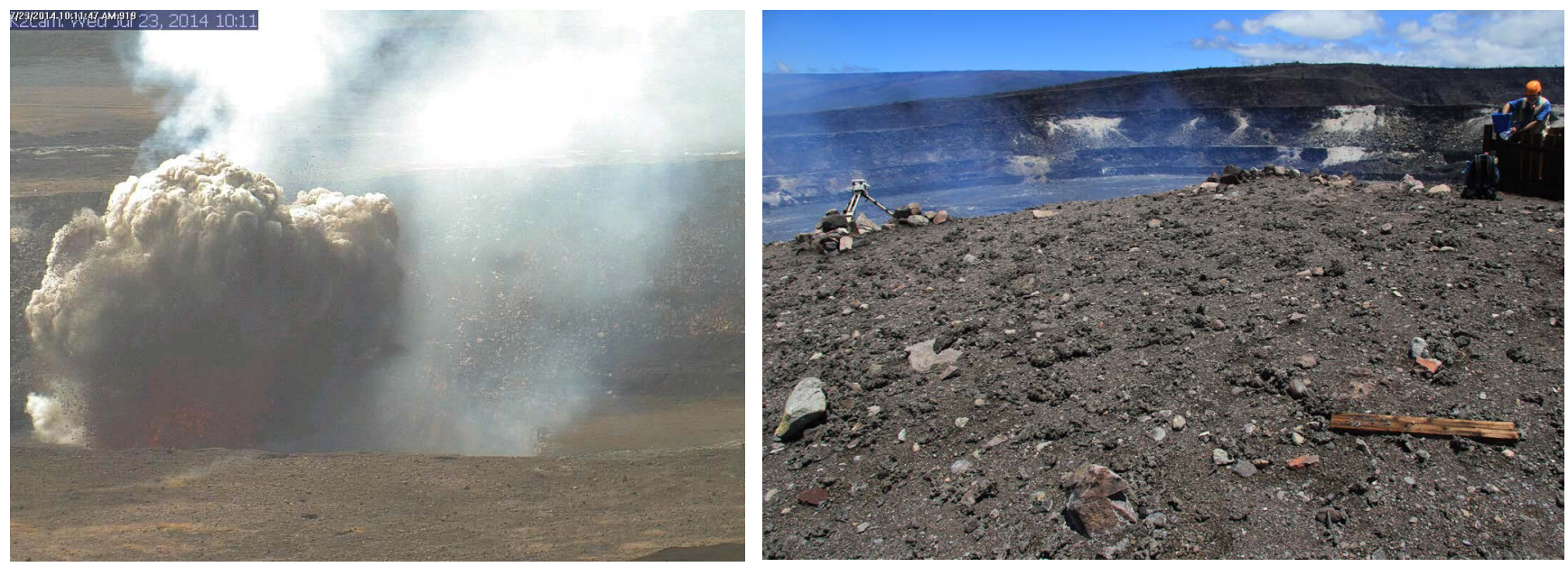

Figure 6. The July 23, 2014, explosion in the Halema'uma'u lava lake. Left, image collected by the K2cam (1.9 km to the north of the crater, in the Hawaiian Volcano Observatory tower) showing incandescent spatter ejected along with a robust plume, originating from the eastern portion of the Overlook crater. Image time was 10:11 Hawaii Standard Time. Right, view of the Halema'uma'u Overlook showing spatter bombs covering the ground. USGS photo by T. Orr, July 23, 2014. 


\section{East Rift Zone Eruption Summary}

\section{Kahauale'a 2 Flow (Episode 61d)}

Eruptive activity in Kīlauea's East Rift Zone in early 2014 was focused on the Kahauale 2 flow (or "K2 flow"; fig. 7), which was intermittently advancing northeast of $\mathrm{Pu}^{6} \mathrm{u}{ }^{'} \overline{\mathrm{O}}^{\natural} \mathrm{o}$. The source of the flow was a vent at the northeast edge of $\mathrm{Pu}^{\prime} \mathrm{u}$ ' $\overline{\mathrm{O}}^{\natural}$ 's's crater that overflowed in May 2013 to form the K2 flow.

The flow generally advanced at a rate of only 30-50 m/day, which was relatively slow compared to other flows in recent years. Progress was further hindered by large DI tilt events reducing (or possibly severing), then restoring, magma supply in January, April, and May, which caused the front of the flow to stall. When the flow recovered after each event, the movement of its distal active edge restarted from a new location that was as much as a few kilometers behind the previous front position. Despite these perturbations, the flow reached a maximum distance of $8.8 \mathrm{~km}$ from the vent before terminating in June.

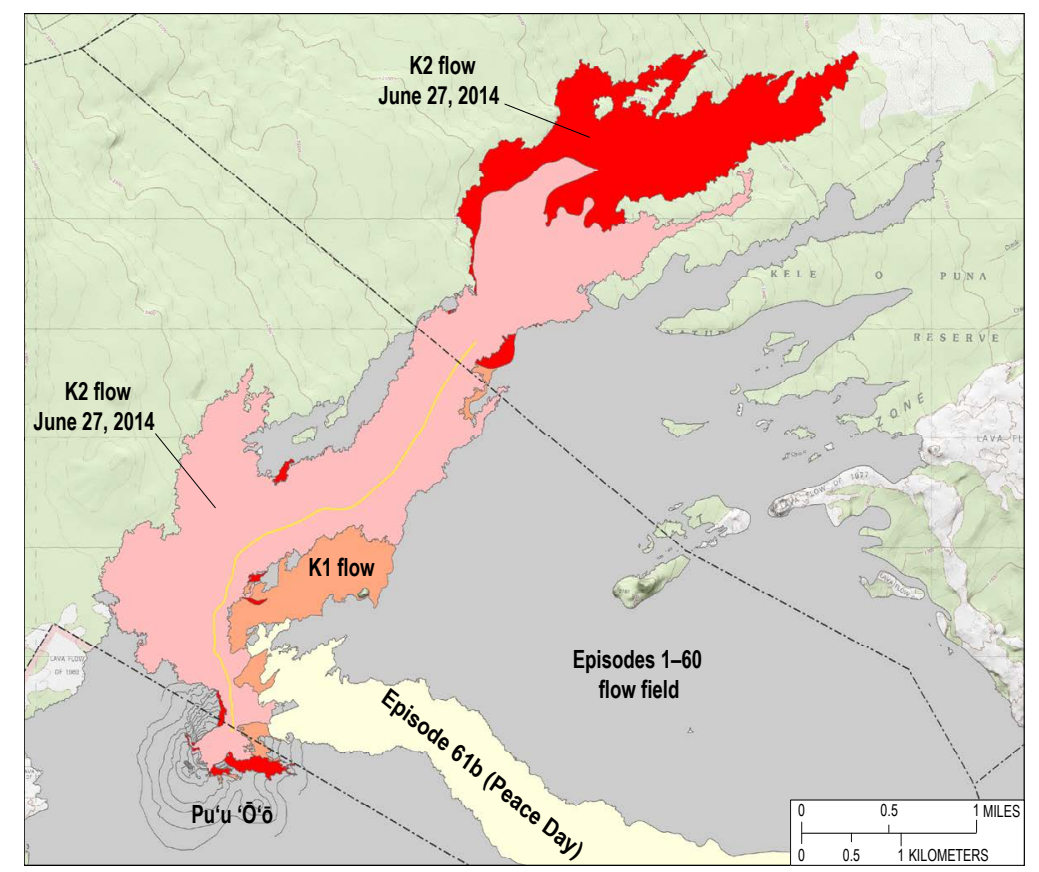

Figure 7. Map showing changes (in red) to the Kahauale'a 2 ("K2") flow field from December 26, 2013 until its stagnation on June 27, 2014.

\section{Pu'u 'Ō'ō Activity During the K2 Flow}

Early 2014 saw the continuation of the monotonous behavior seen at $\mathrm{Pu}^{\prime} \mathrm{u}$ ' ${ }^{\prime}{ }^{\prime} \bar{o}$ over the previous several months. There were four spatter cones on the crater floor, which we referred to as the N, NE, S, and SE spatter cones (fig. $8 A$ ), and the crater floor was only apparent by the remnants of the original tephra cone bounding the north and south rims of the crater. Otherwise, the crater was actually a low composite shield with high points at the four spatter cones. Each of these cones fed occasional brief flows.

The NE spatter cone - the source of the K2 lava flow northeast of $\mathrm{Pu}^{\natural} \mathrm{u}{ }^{\prime} \overline{\mathrm{O}}^{‘} \overline{\mathrm{o}}$ — often held a small, gently pistoning

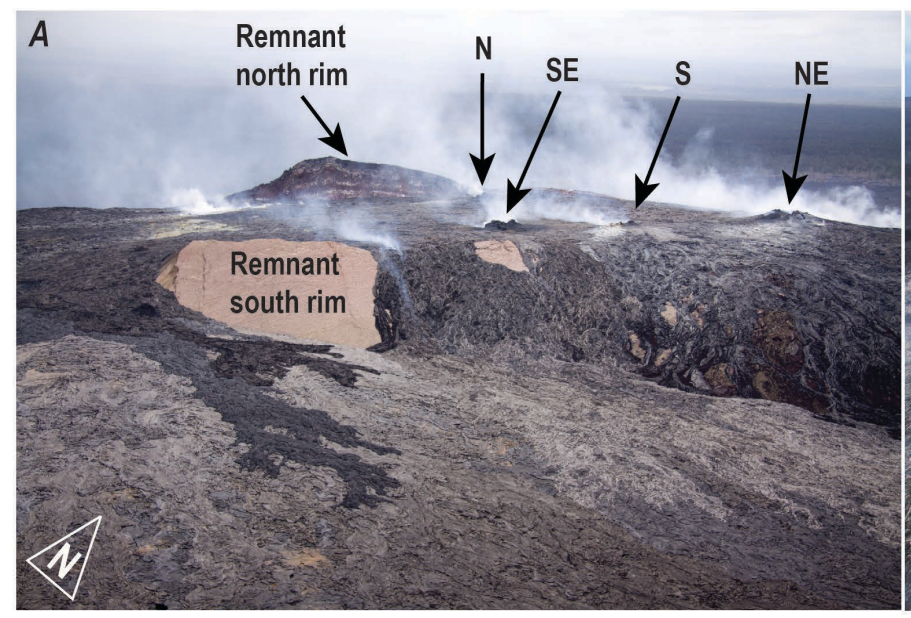

lava pond. Small overflows during pistoning events generally sealed the opening above the pond over a period of a day or two. Invariably, the cap over the pond would fail, perhaps in response to an unusually large drop in the lava level hidden beneath the crust during gas pistoning, and the pond surface would be exposed again.

Activity at $\mathrm{Pu}^{\natural} \mathrm{u}^{`} \overline{\mathrm{O}}^{\natural} \overline{\mathrm{o}}$ changed in late April, when large flows from the $\mathrm{N}$ and $\mathrm{S}$ cones exited the east and west ends of the crater and overtopped the crater's south rim. The flows ceased during a large DI event in early May. Inflation over the next several weeks led to flows from the NE and $\mathrm{N}$ spatter cones that also exited both ends of the crater.

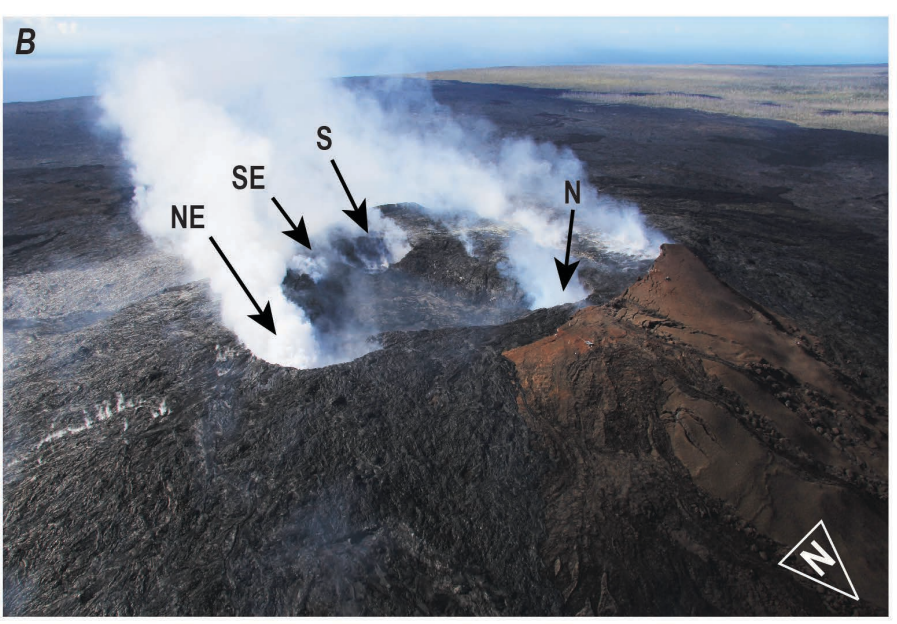

Figure 8. Oblique aerial photographs showing Pu'u 'Ō'ō before $(A)$, and after $(B)$ the June 27, 2014, eruption. The spatter cones and corresponding pits are labeled. USGS photos by T. Orr on May 13 and October 13, 2014. 


\section{June 27th Breakout and Flow}

The heightened activity at $\mathrm{Pu}^{\prime} \mathrm{u}$ ' $\overline{\mathrm{O}}^{‘} \mathrm{o}$ in late June culminated in a new eruption on the northeast flank of $\mathrm{Pu}^{\prime} \mathrm{u} \mathrm{u}^{\prime} \overline{\mathrm{O}}^{`} \mathrm{o}$ on June 27 (called the June 27th flow; episode 61e) (fig. 9A). Lava erupted initially from four fissures, forming several short-lived channelized flows, but within a few days activity focused on the lowest fissure (fissure D) and a perched lava pond began to form (fig. 9B). The $\sim 200$-m-diameter pond eventually became elevated to about $30 \mathrm{~m}$ higher than the fissure $\mathrm{D}$ vent.

On July 10, the lava's static pressure head that had developed in the magma system caused the eruption to shift to the next higher fissure (fissure C), and the perched pond was abandoned. A fast-moving channelized flow coursed downslope from fissure C. Confined between the Kahauale'a flows and the episode 58 perched channel, the flow traveled up to several hundred meters per day (maximum measured rate was about $600 \mathrm{~m} /$ day) to the northeast, eventually extending beyond the eastern edge of the $\mathrm{Pu}^{6} \mathrm{u}{ }^{\prime} \overline{\mathrm{O}}^{\prime} \mathrm{o}$ flow field.

On August 18, the flow intersected a deep ground crack (crack 1), which captured the flow and directed it toward the northeast. Though hidden within the crack, the flow's advance was marked by an ever-lengthening line of steam along the crack. Lava overflowed the crack about $1.3 \mathrm{~km}$ downslope on August 24, forming a short flow bounded by fault structures (lava pad 1), and entered a second crack (crack 2) that likewise carried the flow forward underground. Lava emerged from crack 2 farther downslope on August 29, forming another short flow (lava pad 2) that cascaded into yet another ground crack (crack 3 ) that soon began to steam.

The third crack was filled on September 3, and lava spilled out to form three new flows (lava pads 3-5) as close as $1.2 \mathrm{~km}$ from the Kaohe Homesteads subdivision. The westernmost of these three new flows (lava pad 3) captured the entire flow volume and the lava began to advance toward the north, where it intersected another ground crack (crack 4). This time, the lava traveled back to the southwest within the crack, but when the crack was filled, the flow continued on toward the north from near the point at which it entered the crack. Figure 10 shows the arrangement of cracks and flows utilized by lava during this period of the eruption.

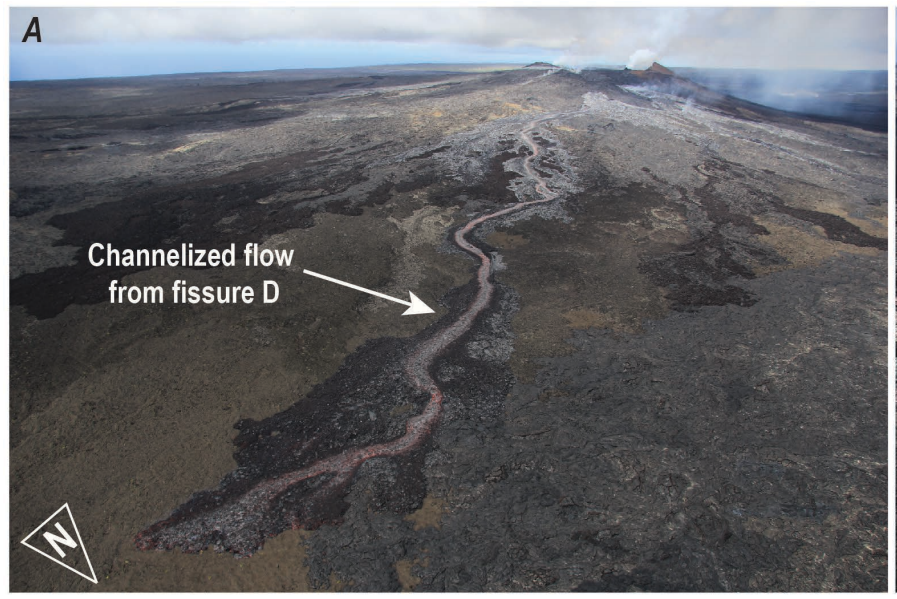

Over the next several weeks, the flow advanced relatively steadily to the northeast, bypassing the inhabited part of Kaohe Homesteads, until the flow front stalled on September 22. The flow recovered slowly over the next several days and began to progress forward again in early October. After advancing another kilometer, the flow slowed to a crawl in mid October. Within a few days, however, the nearly stalled front was bypassed by a narrow breakout that became confined within a shallow drainage and began to race forward.

The rapidly advancing lobe crossed Cemetery Road just south of the Pāhoa Solid Waste Transfer Station on October 25. From there it continued downslope through the Pāhoa Japanese Cemetery and onto the property of Melvin Sugimoto on the outskirts of Pāhoa. On October 30, just when the destruction of houses seemed inevitable, the flow stalled. It was a mere $155 \mathrm{~m}$ from Pāhoa Village Road, the main street through Pāhoa (fig. 11).

Though the flow had stopped advancing, breakouts continued just upslope. Over the next two weeks, flows spilled onto the transfer station property (though only a fence and access road were affected) and a nearby farmhouse was destroyed. In addition, another narrow, relatively fast-moving flow began to advance past the north side of the transfer station, following a drainage that put it on a course toward the Pahoa Marketplace. However, the flow was subsequently beheaded by a large breakout upslope on November 14 and the distal flow front stopped advancing over the next few days before additional damage could occur.

The November 14 breakout that shut down the lower flow field occurred from the tube adjacent to Puu Kahaualea. Over the next few days after the breakout, the tube was gradually reoccupied, forming a downstream progression of breakouts. The last breakout in the series started on November 18 on lava pad 2 within the ground crack system, and lava began to advance rapidly toward the north along the west edge of the earlier flow. Within a few weeks, the flow had diverged from the edge of the previous flow and formed a new flow branch that turned toward the northeast and headed straight for the Pahoa Marketplace and Highway 130 (fig. 12). The flow reached to within $530 \mathrm{~m}$ of the marketplace before stalling December 30 . Many breakouts remained active just behind the front, though, maintaining the threat to the area through the end of the year.

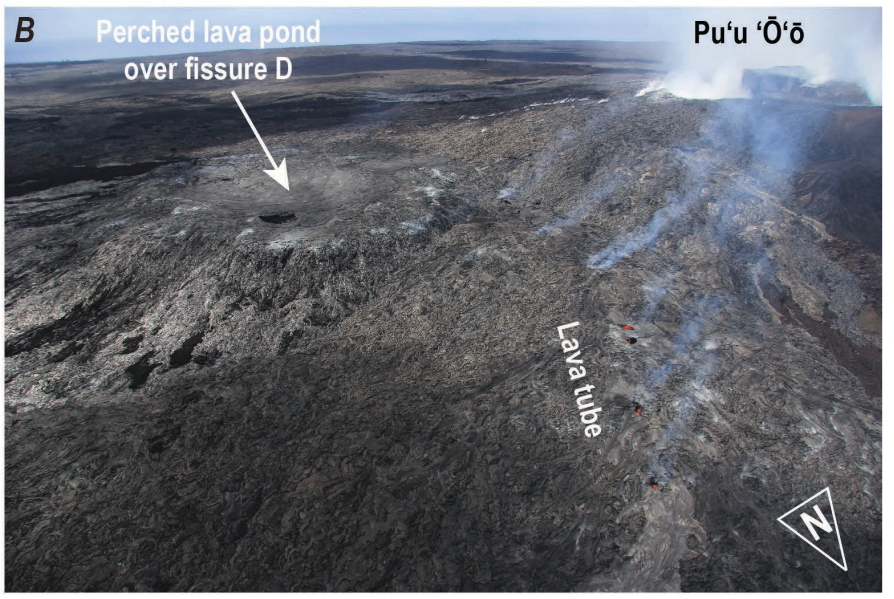

Figure 9. Oblique aerial photographs showing $(A)$ channelized flow at start of June 27 th eruption, and $(B)$ perched lava pond formed over fissure D of June 27th eruption. USGS photos by T. Orr on June 27 and July 18, 2014. 


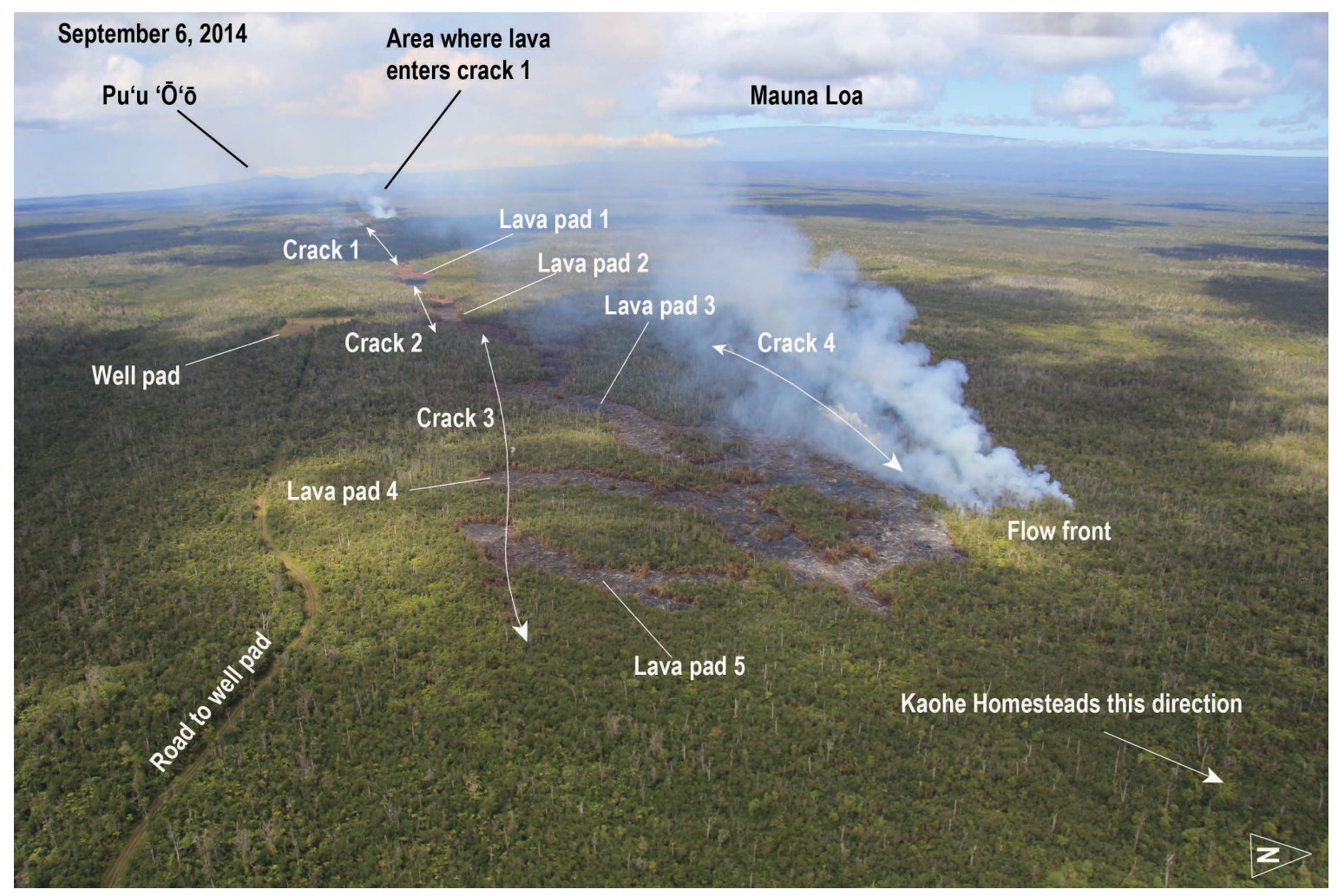

Figure 10. Oblique aerial photograph showing the ground cracks and lava pads near the True/Mid-Pacific geothermal well site on September 6, 2014. USGS photo by T. Orr.

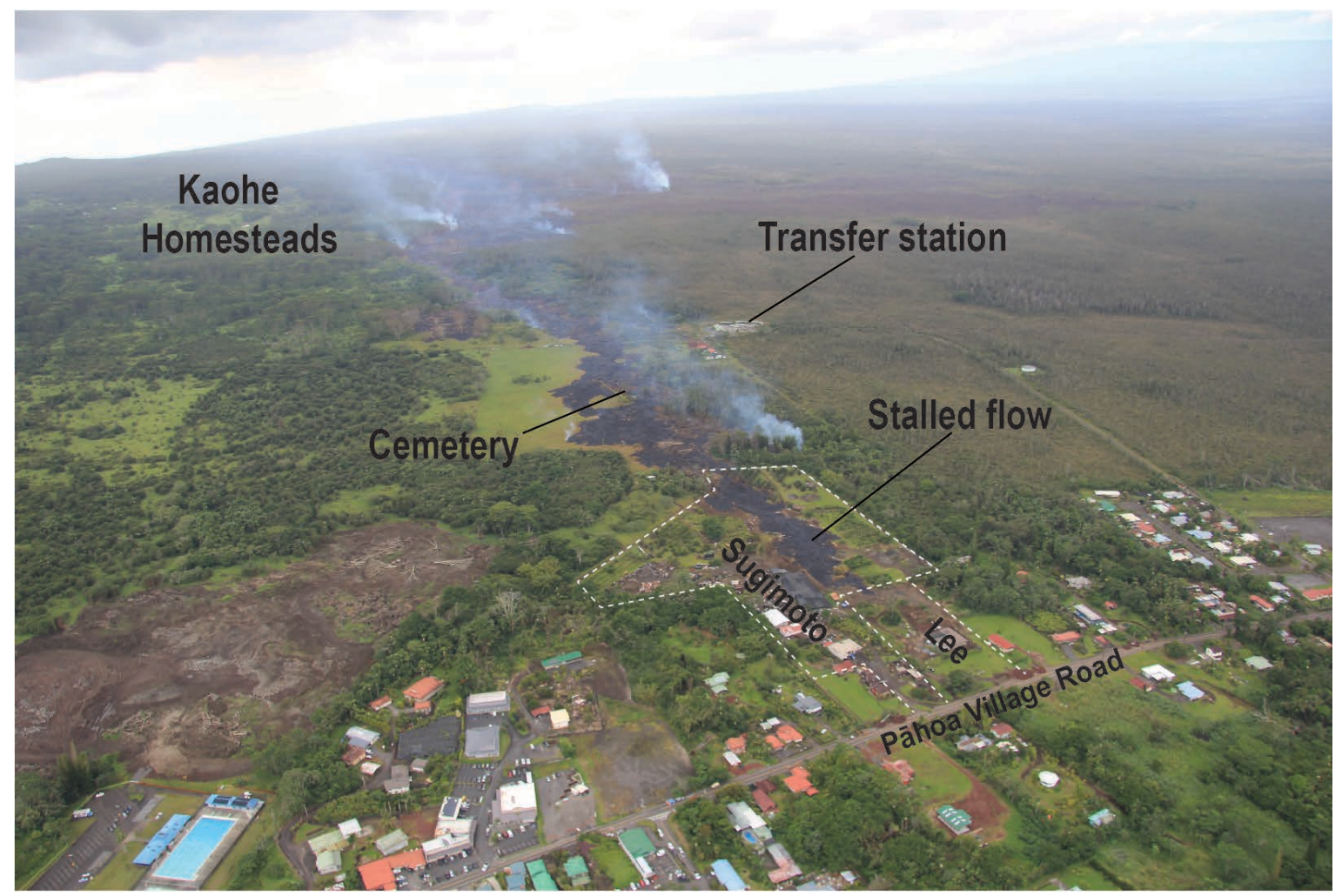

Figure 11. Oblique aerial photograph showing the flow on October 31, after it stalled on Sugimoto's property, $155 \mathrm{~m}$ upslope from Pāhoa Village and before reaching Lee's property. Dashed white lines are rough property boundaries for Sugimoto and Lee. Though the front stalled, many breakouts remained active over a broad area from just below the cemetery to north of Kaohe Homesteads. USGS photo by T. Orr. 


\section{Pưu ‘ōō}

Figure 12. Oblique aerial photograph showing flow upslope from Pahoa Marketplace on December 30, 2014. USGS photo by T. Orr.
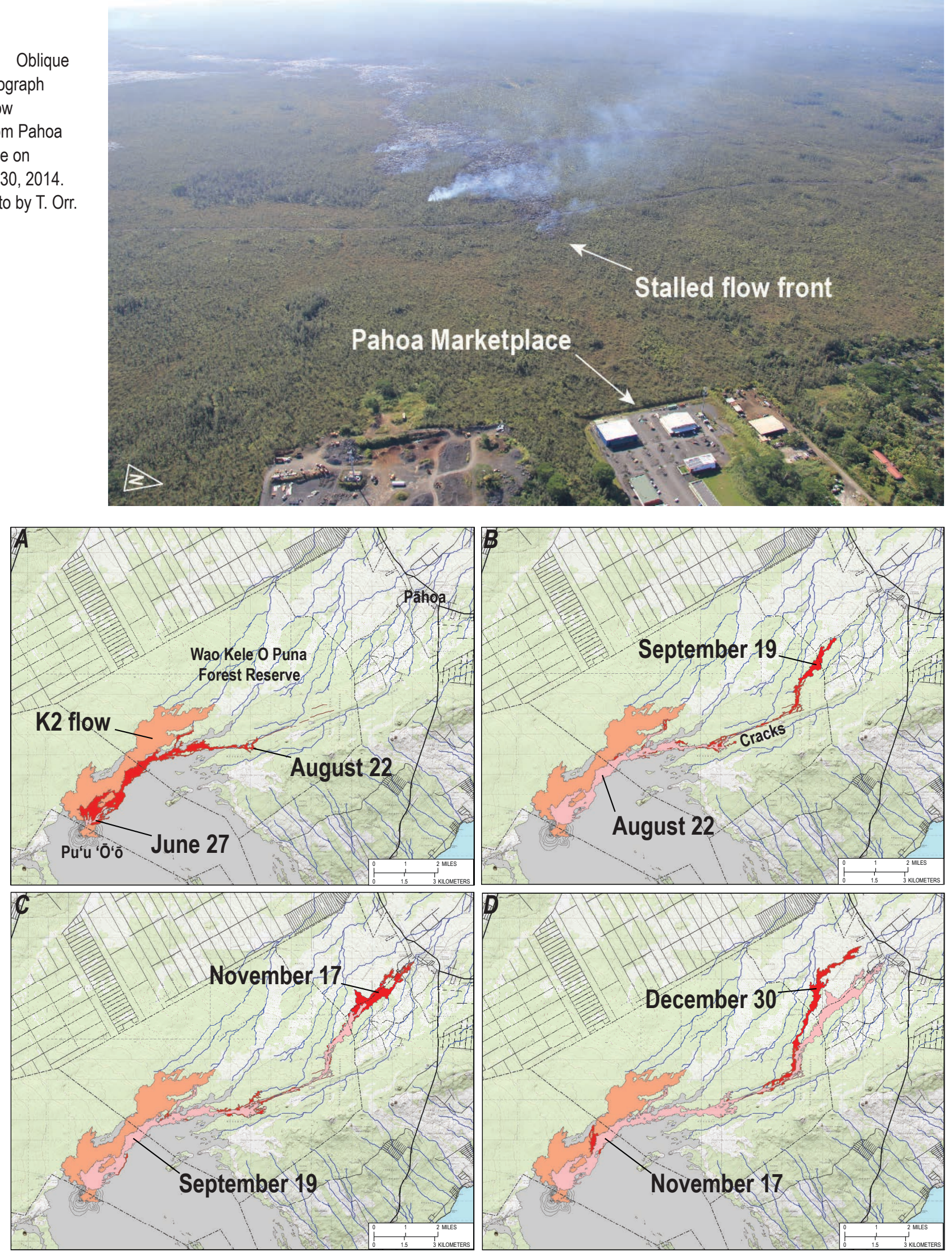

Figure 13. Four maps showing the progress of the June 27th lava flow during the last six months of 2014. 


\section{Pu'u 'Ō'ō's Response to the June 27th Flow}

A new crater formed within $\mathrm{Pu}^{6} \mathrm{u}^{~}{ }^{\circ} \mathrm{O}^{\natural} \mathrm{o}$ following the onset of the June 27 th flow (fig. $8 B$ ). The four $\mathrm{Pu}^{\natural} \mathrm{u}^{`} \overline{\mathrm{O}}^{\natural} \overline{\mathrm{o}}$ spatter cones collapsed within a few days, and pits containing lava ponds formed at their locations around the edges of the initially shallow crater. Pronounced crater subsidence started on July 5 and continued through the end of that month, until the crater was
20-25 m deep. There was minor crater subsidence thereafter through the end of the year.

Brief overflows from the vents in the crater pits occurred occasionally, and the lava ponds within the pits eventually crusted over (some sooner than others). The last lava pond was seen at the southern edge of the crater during the first week of November, and the conditions at $\mathrm{Pu}^{6} \mathrm{u}^{\prime} \overline{\mathrm{O}}^{`} \mathrm{o}$ were uneventful and fairly monotonous thereafter.

\section{Appendix B-1. Kīlauea Summit Eruption Statistics for 2008-2014}

\section{Dates of Important Events}

[All times given are in local time, Hawaii Standard Time]

Fumarole appears: March 12, 2008 (timing uncertain, but before about 11:30)

Vent-opening explosion: March 19, 2008, 02:58

Erupted mass: 403,000 kg

Erupted products: lithic blocks, lapilli, and ash; no juvenile component

Eruptive hiatus 1 (vent choked): December 2008-January 2009

Eruptive hiatus 2 (vent choked): July-August 2009

\section{Other Interesting Facts}

Initial size of vent opening: $36 \mathrm{~m}(\mathrm{NE}-\mathrm{SW})$ by $29 \mathrm{~m}(\mathrm{NW}-\mathrm{SE})$

2014 end-of-year vent opening size: $170 \mathrm{~m}$ (NE-SW) by $220 \mathrm{~m}$ (NW-SE)

Maximum height of lava lake: $22 \mathrm{~m}$ below pit rim (October 26, 2012)

Total erupted mass: $\sim 1.9 \times 10^{6} \mathrm{~kg}$ (excludes several hundred thousand kilograms of mostly lithic block and ash erupted March 23-31, 2008, before the collection routine was fully implemented)

Juvenile-to-lithic ratio in 2014: 42/58 (slight increase from 2013 in juvenile fraction due to increasing stability of the Overlook crater walls)

Number of explosive events that ejected large lapilli and bombs onto Halema'uma'u Crater rim: 19 


\section{Appendix B-2. Kïlauea East Rift Zone Eruption Statistics for 1983-2014}

\section{Miscellaneous Statisitics and Fascinating Facts}

Net total lava flow surface area (from January 1983 to December 2014): $137.9 \mathrm{~km}^{2}\left(53.3 \mathrm{mi}^{2}\right)$

Net volume erupted (dense rock equivalent): $\sim 4 \mathrm{~km}^{3}\left(\sim 1 \mathrm{mi}^{3}\right)$

Flowfield area increase since the end of 2013: $9.5 \mathrm{~km}^{2}\left(3.7 \mathrm{mi}^{2}\right)$

Net total land added to the island: (from November 1986 to December 2014): 201.5 hectares (498.0 acres; no significant change from 2013)

\begin{tabular}{|c|c|c|c|}
\hline ERZ eruptive episode & $\begin{array}{c}\text { Total surface area of } \\
\text { flow }\left(\mathrm{km}^{2}\right)\end{array}$ & $\begin{array}{l}\text { Area currently } \\
\text { exposed }\left(\mathrm{km}^{2}\right)\end{array}$ & $\begin{array}{c}\text { Volume of flow } \\
\left(\mathrm{km}^{3}\right)^{*}\end{array}$ \\
\hline 48c-49 (Kupaianaha; fissures west of Kupaianaha) & 44.1 & 16.2 & 0.51 \\
\hline 57-58 (crater fill and fissures east of $\mathrm{Pu}^{`} \mathrm{u}^{\prime}{ }^{\mathrm{O}}{ }^{`} \mathrm{o}$ ) & 41.1 & 28.5 & 0.63 \\
\hline 59-60 (Kamoamoa fissures; $\mathrm{Pu}^{`} u$ ‘ $\overline{\mathrm{O}}^{`} \mathrm{o}$ overflows and west flank vent) & 3.5 & 3.3 & 0.04 \\
\hline
\end{tabular}

*Dense rock equivalent volumes.

**Calculated by taking 2013's volume (0.15) and adding 1-2 $\mathrm{m}^{3} / \mathrm{s}$ average effusion, based on TanDEM-X InSAR volume change with time estimates (see Poland, 2014b).

Maximum height of $\mathrm{Pu}^{‘} \mathrm{u}$ ' ${ }^{`}{ }^{\prime} \mathrm{o}$ cone above pre-1983 surface: $255 \mathrm{~m}$ in 1986

Height of $\mathrm{Pu}^{‘} \mathrm{u}$ ' $\overline{\mathrm{O}}^{`} \overline{\mathrm{o}}$ cone at the end of 2014: $171 \mathrm{~m}$ (NW rim)

Height the cone has lost to collapse since 1986: $84 \mathrm{~m}$

Maximum dimensions of $\mathrm{Pu}^{‘} \mathrm{u}$ ' $\overline{\mathrm{O}}^{`}{ }^{\circ}$ crater: $\sim 450 \mathrm{~m}$ by $\sim 300 \mathrm{~m}$

Height of Kupaianaha lava shield above pre-Episode 48 surface: $56 \mathrm{~m}$

Height of Thanksgiving-Eve-Breakout lava shield above pre-Episode 58 surface: $41 \mathrm{~m}$ (total station; January 2008)

Length of highway cut off by lava flow: $13.5 \mathrm{~km}$ (Highway 130 and Chain of Craters; measured end to end in straight-line distance)

Number of days on which lava entered the ocean in 2014: 0

Percentage of time lava has entered the ocean since the first entry began: 56

Primary structures destroyed, 2014: 1 (in Pāhoa)

Total primary structures destroyed, 1983-2015: 215 


\title{
Chapter C
}

\section{Seismology}

\author{
By Wes Thelen and Matt Burgess
}

\section{Introduction}

The U.S. Geological Survey (USGS) Hawaiian Volcano Observatory (HVO) is the authoritative organization that monitors seismic phenomena across the Hawaiian Islands from O'ahu to Hawai'i. HVO has operated seismometers of various types since 1912, and has been producing a modern seismic catalog since October 1, 1959 (Klein and Wright, 2000). Some of the first prototype electromagnetic seismometers, built and tested at HVO in the late 1950s, had dramatically improved sensitivity compared to seismometers in use at the time (Okubo and others, 2014). The first telemetered seismograph was also pioneered at HVO. HVO followed the computer revolution, switching to new computer processing systems in 1970 (punchcards), 1979 (Eclipse/HYPOINVERSE), 1985 (CUSP), and 2009 (AQMS) (Okubo and others, 2014). Finally, the seismic network was entirely converted to digital recording and telemetry between 2011 and 2013 as part of the American Recovery and Reinvestment Act (ARRA). The conversion to digital recording improved signal fidelity and dynamic range over previous analog systems. Along with the digital conversion, several new broadband and strong motion sensors replaced existing short-period instruments, allowing the seismic network to better record a range of amplitudes and frequencies of both large tectonic earthquakes and small volcanic earthquakes.

The HVO summaries have been published in various forms since 1956. Summaries before 1974 were issued quarterly, but cost, convenience of preparation and distribution, and the large quantity of data necessitated an annual publication, beginning with Summary 74 for the year 1974. Since 2004, summaries have been identified simply by year, rather than by summary number. Summaries originally issued as administrative reports were republished in 2007 as Open-File Reports. All the summaries since 1956 are available at http://pubs.usgs.gov/of/2007/1316-1345/ (last accessed January 29, 2013).

The present report includes background information about the seismic network to provide the end user with an understanding of the staff, network configuration, processing, improvement, and research activity that has taken place in the past year. In addition, epicenter maps are presented with a brief interpretation of the activity across the island.

\section{People}

Along with the HVO seismic network staff, we thank the following volunteers for their help during 2014:

- Marci Frenz: data entry into the felt-earthquake database

- Clare Donaldson: tracking seismic velocity changes at Kīlauea Volcano.

- Josiah Judson: relative relocations of earthquakes in the uppermost Southwest Rift Zone, Kīlauea Volcano.

- Rebecca Kramer: seismic velocity changes at Mauna Loa volcano.

\section{The Second Great Hawaii Shakeout}

The second annual Great Hawaii Shakeout took place October 16, 2014, and was a rousing success (http://shakeout.org/ hawaii/). HVO was the leading organizer, but we also partnered with State and County civil defense; the Center for the Study of Active Volcanism, the National Oceanic and Atmospheric Administration; the University of Hawaii, Hilo; American Red Cross; and Federal Emergency Management Agency. The second annual shakeout had almost 30,000 participants across all of the islands, nearly doubling the participants from 2013. HVO generated a substantial amount of information for the Web site, produced several press releases, attended preparedness fairs, and gave public talks.

\section{Earthquake Early Warning Assessment in Hawaii}

In 2014, the Hawaiian Volcano Observatory began collaboration with the Pacific Northwest Seismic Network (PNSN) at the University of Washington to assess the feasibility of Earthquakes Early Warning (EEW) in Hawaii with specific application to the 30-meter telescope atop Mauna Kea. The project is funded by a two-year grant from the Moore Foundation. The grant aims to assess the theoretical and practical aspects of EEW 
in Hawaii. Collaborators at the PNSN include John Vidale, Paul Bodin, and Alicia Hotovec. In 2014, work concentrated on the theoretical aspects of EEW and what kinds of warning times would be available in an ideal case. A primary goal in 2015 is to implement the algorithms behind EEW with the current seismic network to measure the performance.

\section{Moving Toward 24/7 Volcano Monitoring}

HVO currently achieves monitoring 24 hours a day, 7 days a week using automated alarms for any data occurring out of background ranges; human data checks are only routine during the work week. In collaboration with the National Earthquake Information Center (NEIC), significant progress was made in 2014 on a program to implement complete night and weekend seismic checks for the USGS Volcano Science Center (VSC). The VSC began funding an analyst staff position at the NEIC, and training was conducted by NEIC and VSC staff throughout the year. In addition, data exports from the Alaska Volcano Observatory and HVO to NEIC were established and procedures generated to complete the activity checks. In December 2014, the NEIC began regularly doing nightly checks of HVO data. In 2015, activity checks will be expanded to include weekends.

\section{HVO Instrumentation Plan Released}

The HVO Seismic Instrumentation Plan, released in late 2014, details the current capabilities of the seismic network in terms of detection and location thresholds and models the number and types of stations required to meet National Volcanic Early Warning System (NVEWS) standards. The report also lays out priorities for future upgrades to the seismic network. The report can be found at http://pubs.er.usgs.gov/ publication/sir20145179.

\section{New Capabilities}

Several new capabilities have been added to the operations of the seismic network at HVO. Each of these capabilities has included interactions with external groups for support including the NEIC, the Berkeley Seismological Laboratory, Caltech Seismological Laboratory, and the Pacific Northwest Seismic Network.

\section{Continuous Data Archiving}

Our ability to archive continuous seismic data has improved markedly with the introduction of the Continuous Waveform Buffer (CWB). Several configuration changes took place in 2014 that made our data archiving more robust.
1. The CWB was linked directly to the Reftek Transfer Protocol Daemon (RTPD), which has resulted in a more continuous and robust archive than could be achieved with Earthworm.

2. Our data export to our public archive at the Incorporated Research Institutions for Seismology (IRIS) is now funneled through the CWB and NEIC. The result is a consolidation of exports; with it comes a dramatic increase in reliability of the transfer and a four-fold decrease in the bandwidth required.

3. Backfilling of archive data starting in 2007 continues. Having continuous data from nearly 10 years of volcanic activity available from one source will enable better scientific analysis from HVO staff and their colleagues.

\section{Firmware Upgrades Improve Data Continuity}

The field digitizers were upgraded in 2014 to locally store up to seven days of data if a communications dropout prevented real-time data transfer. When communications are reestablished, the data are backfilled automatically. The effort required hardware and firmware upgrades at the digitizers and software changes on the computers that acquire and store the data at HVO. Though not fully implemented at every digitizer at the time, the added capabilities of the new data import process was tested by Hurricane Iselle and significantly reduced the amount of data that would have been lost using the previous method.

\section{Kīlauea Summit Broadband Upgrade Commences}

The broadband seismic network around Kīlauea Caldera has been a critical tool in understanding long-period and verylong-period earthquakes. The network was originally installed with Guralp 40-T broadband seismometers, but those are aging and the summit network needs an instrumentation upgrade to continue to be the state-of-the-art resource for seismic studies that it always has been. In 2014, the upgrade of the network began modestly with the installation of a Nanometrics Compact Trillium Broadband at the North Pit instrument site (NPT). In addition, HVO bought equipment for three more stations to be installed in 2015. If fully funded, the summit upgrade (Thelen, 2014) will be finished in 2016 or 2017.

\section{Automated Tremor Detection and Location}

In 2014 the Hawaiian Volcano Observatory began running an automated tremor detection and location algorithm in near-real time, which was made possible by cooperation with Aaron Wech at the Alaska Volcano Observatory. The algorithm results are displayed through a browser-based user interface that makes exploring the catalog fast and efficient. 


\section{Network}

The 2014 HVO network (fig. 1) consisted of 57 realtime continuous station sites, 25 broadband sites, 21 strongmotion sites (most sites shared with broadband or shortperiod stations), 7 three-component short-period sites, and 25 vertical-component short period sites (figs. 2, 4). There are 15 Netquake instruments now installed on the islands of Hawai' $i$ and Maui. Netquake devices are inexpensive accelerometers installed in buildings and residences; they have become an important part of the seismic network in areas where vandalism is rampant or telemetry infrastructure is nonexistent. The network coverage is most dense on and around Kîlauea and Mauna Loa Volcanoes (fig. 4).

Each continuous seismic station operated by HVO (HV network code) consists of a seismometer connected to a Reftek RT130 or RT130-SM digitizer, which is connected to one of a variety of digital radios (for example, Intuicom EB-6+, AFAR $800 \mathrm{MHz}$, or $2.4 \mathrm{GHz}$ wi-fi). Data from our permanent continuous seismic stations is transmitted to the digital backbone (see fig. 3) or received directly at HVO. There are a variety of seismometers at stations within the HVO realtime system. The complete and authoritative source SEED (Standard for the Exchange of Earthquake Data) volumes for each HV station are available from IRIS (http://www.iris. washington.edu/mda/HV).

HVO has several partners that share seismic data in real time (table 1, figs. 6-10). The Pacific Tsunami Warning Center (PTWC) operates and maintains a network of stations on the islands of Hawai'i, Maui, Moloka'i, O'ahu, and Kaua'i. PTWC has two stations on Kauai, three stations on $\mathrm{O}^{\prime} \mathrm{ahu}$, one station on Moloka' $i$, two stations on Maui, and nine stations on the Island of Hawai' $i$. HVO also receives data from the Global Seismic Network (GSN), which has one station on $\mathrm{O}^{\prime}$ ahu and one station on the Island of Hawai ${ }^{i} i$. Seismic and infrasound data are shared with the Infrasound Laboratory at the University of Hawai' $i$, Mānoa; the university has two infrasound arrays that complement HVO's existing infrasound network.

The combined networks of $\mathrm{HVO}$ and its partners allow HVO to have an authoritative region that surrounds the Island of Hawai' $i$ and extends to the channel between $\mathrm{O}^{\prime}$ ahu and Kaua'i (fig. 10). In general, we can locate events that are $M 2.5$ or greater even within the sparsest areas of our network.

All continuous seismic data are available in near-real time from IRIS (http://www.iris.washington.edu/mda/HV). Data latency for real-time data are typically around $100 \mathrm{~s}$. Continuous data are made available to partners within seconds of processing via Earthworm import-export pairs.

Table 1. Number of stations in each network whose data are collected by the Hawaiian Volcano Observatory.

[Letters in parentheses denote the network code. Stations operated by the National Strong Motion Program produced triggered data only for large magnitude earthquakes, $M>3.5$ ]

\begin{tabular}{ll}
\hline \multicolumn{1}{c}{ Network } & Number of stations \\
\hline Hawaiian Volcano Observatory (HV) & 72 \\
Pacific Tsunami Warning Center (PT) & 19 \\
Puna Geothermal Ventures (PH) & 7 \\
Global Seismograph Network (IU) & 2 \\
National Strong Motion Program (NP) & 30 \\
Infrasound Lab at the University of Hawai‘i (UH) & 2 (infrasound arrays) \\
\hline
\end{tabular}




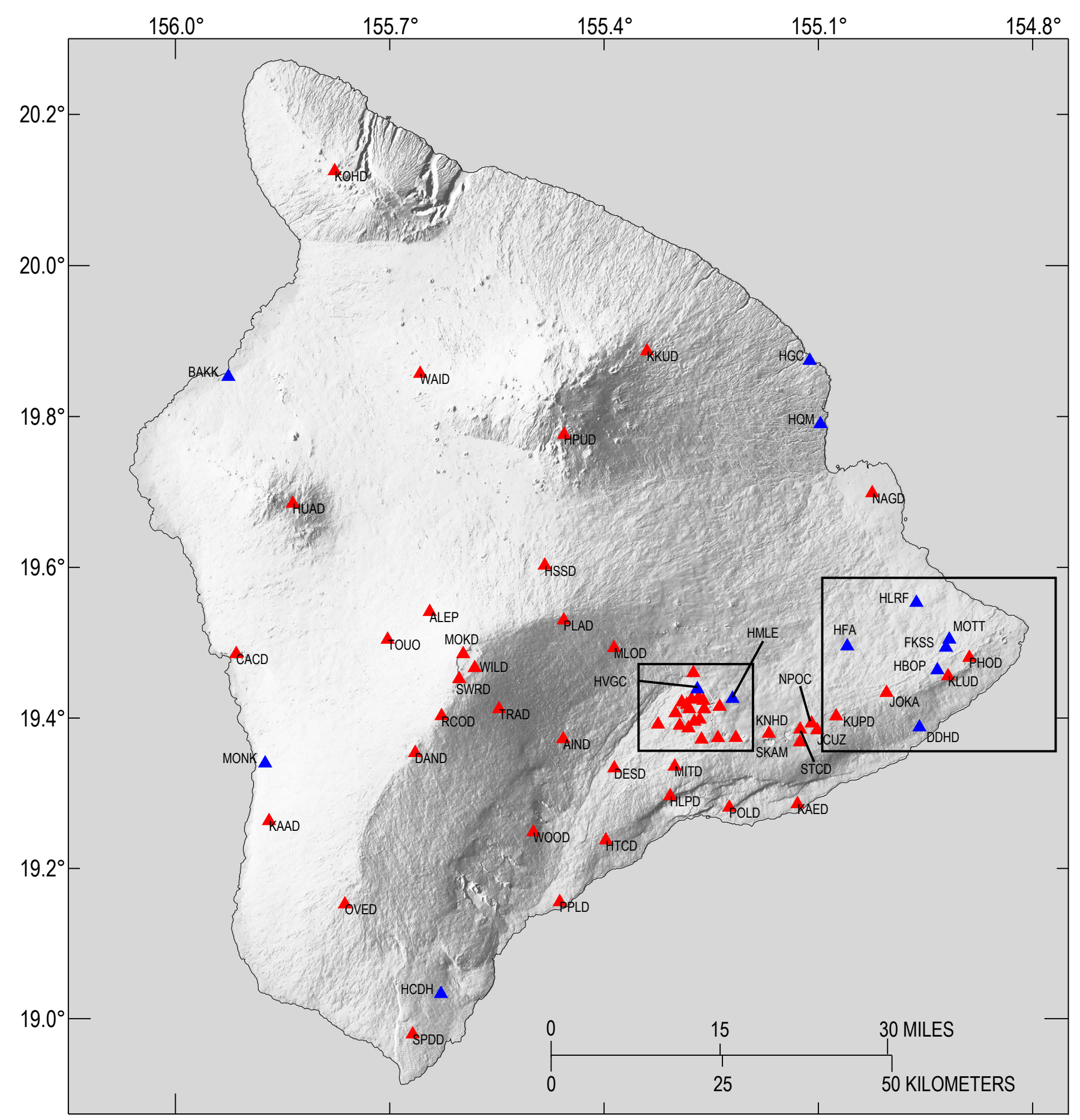

Figure 1. Map of seismic stations (red triangles) operated by the Hawaiian Volcano Observatory during 2014. Netquakes instruments are shown as blue triangles. Boxes show areas of figures 2 and 7. 


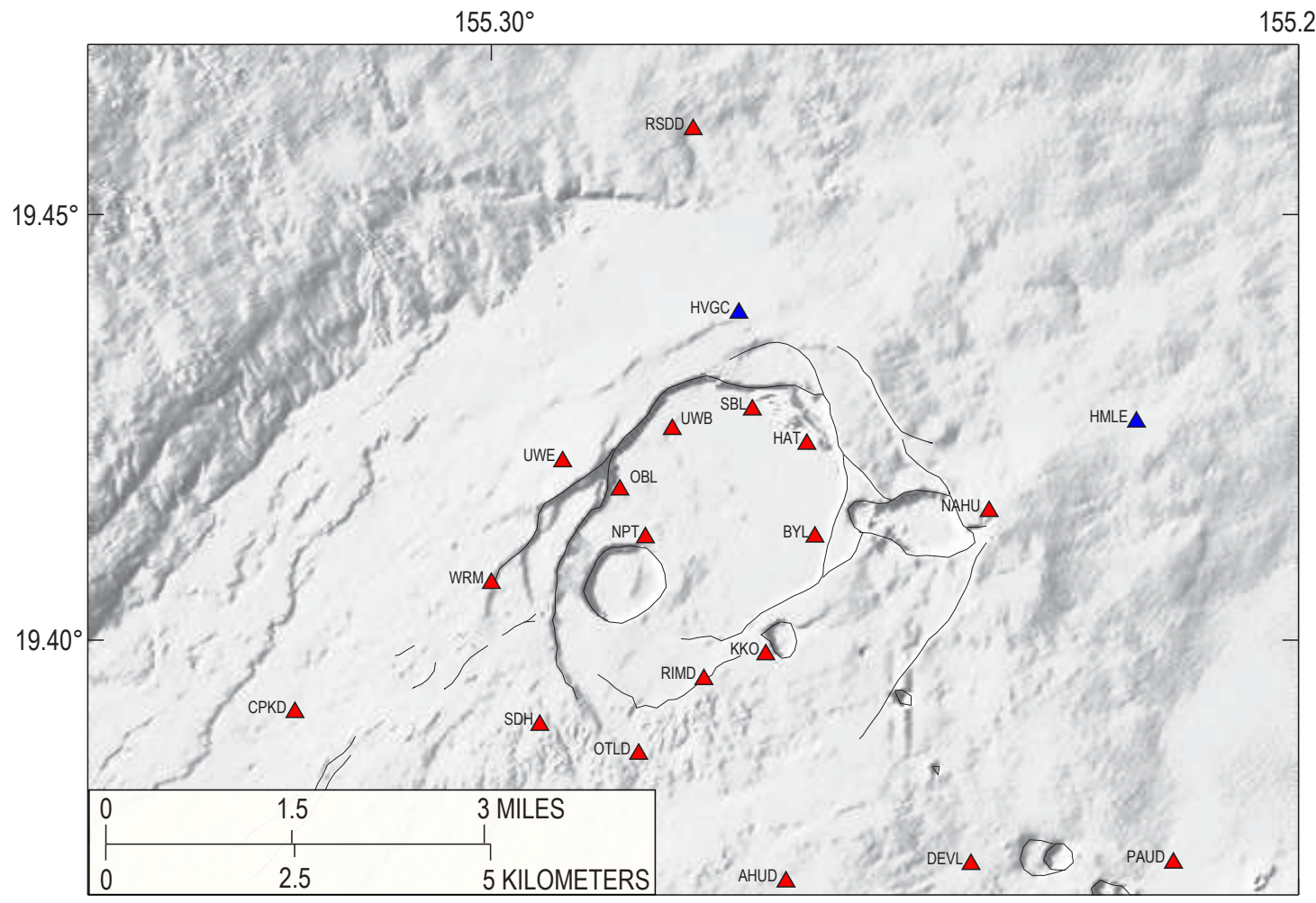

Figure 2. Map of seismic stations around Kïlauea Caldera. HVO stations are shown with red triangles; Netquakes instruments are shown with blue triangles. Station UWE also has hardware owned by the Pacific Tsunami Warning Center.

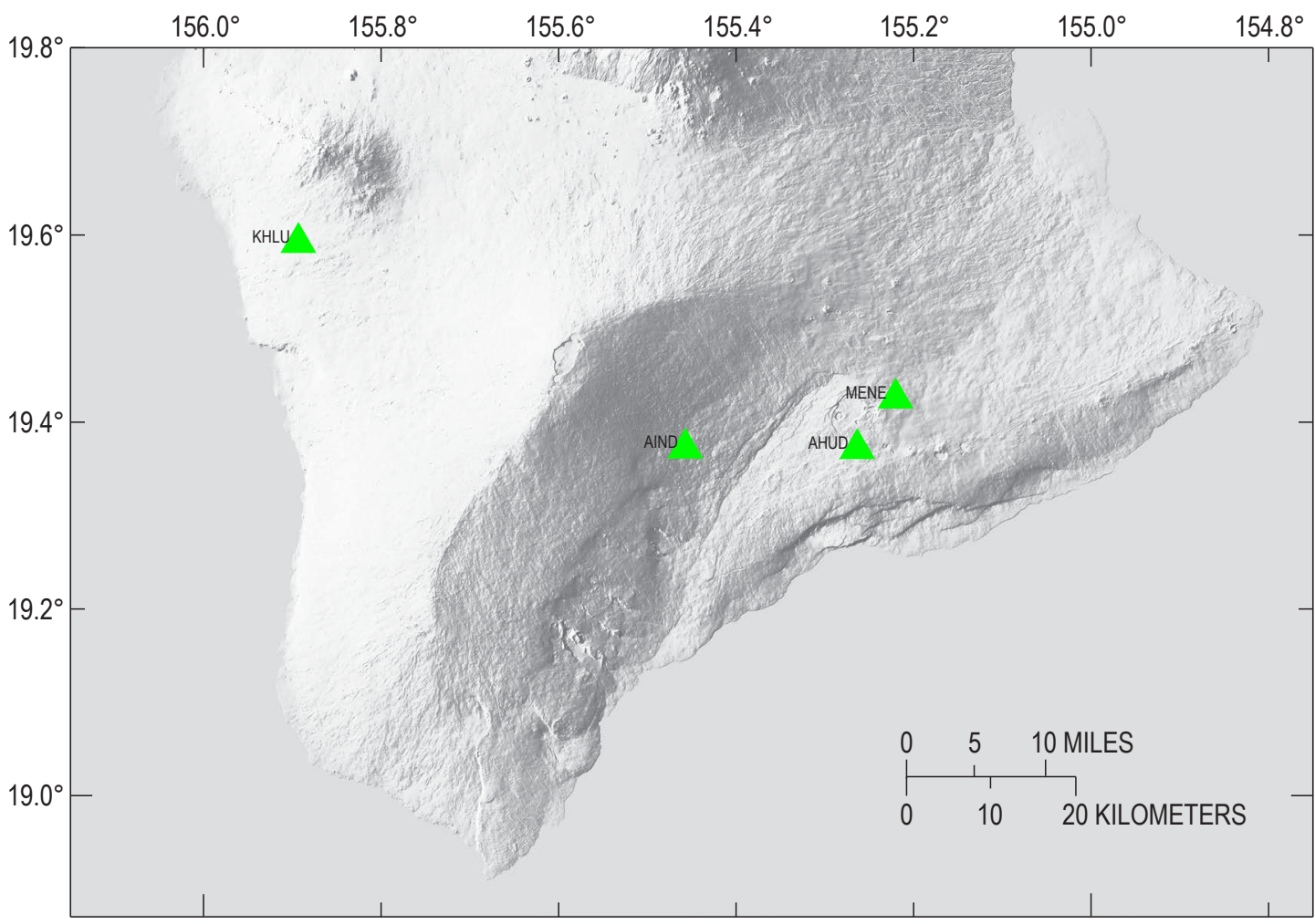

Figure 3. Map showing infrasound arrays across the Island of Hawai'i. Arrays AIND and AHUD are operated by the Hawaiian Volcano Observatory. Arrays MENE and KHLU are maintained by the Infrasound Laboratory at the University of Hawaíi. 


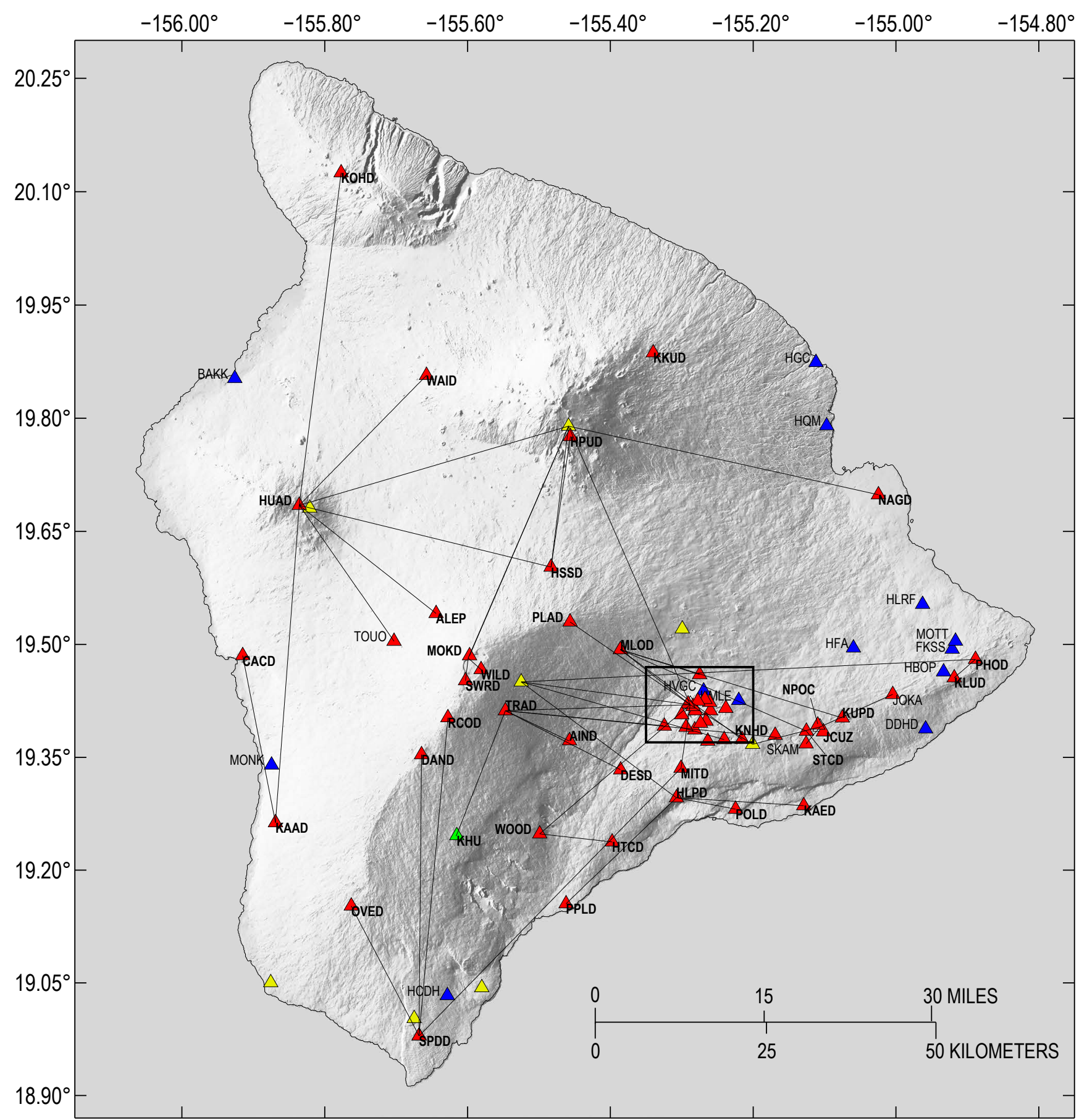

Figure 4. Telemetry map of stations maintained by the Hawaiian Volcano Observatory (HVO) (red triangles). Lines show telemetry paths. Station KHU has hardware owned by the Pacific Tsunami Warning Center, but the radio infrastructure is HVO's and thus included here. Netquakes instruments (blue triangles) are telemetered back to Menlo Park, California, via wireless Internet connection. KKUD is telemetered via cell modem. Yellow triangles are digital backbone nodes. Inset box shows extent of map in figure 5 . 


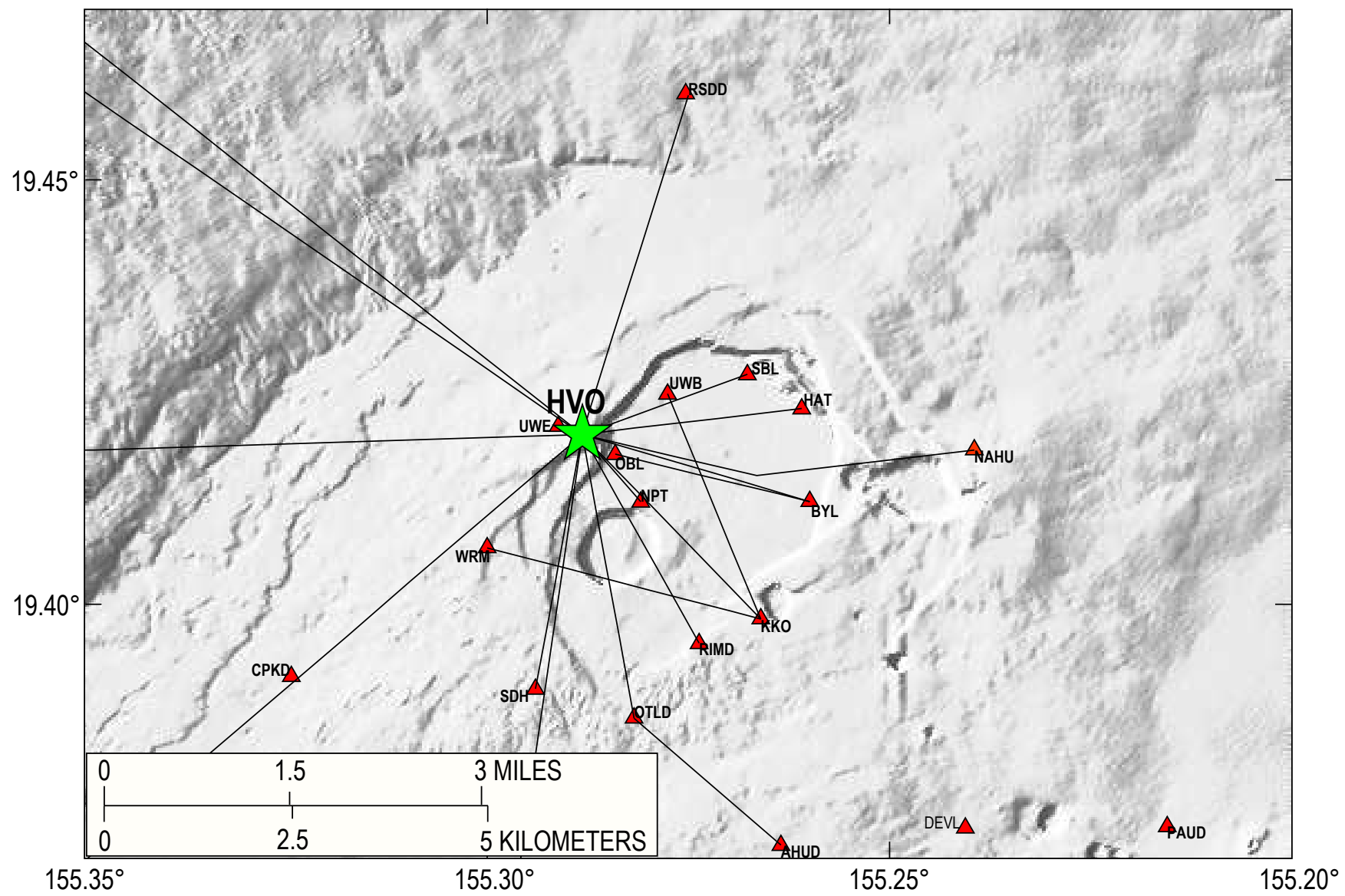

Figure 5. Telemetry map of Kïlauea Caldera (location shown in fig. 4). Star shows location of the Hawaiian Volcano Observatory. Red triangles are seismic stations. Lines show telemetry paths. 


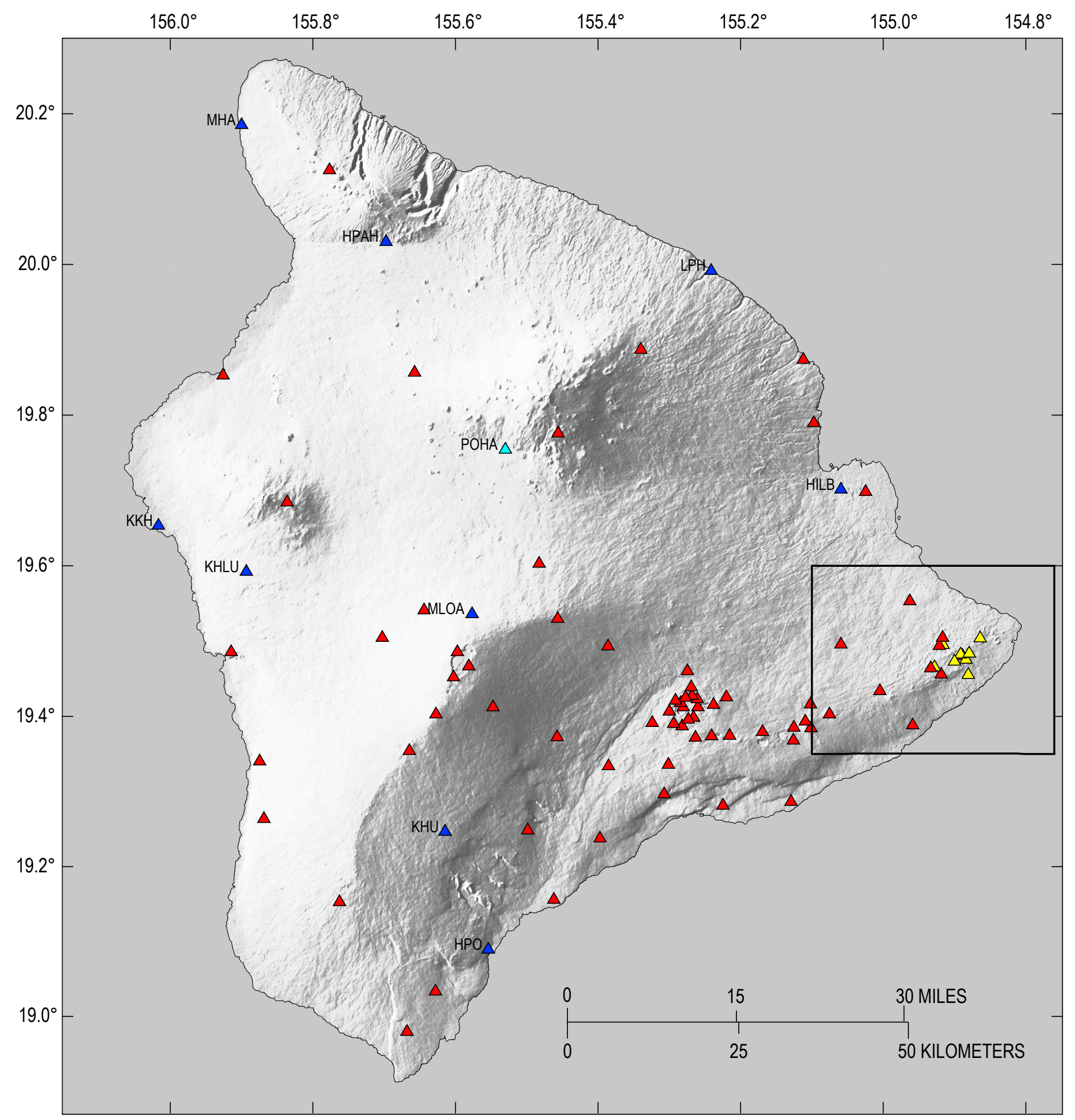

Figure 6. Seismic stations of partner agencies on the Island of Hawai'i. Blue triangles ( 9 stations) are operated by the Pacific Tsunami Warning Center (network code PT), light blue triangle (1) is in the Global Seismograph Network (IU) and yellow triangles (8) are in the Puna Geothermal Network (PH). Red triangles are Hawaiian Volcano Observatory stations from figs. 1 and 2. Box shows extent of map in figure 7. 


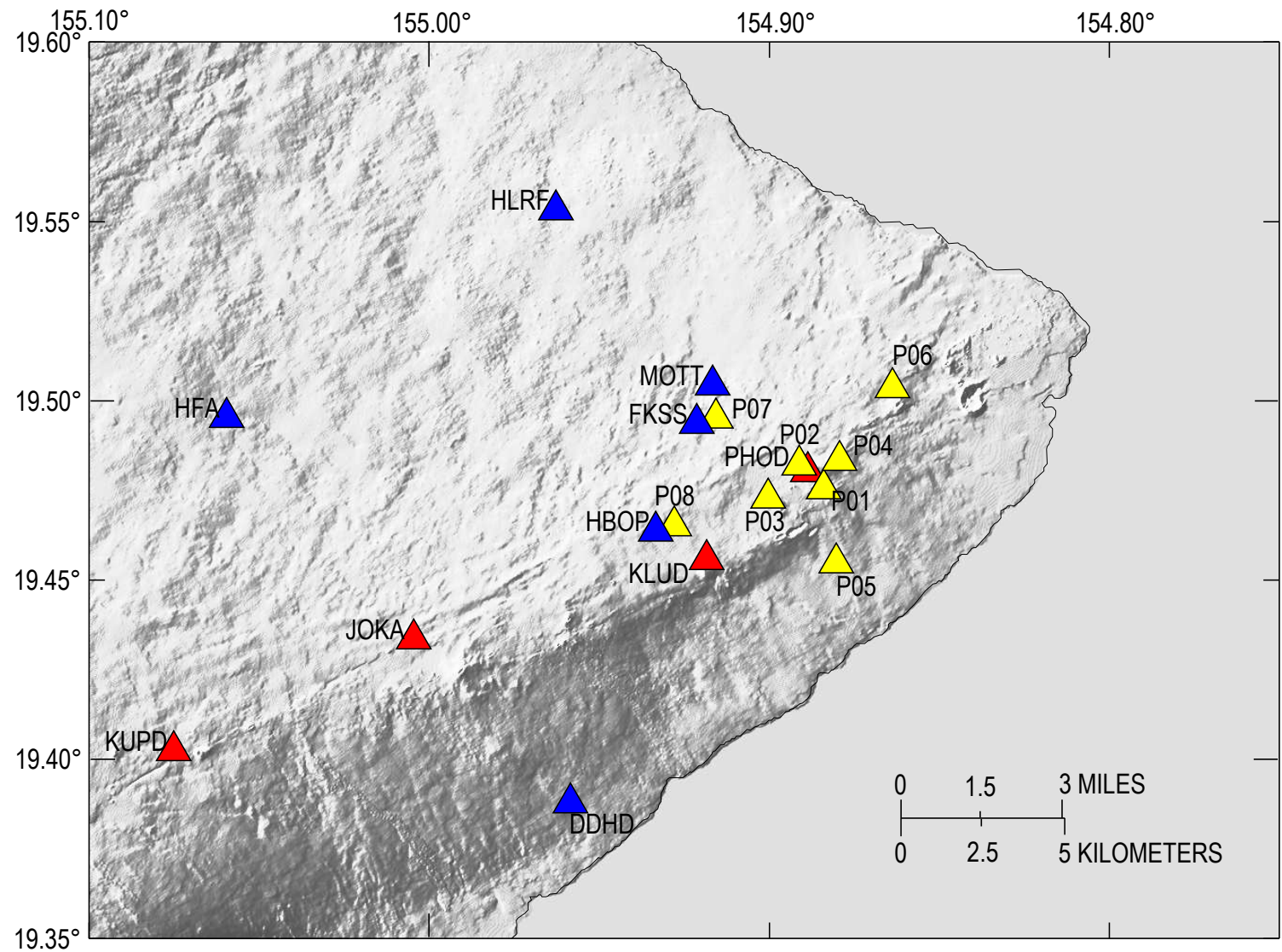

Figure 7. Map showing the seismic stations on the lower East Rift Zone (location shown in fig. 6). Red triangles are Hawaiian Volcano Observatory stations, blue triangles are Netquake instruments, and yellow stations are seismometers of the Puna Geothermal Venture plant.

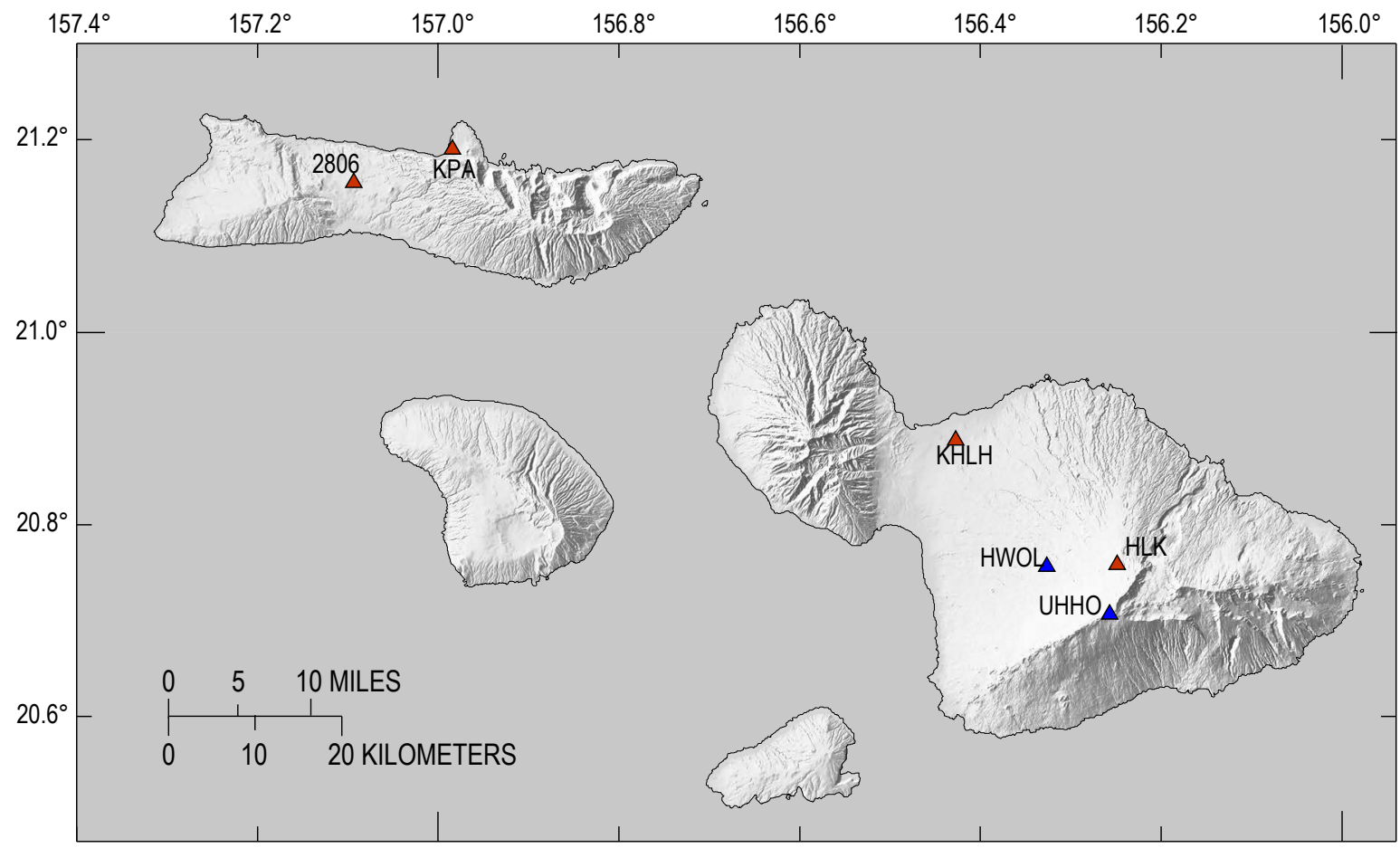

Figure 8. Seismic network in Maui County. Red triangles (4) are stations of the Pacific Tsunami Warning Center; blue triangles (2) are Netquake instruments. 


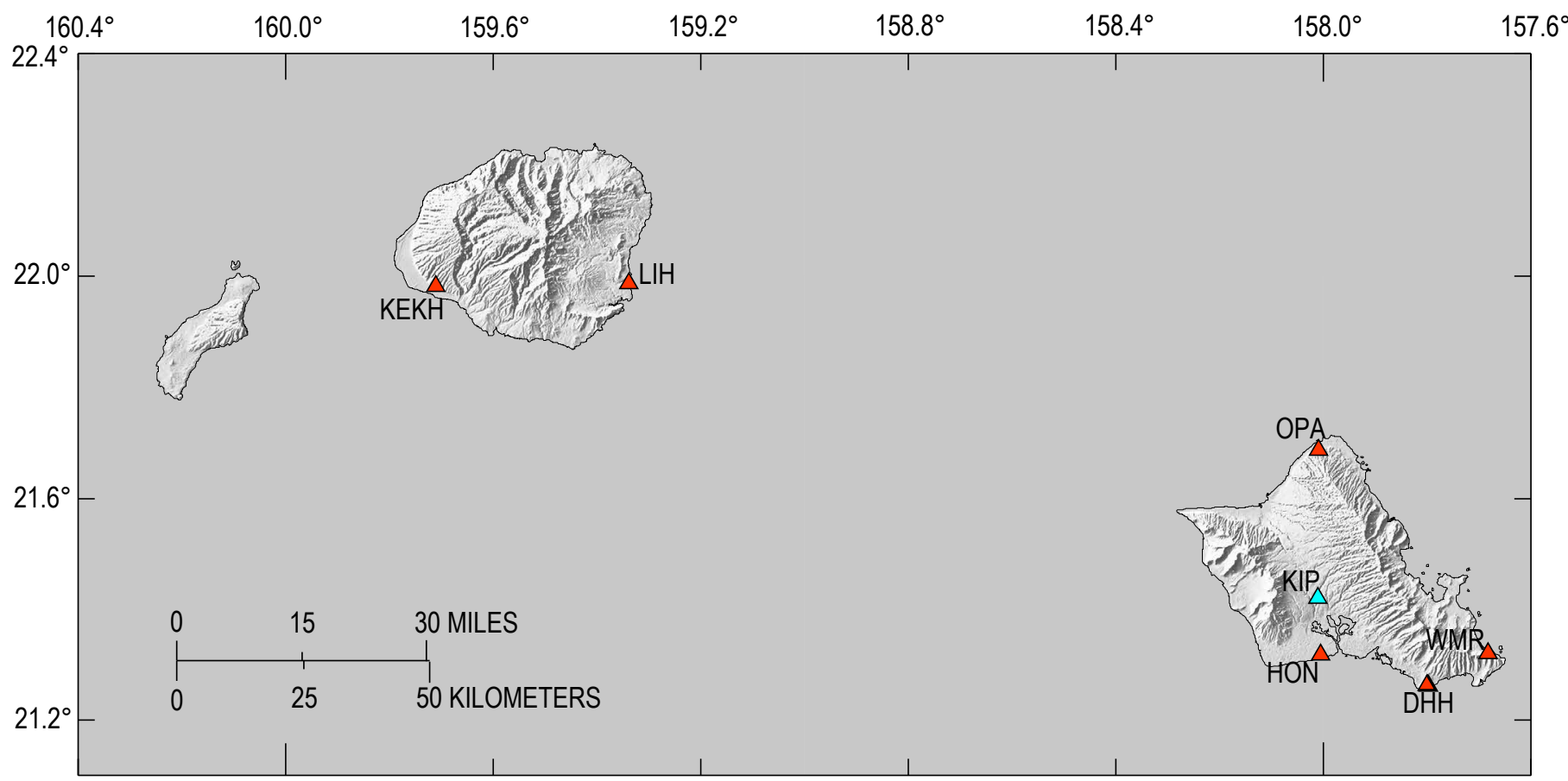

Figure 9. Seismic network in O'ahu and Kaua'i Counties. Red triangles are stations of the Pacific Tsunami Warning Center; light blue triangle is a station from the Global Seismograph Network.

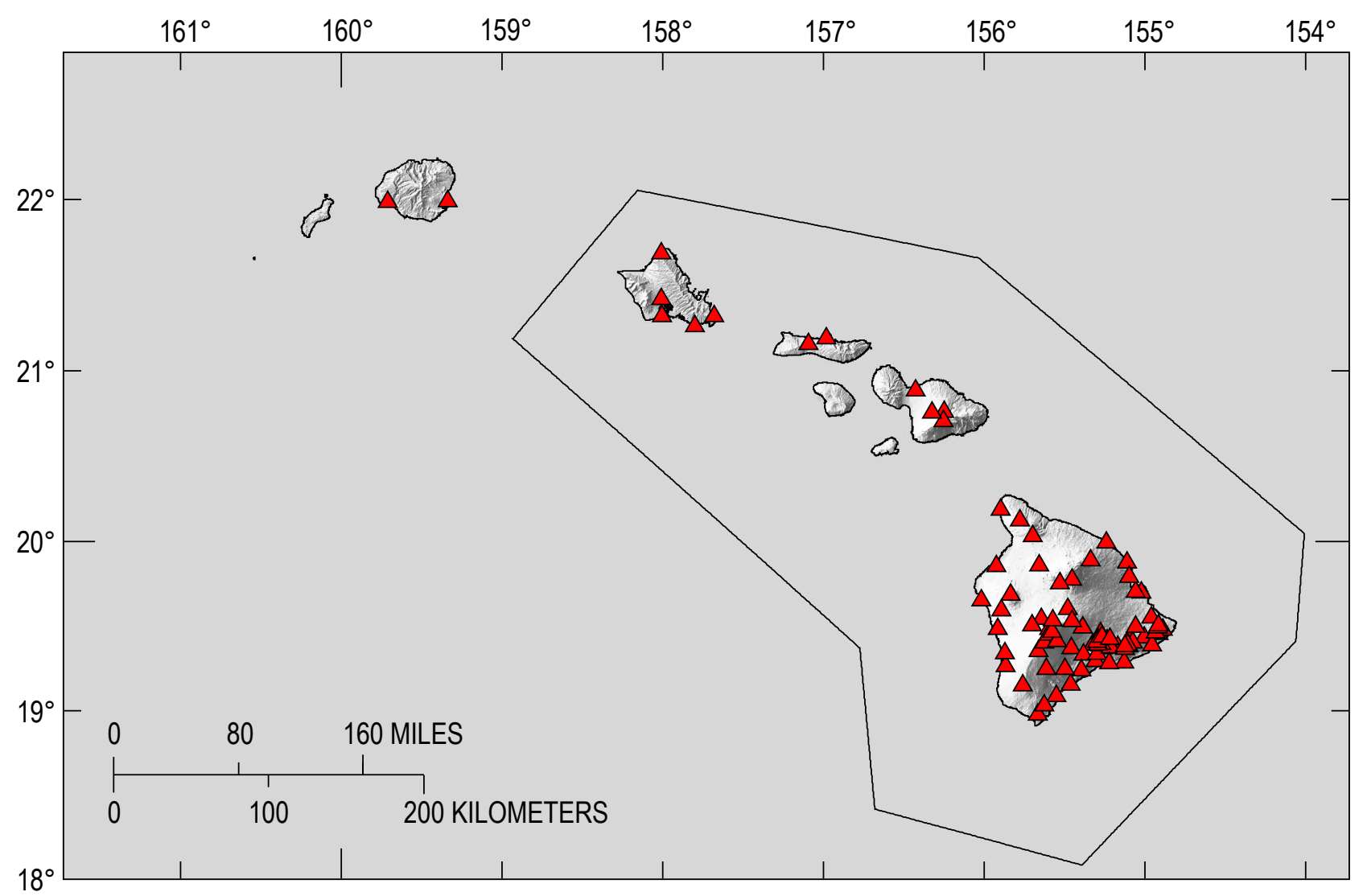

Figure 10. Authoritative region of Hawaiian Volcano Observatory (black line). Red triangles show locations of permanent, continuously operated seismic stations and Netquakes instruments. National Strong Motion Project stations are excluded from this map because their high triggering threshold $(M>3.5)$ results in data for only a handful of located earthquakes each year. 


\section{Processing}

Since the second quarter of 2009, the AQMS system (ANSS Quake Management Software) was adopted as the daily processing routine, which is an Oracle database frontend around an Earthworm software back-end. Real-time detection schemes are all carried out by the Earthworm modules pickFP and carlSta* modules. Locations (automatic and reviewed) are calculated by HYPOINVERSE with magnitudes calculated by localmag and codamag modules. Results are stored in an Oracle database. The AQMS database runs on three Solaris servers, a primary and backup real-time server, and a post-processing server. Earthquake review uses a Java software package named Jiggle. Earthquake hypocenters are published in the ANSS Comprehensive Catalog (Comcat: http://earthquake.usgs.gov/earthquakes/search/) and to Volcweb, HVO's webpage for serving earthquake data to the public (http://hvo.wr.usgs.gov/seismic/volcweb/earthquakes/). Automatically determined earthquake locations above $M 1.7$ are published publicly (Comcat and Volcweb). Reviewed solutions are published publically regardless of magnitude. Earthquake locations and magnitudes are generally posted within 5 minutes of their occurrence. Earthquake information and triggered waveforms are available on request. Phase picks are not currently posted publically. The development of the quakeML module to share earthquake information, phase information, and focal mechanisms with NEIC is eagerly anticipated. Amplitude data are available from automatic and reviewed solutions within the AQMS database within a minute of an earthquake solution. Those amplitude data are made available to the NEIC for creating a Shakemap.

\section{Seismic Catalog}

The emphasis of both station coverage and detailed data analysis is on the highly active southern half of the Island of Hawai' ${ }^{\prime}$. The data set of well-recorded, located earthquakes in that region is nearly complete above magnitude 2.0 with nearly all earthquake solutions having gone through a formal review (fig. 11). All events above magnitude 3.0 have been formally reviewed. Many earthquakes smaller than magnitude 2.0 are locatable in the Kilauea region because of the dense instrumental coverage. Substantial effort is made to locate earthquakes elsewhere within the Hawaiian Archipelago, and although such coverage cannot be as complete as it is in southern Hawai' $i$, nearly all events above magnitude 3.0 are located with limited precision. Events greater than M2.95 are listed in the appendix. Despite the presence of automatic solutions in the catalog, the errors in those locations are largely within the ANSS standard for areas with a high seismic hazard (fig. 12).

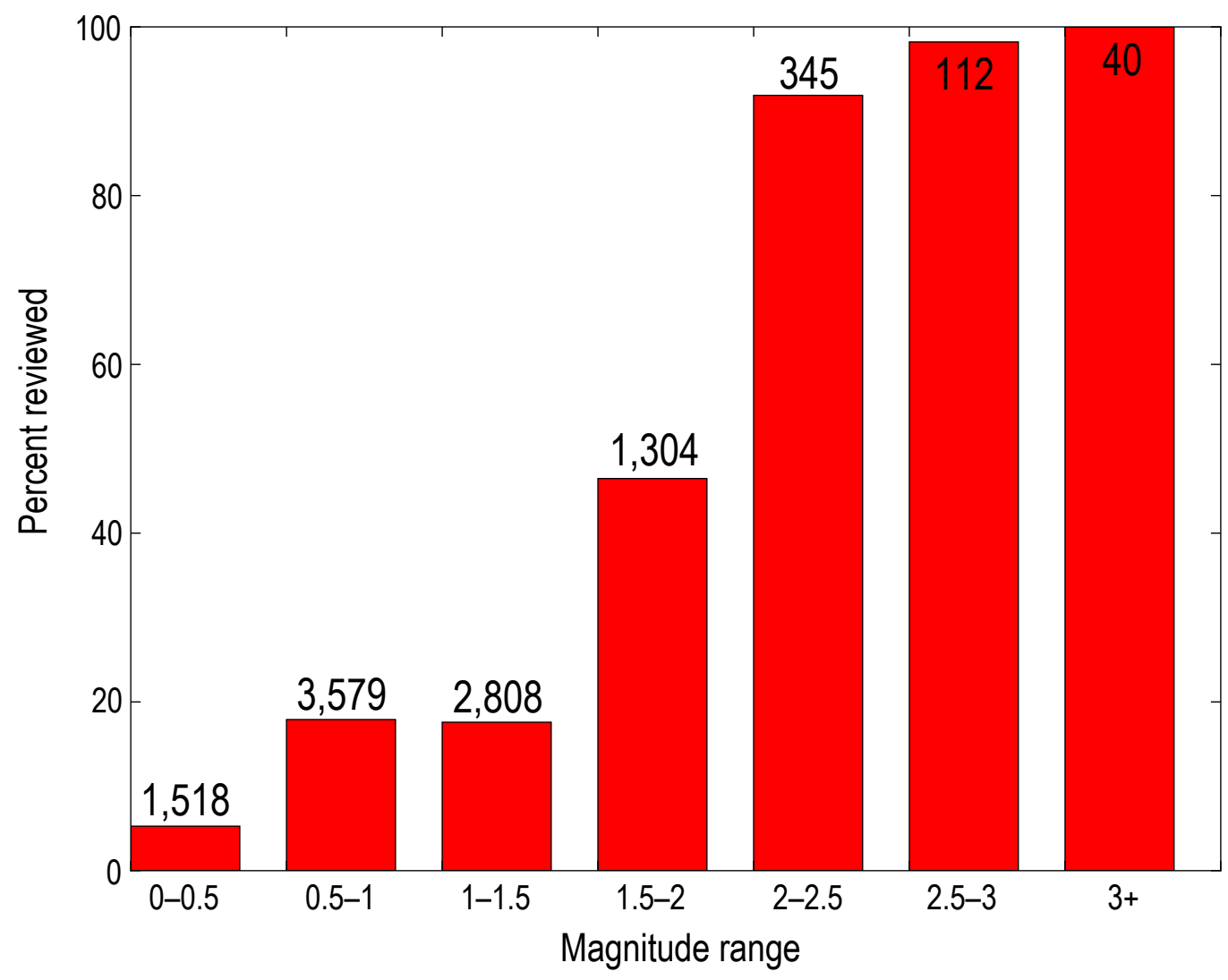

Figure 11. Chart of the percentage of earthquakes reviewed with respect to magnitude. During review, an analyst manually picks the individual arrivals and location and recalculates the magnitude. Number above the bar indicates the total number of catalogued earthquakes in that magnitude bin (both reviewed and nonreviewed). 

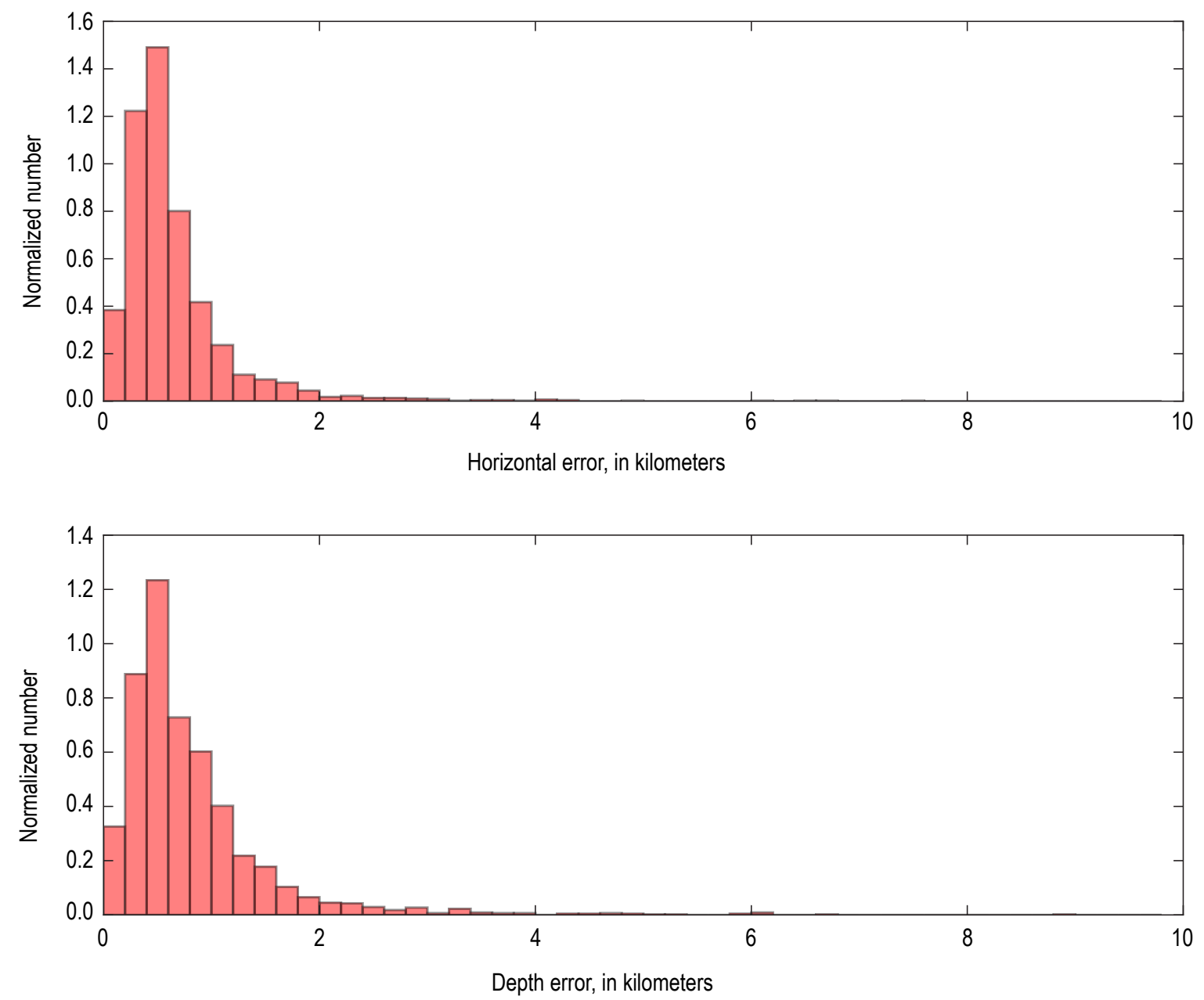

Figure 12. Histogram of horizontal and depth positional errors of earthquakes above M0.1 during 2014. The ANSS standard for earthquake locations in high-risk urban areas is $2 \mathrm{~km}$ in map view and $4 \mathrm{~km}$ in depth, a standard met by nearly every reviewed earthquake in the Hawaiian Volcano Observatory catalog. Earthquake counts are normalized to the total number of earthquakes located in 2014.

Earthquake hypocenters are computed within a onedimensional velocity model (table 2). Velocity at any depth above a homogeneous half-space is given by linear interpolation between points.

Table 2. Velocity model used for earthquake locations.

[The model consists of gradients between nodes and was originally derived from Klein (1981)]

\begin{tabular}{cc}
\hline $\begin{array}{c}\text { Velocity } \\
(\mathbf{k m} / \mathbf{s e c})\end{array}$ & $\begin{array}{c}\text { Depth } \\
(\mathbf{k m})\end{array}$ \\
\hline 1.9 & 0.0 \\
6.5 & 4.6 \\
6.9 & 15.0 \\
8.3 & $\geq 16.5$ \\
\hline
\end{tabular}

Two empirical sets of station delays or corrections are used in the HYPOINVERSE locations. The delay models are separated by a circle of radius $34 \mathrm{~km}$, centered at $19^{\circ} 22^{\prime} \mathrm{N}$ and $155^{\circ} 10^{\prime} \mathrm{W}$. Delay model 1 is used for epicenters occurring within a circle of radius $31 \mathrm{~km}$ from the center. This region includes Kîlauea and its south flank. A combination of both delay models is used for epicenters that fall in a 6-km-wide transition zone around this $31-\mathrm{km}$ circle. Delay model 2 is applied to the rest of the island and to offshore earthquakes. For a detailed description, refer to the documentation for HYPOINVERSE-2000 (Klein, 2002).

Magnitudes for events are computed using either a local magnitude or a duration magnitude. Both types of magnitude are calculated as part of the real-time processing, but the local magnitude - if it can be calculated - is preferred in the automatic solutions because it is more reliable. Reviewed solutions using Jiggle also include calculated local magnitude and duration magnitude. The preferred magnitude is chosen at the discretion of the analyst. In general, local magnitudes are preferred in the 
reviewed solutions, but some circumstances may necessitate the use of a duration magnitude (especially for events of $M<1$ ). Both magnitude types were calibrated in 2009 to loosely match magnitudes from the legacy system. Because new hardware was installed during the digital upgrade of the seismic network, magnitudes will be recalibrated in 2015, with the new magnitude values reflected in Comcat.

\section{Interesting Activity}

Figures 14 through 27 show seismicity recorded during 2014 at various locations around the island. Earthquake locations are a combination of automatic and reviewed locations (so-called best possible) with horizontal position errors less than $2 \mathrm{~km}$ and vertical errors less than $4 \mathrm{~km}$, consistent with the ANSS standard for high-risk urban areas.

\section{Mauna Loa}

Mauna Loa had activity above background levels throughout 2014. Seismic activity on Mauna Loa was focused around three locations: $\sim 10 \mathrm{~km}$ west of the summit at depths of 7 to $13 \mathrm{~km}$, beneath Moku'āweoweo Caldera from 0 to $5 \mathrm{~km}$ depths, and beneath the Southwest Rift Zone in an area centered around Sulfur Cone typically from 2 to $5 \mathrm{~km}$ depths. Earthquakes occurred within different parts of the volcano throughout the year and there is some indication of a temporal relation between each series of events, but a source mechanism for each or a cause-and-effect relation between them is not clear.

The area west of the summit experienced high levels of seismicity in April and September. These swarms were located in the same place as those observed in September 2013 as well as the pre-eruptive swarms in 1984 and 1975, though the earthquakes recorded in 2014 were much smaller in magnitude than the pre-eruptive sequences.

Activity in the upper Southwest Rift Zone near Sulfur Cone and in the summit caldera of Mauna Loa was above the background levels customary since 1984 . While both those areas experienced an overall increased rate of seismicity, the activity on the west flank of the volcano is more swarm-like in nature. However, the energy release during the current period of Mauna Loa unrest is significantly less than that preceding the eruptions in 1975 and 1984.

In addition, several deep long period (DLP) earthquakes occurred in two zones - the first centered at approximately $13 \mathrm{~km}$ depth and the second between 40 and $50 \mathrm{~km}$ depth. These types of earthquakes are often attributed to magmatic processes. The number of DLP earthquakes in 2014 was the highest since the previous period of deformation at Mauna Loa, between 2002 and 2005.

The increase in seismic activity has been accompanied by deformation in the upper Southwest Rift Zone and summit region as detected by Global Positioning System (GPS) and interferometric synthetic aperture radar (InSAR). Deformation began in early 2014 and was localized in two pulses roughly between July and September 2014 and between October and December 2014 (see chapter C, "Deformation").

\section{Kīlauea}

Activity at Kîlauea was generally low compared to other years since the summit eruption began in 2008, except in the Southwest Rift Zone. Tremor was a ubiquitous feature of the seismicity at the summit, with amplitudes modulated by the presence or absence of spattering in the lava lake within Halema'uma'u.

Seismicity along the Southwest Rift Zone was above the long-term average in 2014. Swarms of activity occurred in late March/early April and in May. Between March 25 and April 9, seismicity in the southern part of the summit caldera increased substantially. This occurred along with inflation in the caldera as measured by the tiltmeter at station UWE. Seismicity increased in the southern part of the caldera about May 1. Events were of the same type and at similar depths as those that occurred in late March and early April. Tilt initially showed weak deflation in the presence of a generally high lava-lake level. Beginning around May 7, discrete very long period (VLP) and long period (LP) events were recorded in greater number. On May 10 at 16:25 UTC (06:25 HST) a VLP/LP swarm began, consisting of overlapping VLP codas. Subsequently the LP event rate increased and was replaced by tremor and rapid deflationary tilt. Earthquakes in the south caldera/upper Southwest Rift Zone increased dramatically once deflation commenced. Such an increase in seismicity in the south caldera area is highly anomalous during a steep deflation in the caldera (it is more often associated with magma movement into the East Rift Zone). Though not constrained by the geodetic data sets, the seismic evidence is consistent with an intrusion into the south caldera or farther afield into the Southwest Rift Zone.

Earthquake rates in the Southwest Rift Zone remained high for more than 3 weeks after the activity in the caldera on May 10. Earthquakes gradually decreased in areas to the south and west of the caldera, except for one area of seismicity southwest of Maunaiki. A swarm of events near Maunaiki also occurred between July 26 and July 29. The distribution of seismicity immediately after the activity on May 10 further supports an intrusion in the south caldera, but exactly how far this intrusion may have propagated into the Southwest Rift Zone, if at all it, is not clearly explained by the temporal or spatial patterns in seismicity.

On June 27 at 16:53 UTC (6:53 HST), a sudden deflation in tilt near $\mathrm{Pu}^{6} \mathrm{u}$ ' $\overline{\mathrm{O}}^{`} \overline{\mathrm{o}}$ culminated in a lava breakout (informally called the June 27th lava flow) from the north-northeast flank of $\mathrm{Pu}^{\prime} \mathrm{u}$ ' $\overline{\mathrm{O}}^{`} \overline{\mathrm{o}}$ cone. Tremor associated with the acceleration of deflation (and breakout) was recorded on seismic stations closest to $\mathrm{Pu}^{6} \mathrm{u}$ ' $\mathrm{O}^{`} \mathrm{o}$. In the hour before the tremor started, several high frequency earthquakes were recorded at two stations. Similar earthquakes happened immediately before the breakout in August 2011, but in much larger numbers. 


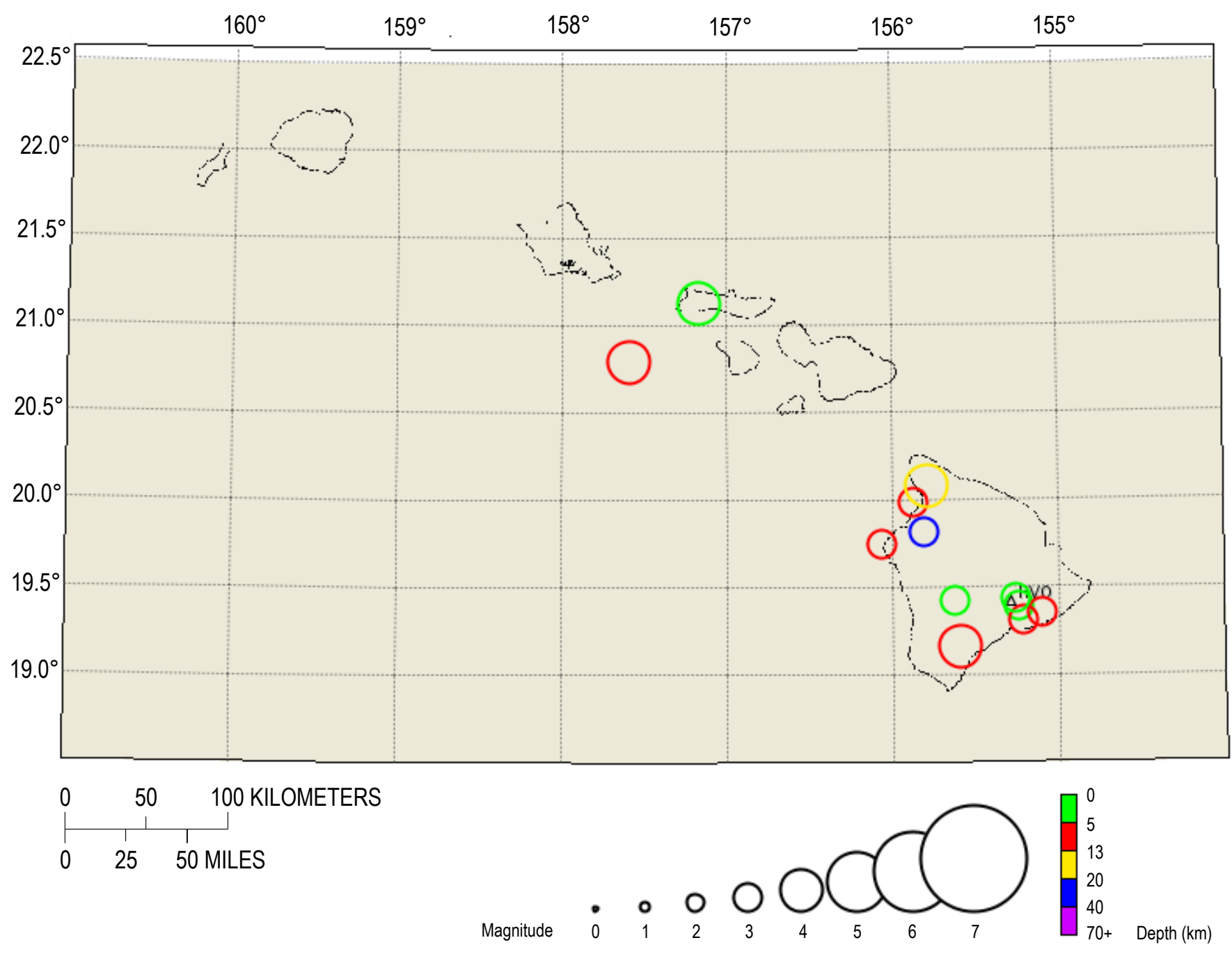

Figure 13. Map of earthquake locations in the Hawaiian Islands during 2014, showing earthquakes that were 0-60 km deep and having $M>3.5$. Symbol color reflects earthquake depth; symbol size depicts magnitude. All plotted earthquakes have been reviewed by an analyst. 


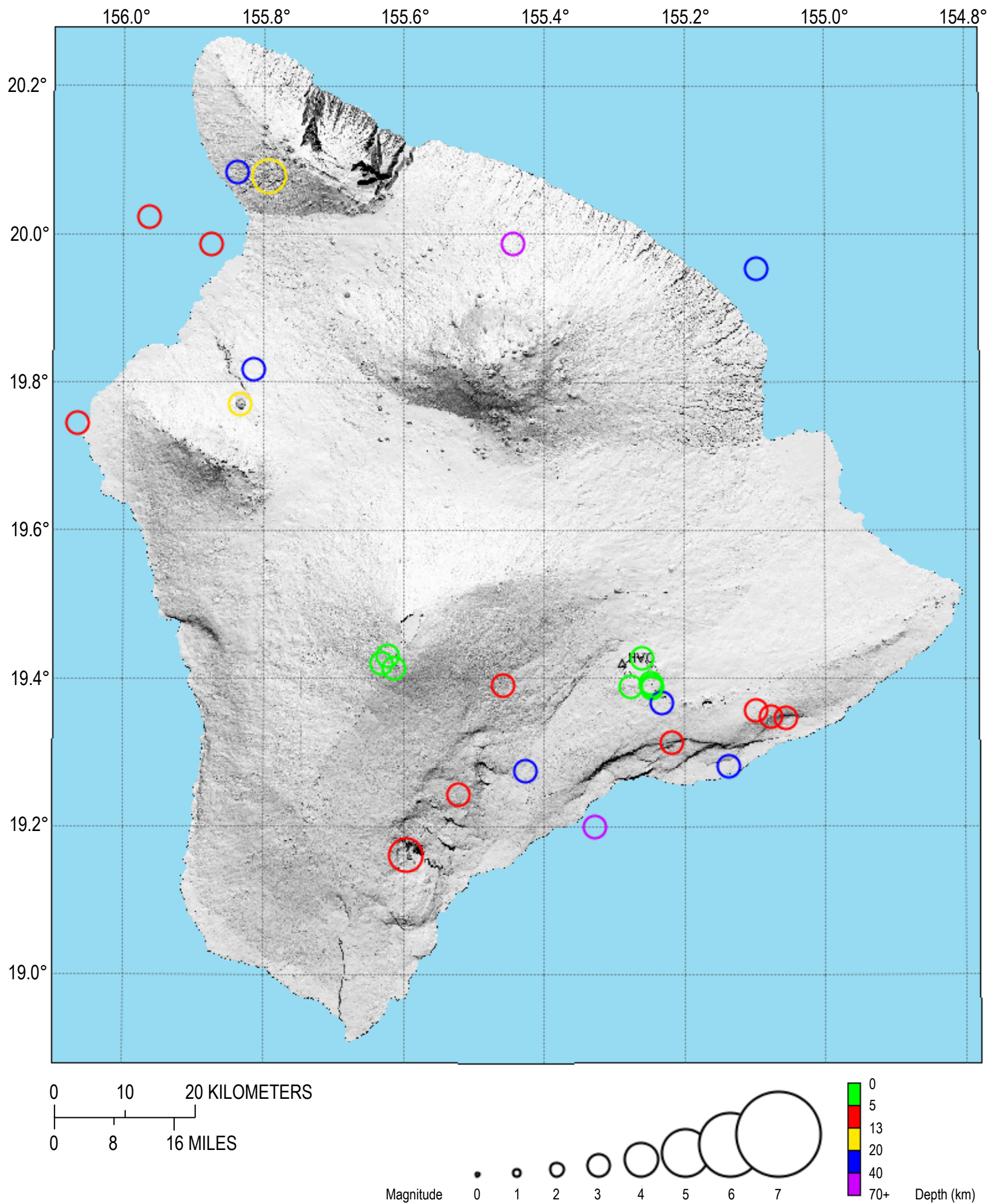

Figure 14. Map of earthquake locations on the Island of Hawaili during 2014, showing earthquakes that were 0-60 km deep having $M \geq 3$.0. Symbol color reflects earthquake depth; symbol size depicts preferred magnitude. All plotted earthquakes have been reviewed by an analyst. 


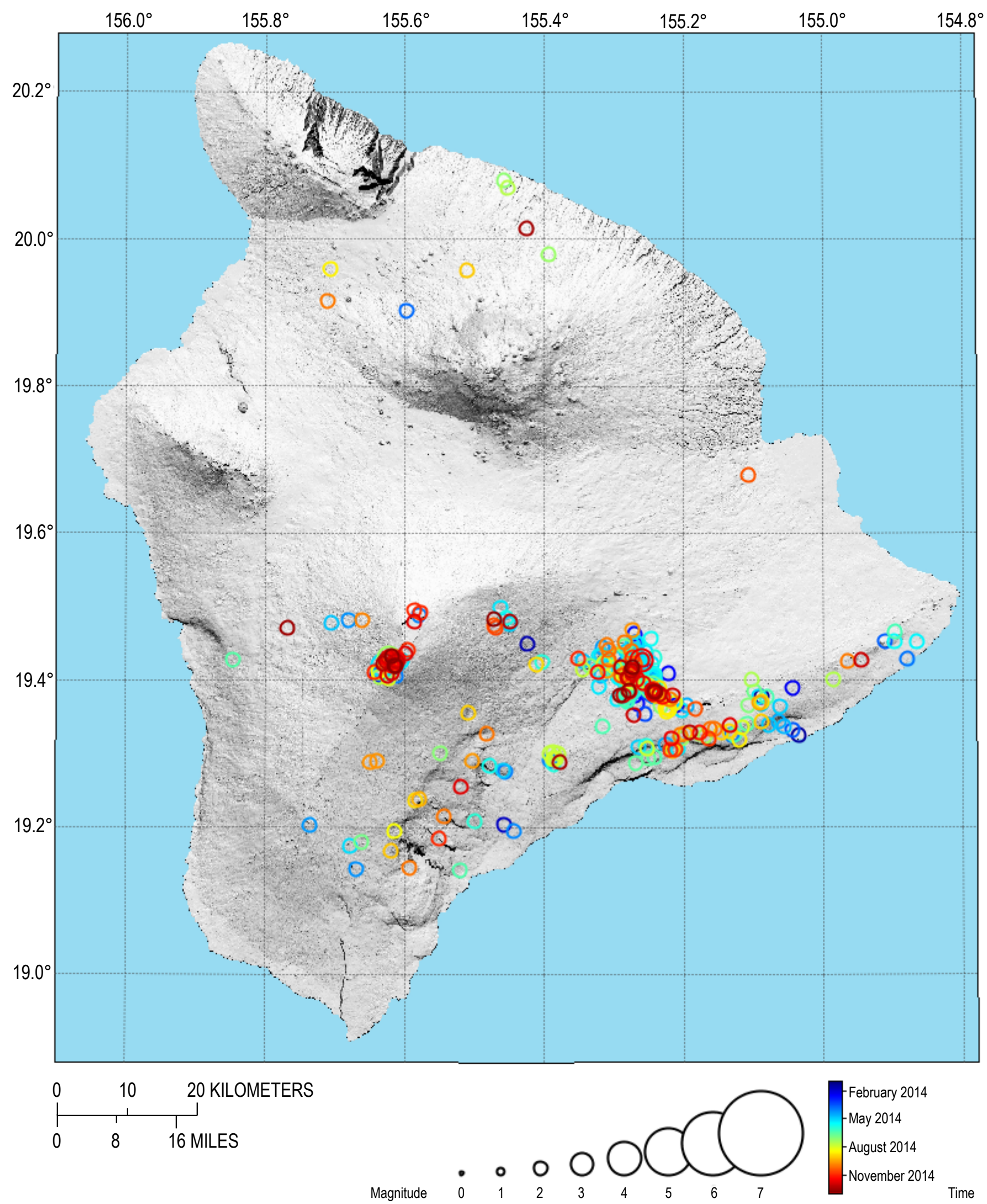

Figure 15. Map of earthquake locations on the Island of Hawaili during 2014 showing shallow ( $0-5 \mathrm{~km}$ deep) earthquakes having $M \geq 2$.0. Symbol color reflects date of earthquake. Symbol size depicts the preferred magnitude. Plotted events include both reviewed and automatically determined locations that have horizontal errors $<2 \mathrm{~km}$ and vertical errors $<4 \mathrm{~km}$. 


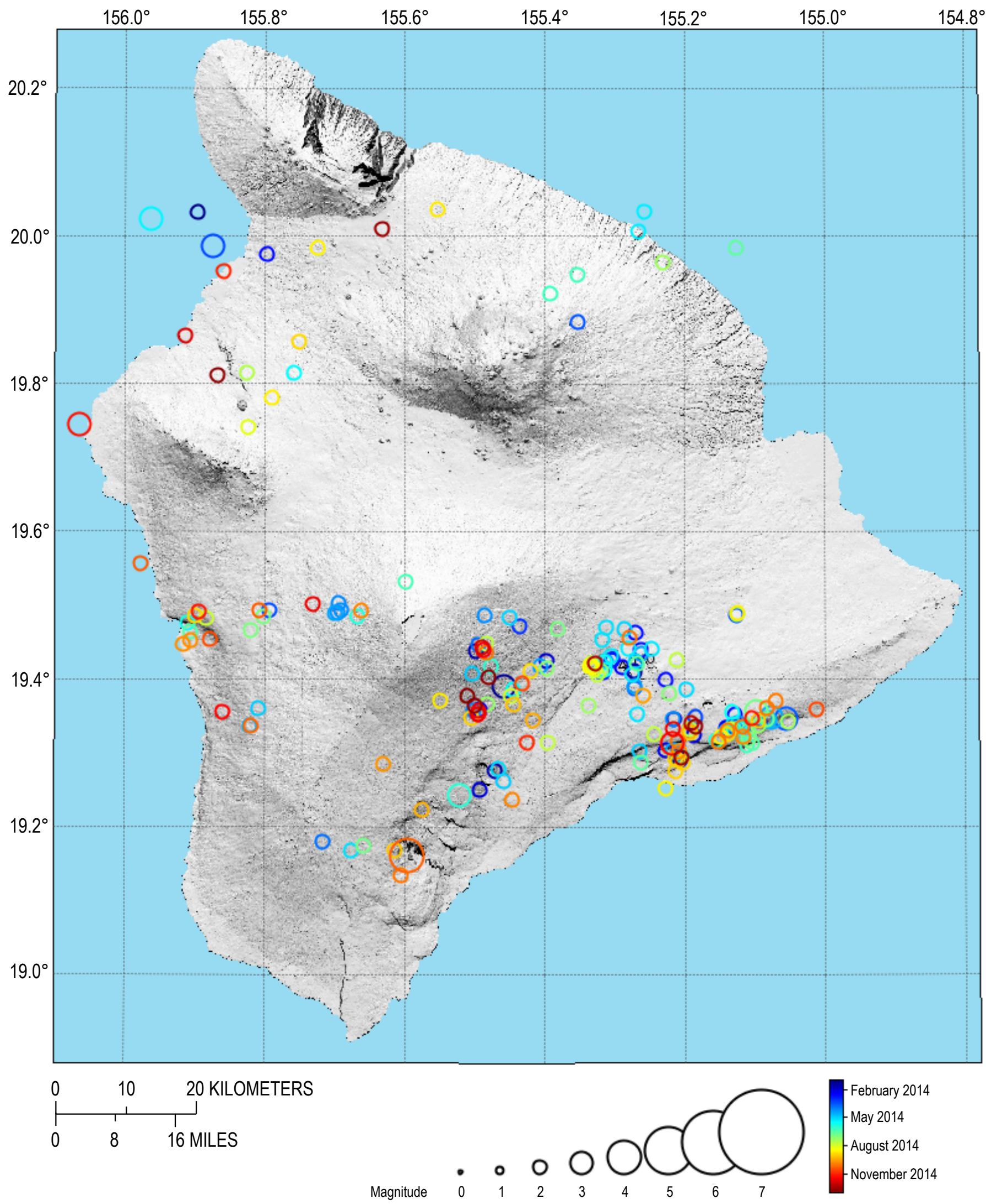

Figure 16. Map of earthquake locations on the Island of Hawaii during 2014 showing earthquakes of intermediate depth (5.1-13.0 km) having $M \geq 2.0$. Symbol color reflects date of event. Symbol size depicts the preferred magnitude. Plotted events include both reviewed and automatically determined locations that have horizontal errors $<2 \mathrm{~km}$ and vertical errors $<4 \mathrm{~km}$. 


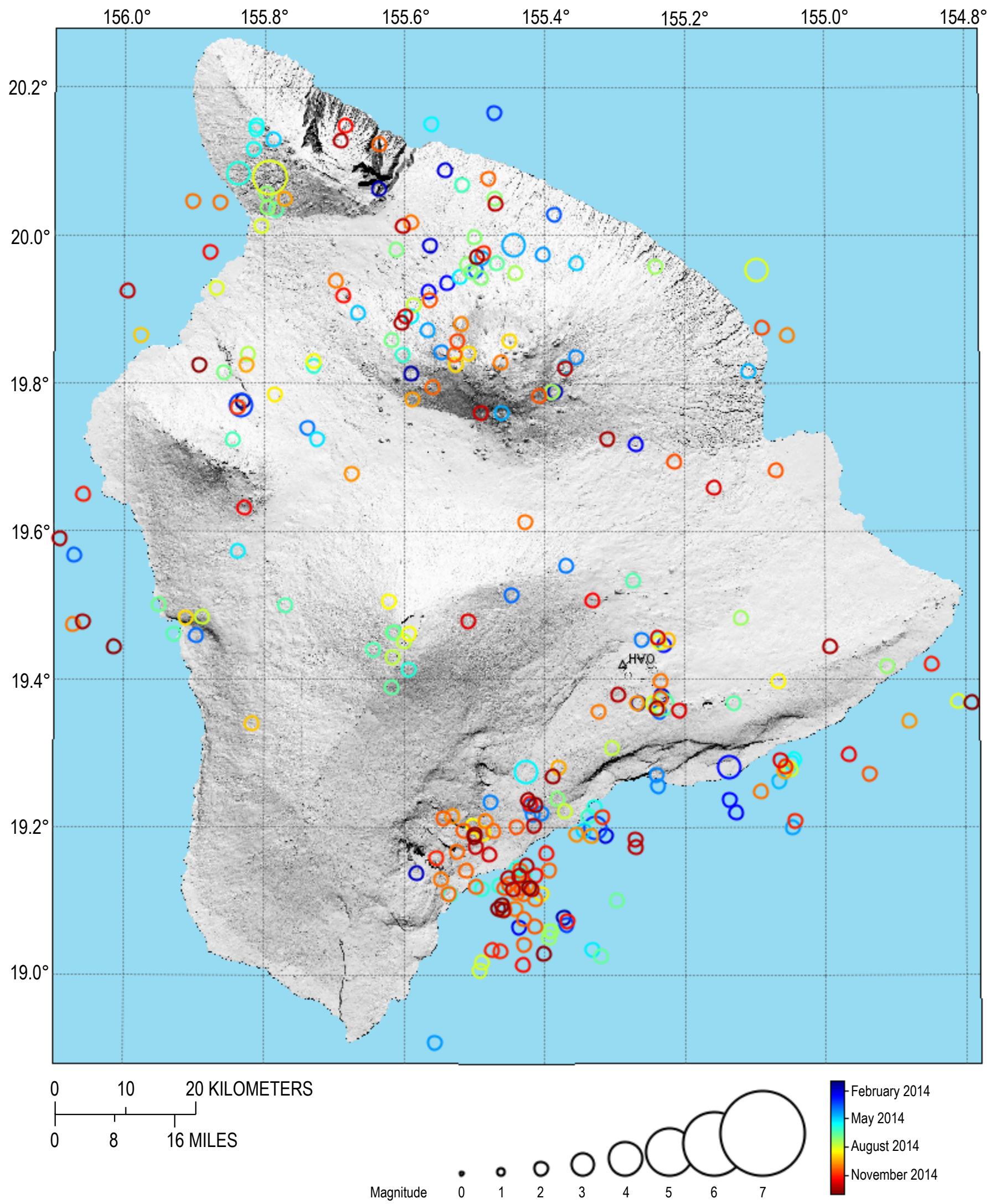

Figure 17. Map of earthquake locations on the Island of Hawaii during 2014 showing deep earthquakes $(13.1-60.0 \mathrm{~km})$ having $M \geq 2.0$. Symbol color reflects date of earthquake. Symbol size depicts the preferred magnitude. Plotted events include both reviewed and automatically determined locations that have horizontal errors $<2 \mathrm{~km}$ and vertical errors $<4 \mathrm{~km}$. 


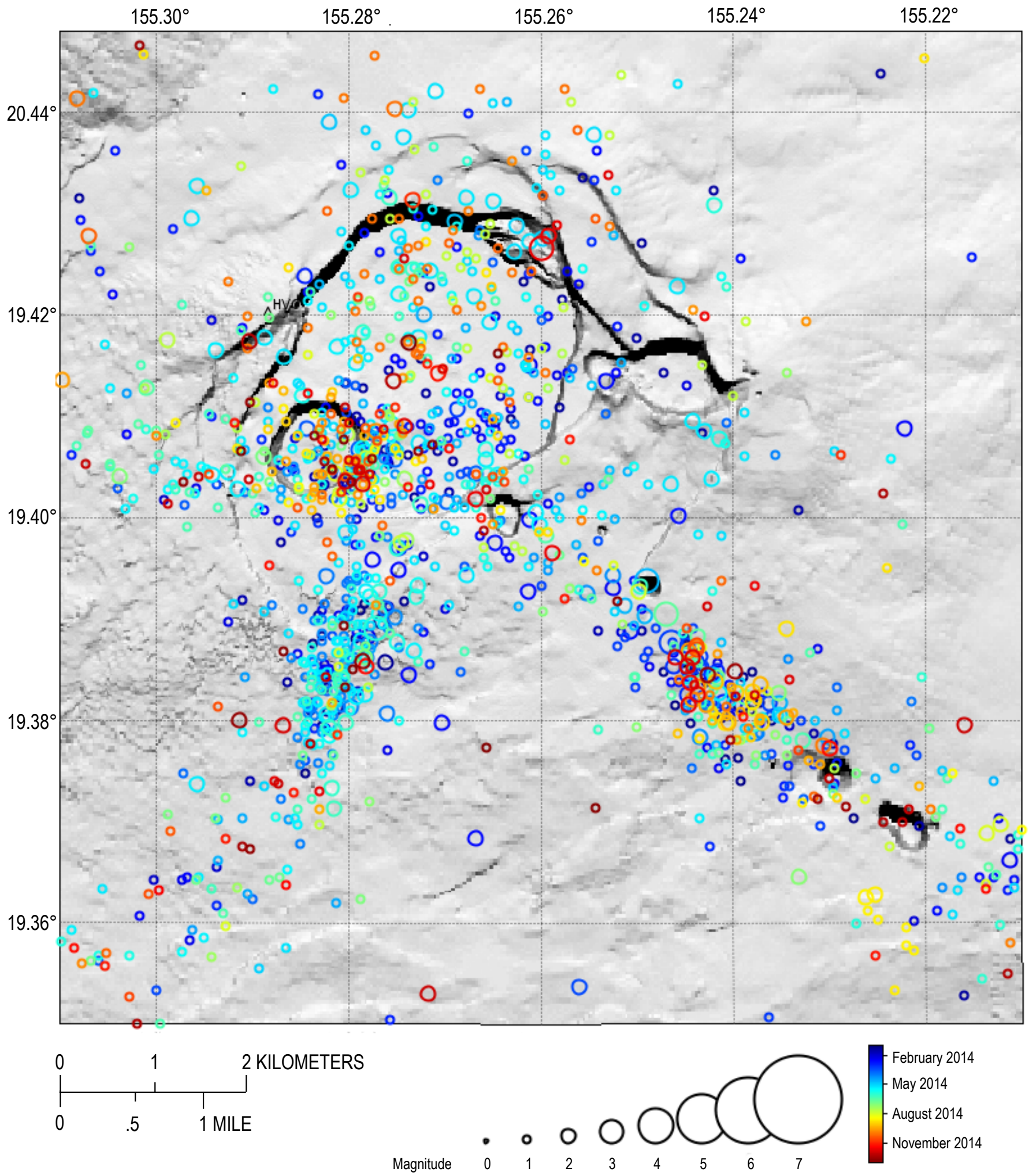

Figure 18. Map of earthquake locations at the Kïlauea summit during 2014 showing shallow earthquakes $(0-5.0 \mathrm{~km}$ deep) having $M \geq 1.0$. Symbol color reflects date of event. Symbol size depicts the preferred magnitude. Plotted events include both reviewed and automatically determined locations that have horizontal errors $<2 \mathrm{~km}$ and vertical errors $<4 \mathrm{~km}$. 


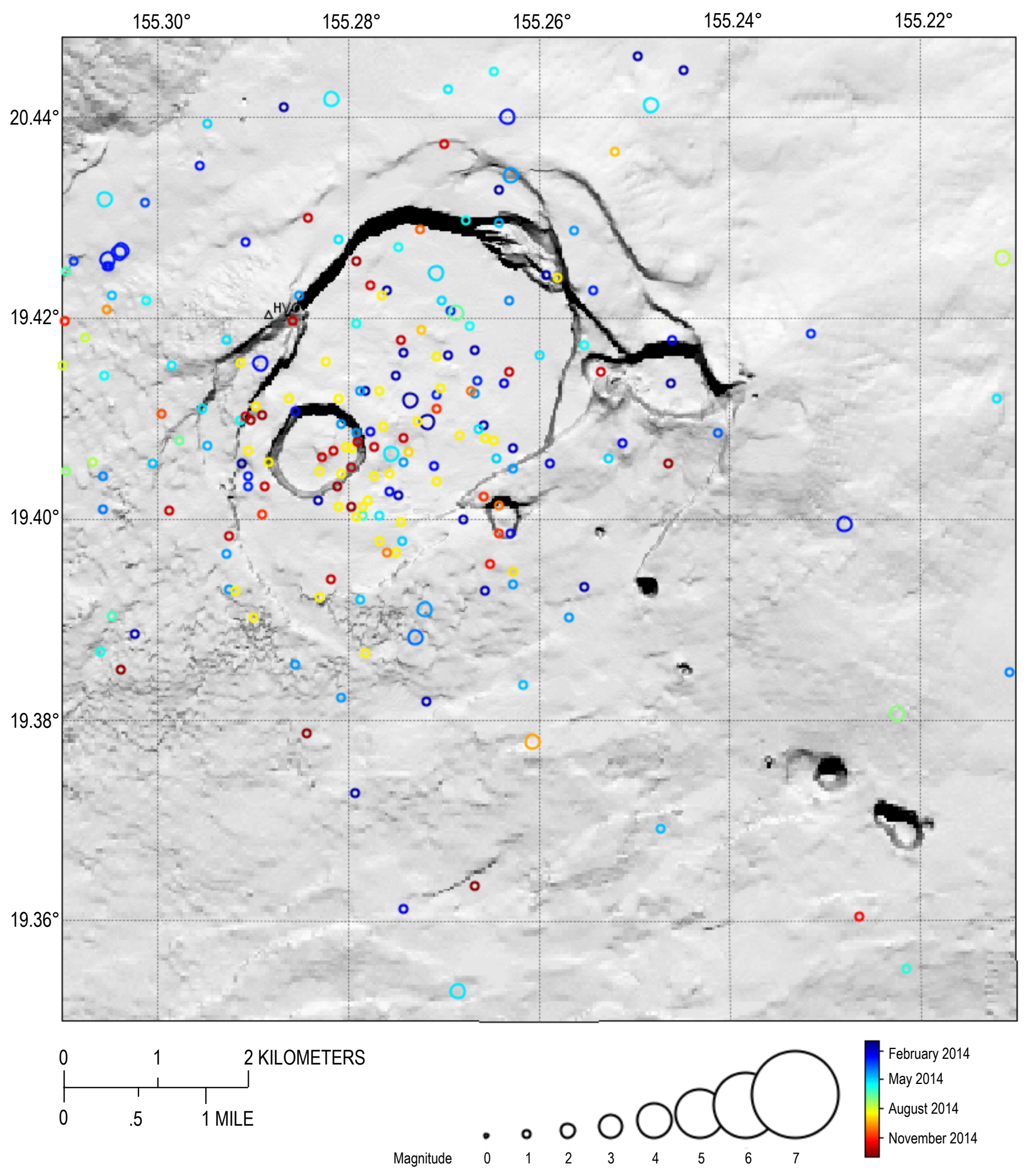

Figure 19. Map of earthquake locations at Kīlauea summit during 2014 showing earthquakes of intermediate depth (5.1-13.0 km) having $M \geq 1.0$. Symbol color reflects date of event. Symbol size depicts preferred magnitude. Plotted events include both reviewed and automatically determined locations that have horizontal errors $<2 \mathrm{~km}$ and vertical errors $<4 \mathrm{~km}$. 


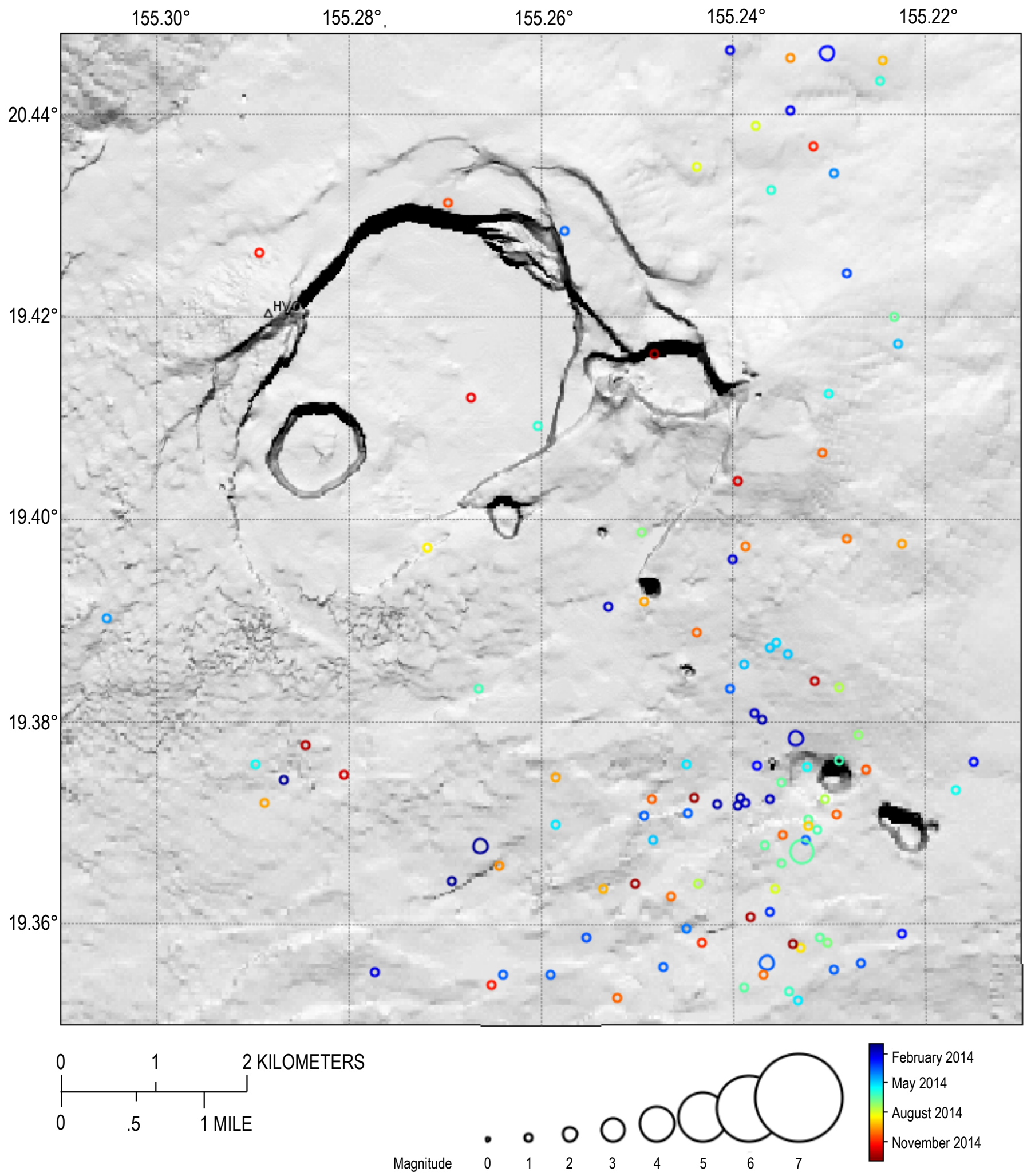

Figure 20. Map of earthquake locations at Kïlauea summit during 2014 showing deep earthquakes $(13.1-60.0 \mathrm{~km})$ having $M \geq 1.0$. Symbol color reflects date of event. Symbol size depicts preferred magnitude. Plotted events include both reviewed and automatically determined locations that have horizontal errors $<2 \mathrm{~km}$ and vertical errors $<4 \mathrm{~km}$. 


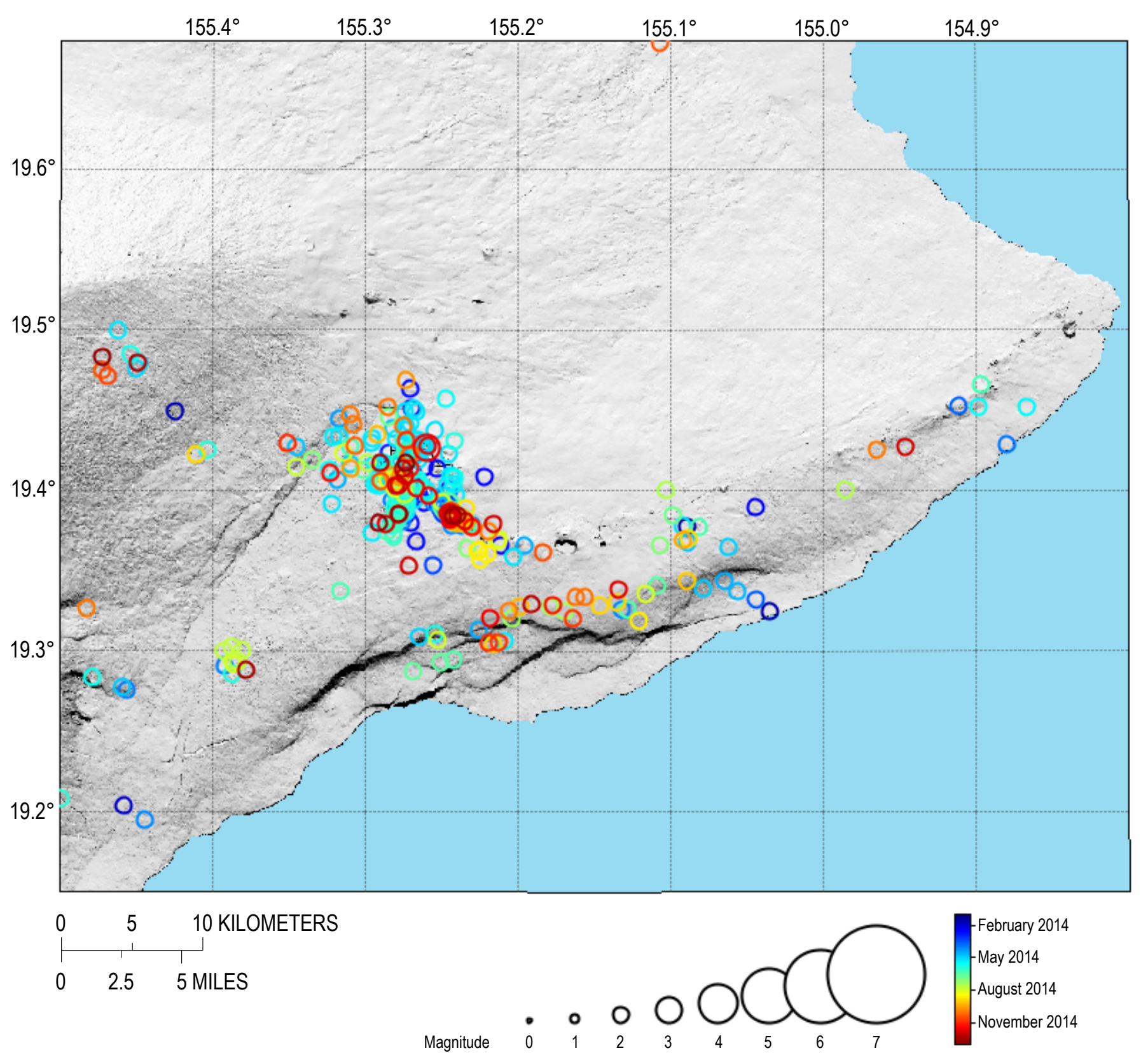

Figure 21. Map of earthquake locations along Kīlauea's East Rift Zone and south flank during 2014 showing shallow earthquakes (0-5.0 km) having $M \geq 2.0$. Symbol color reflects date of event. Symbol size depicts preferred magnitude. Plotted events include both reviewed and automatically determined locations that have horizontal errors $<2 \mathrm{~km}$ and vertical errors $<4 \mathrm{~km}$. 


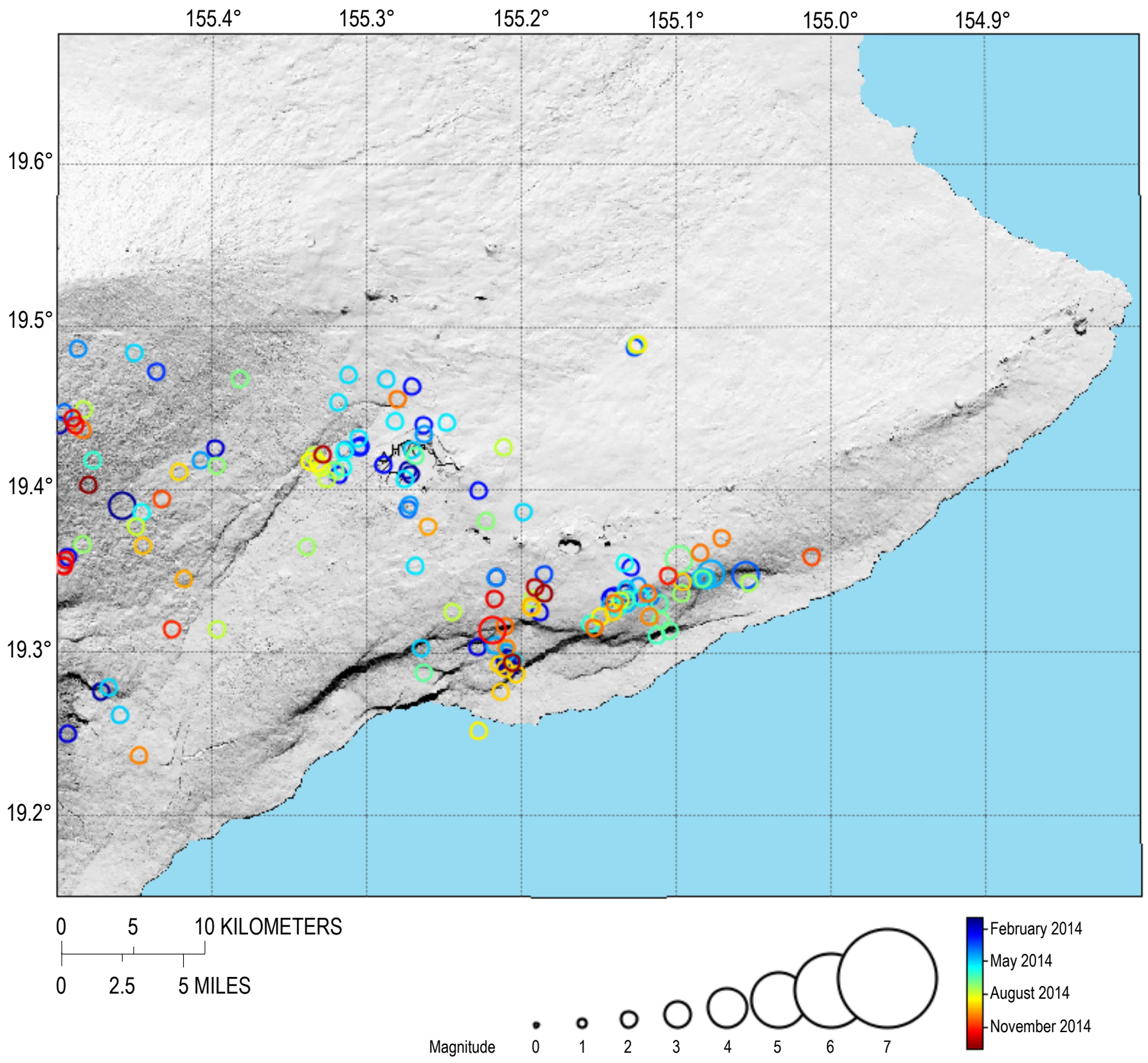

Figure 22. Map of earthquake locations along Kïlauea's East Rift Zone and south flank during 2014 showing earthquakes of intermediate depth (5.1-13.0 km) having $M \geq 2.0$. Symbol color reflects date of event. Symbol size depicts preferred magnitude. Plotted events include both reviewed and automatically determined locations that have horizontal errors $<2 \mathrm{~km}$ and vertical errors $<4 \mathrm{~km}$. 


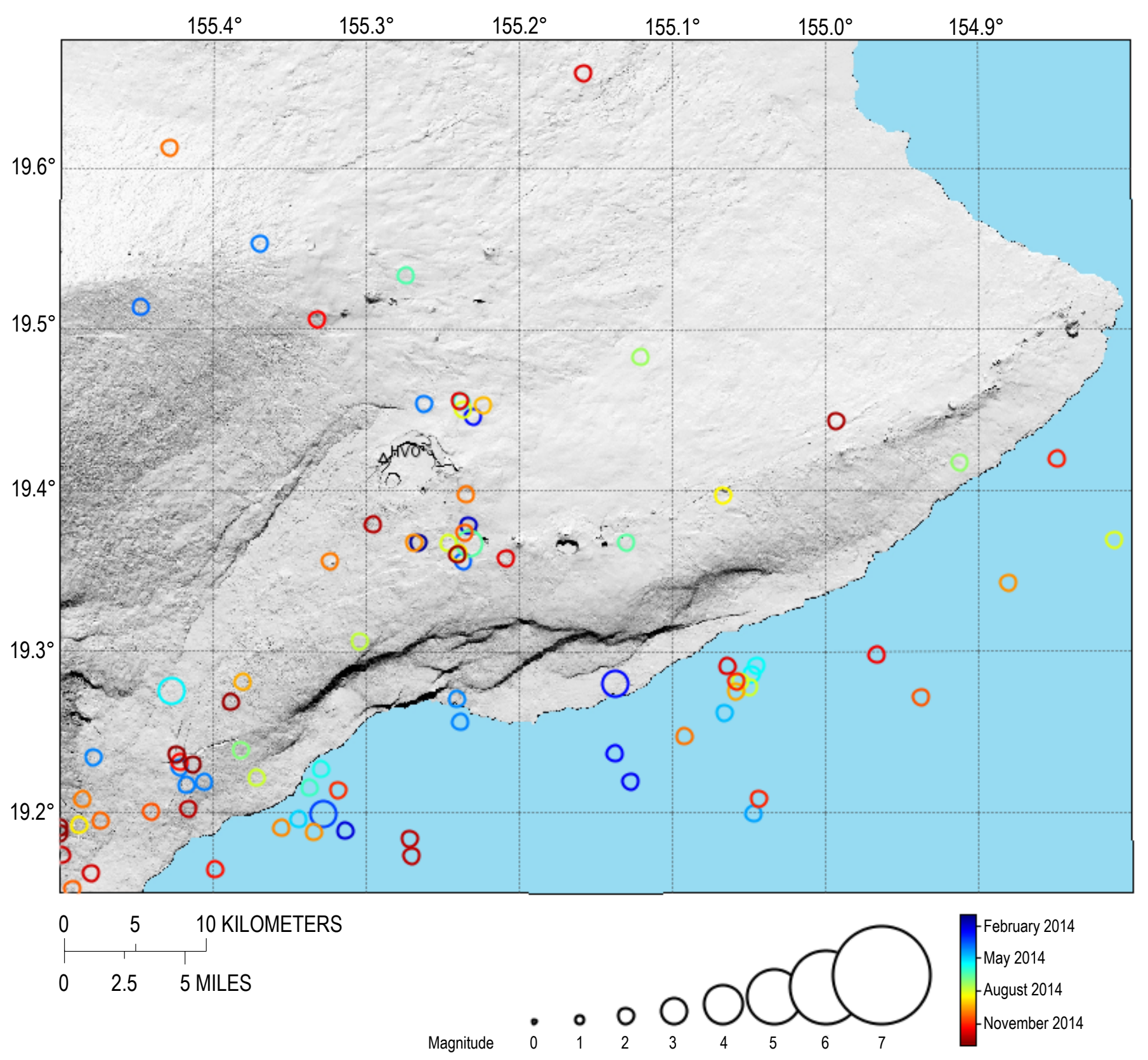

Figure 23. Map of earthquake locations along Kïlauea's East Rift Zone and south flank during 2014 showing deep earthquakes (13.1-60.0 km) having $M \geq 2.0$. Symbol color reflects date of event. Symbol size depicts preferred magnitude. Plotted events include both reviewed and automatically determined locations that have horizontal errors $<2 \mathrm{~km}$ and vertical errors $<4 \mathrm{~km}$. 


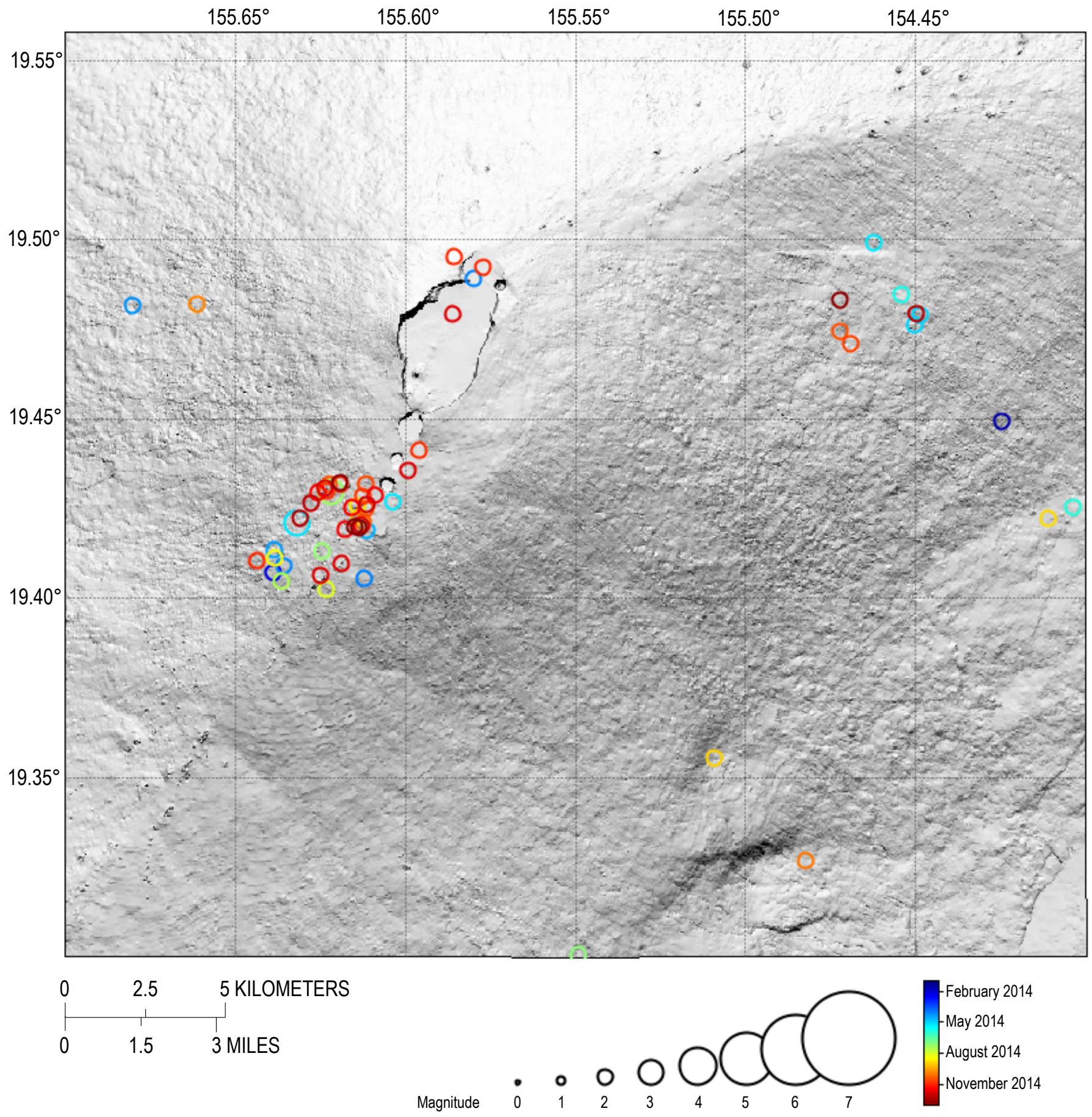

Figure 24. Map of earthquake locations near the Mauna Loa summit during 2014 showing shallow earthquakes $(0-5.0 \mathrm{~km})$ having $M \geq 2.0$. Symbol color reflects date of event. Symbol size depicts preferred magnitude. Plotted events include both reviewed and automatically determined locations that have horizontal errors $<2 \mathrm{~km}$ and vertical errors $<4 \mathrm{~km}$. 


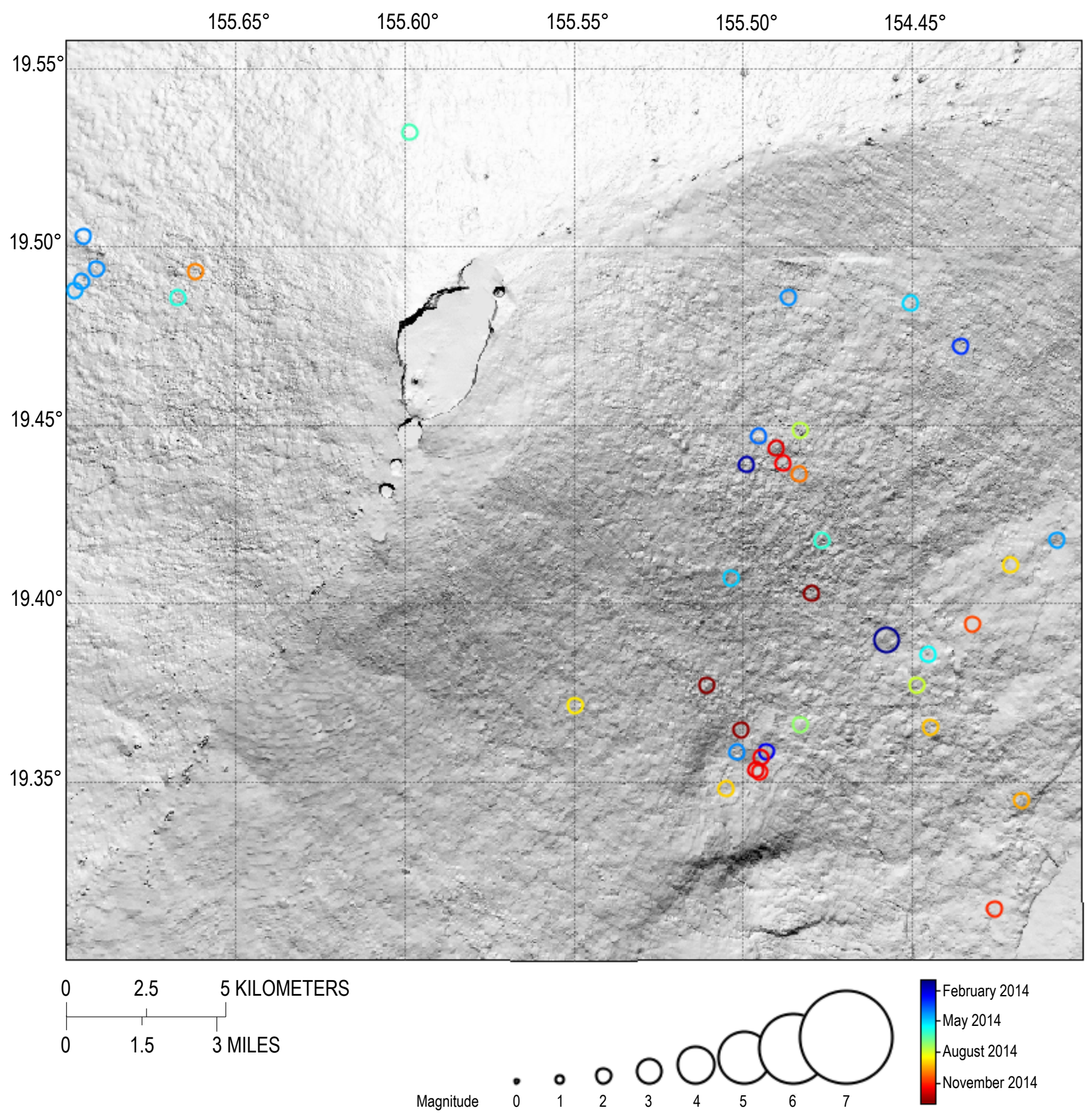

Figure 25. Map of earthquake locations near the Mauna Loa summit during 2014 showing earthquakes of intermediate depth (5.1-13.0 km) having $M \geq 2.0$. Symbol color reflects date of event. Symbol size depicts preferred magnitude. Plotted events include both reviewed and automatically determined locations that have horizontal errors $<2 \mathrm{~km}$ and vertical errors $<4 \mathrm{~km}$. 


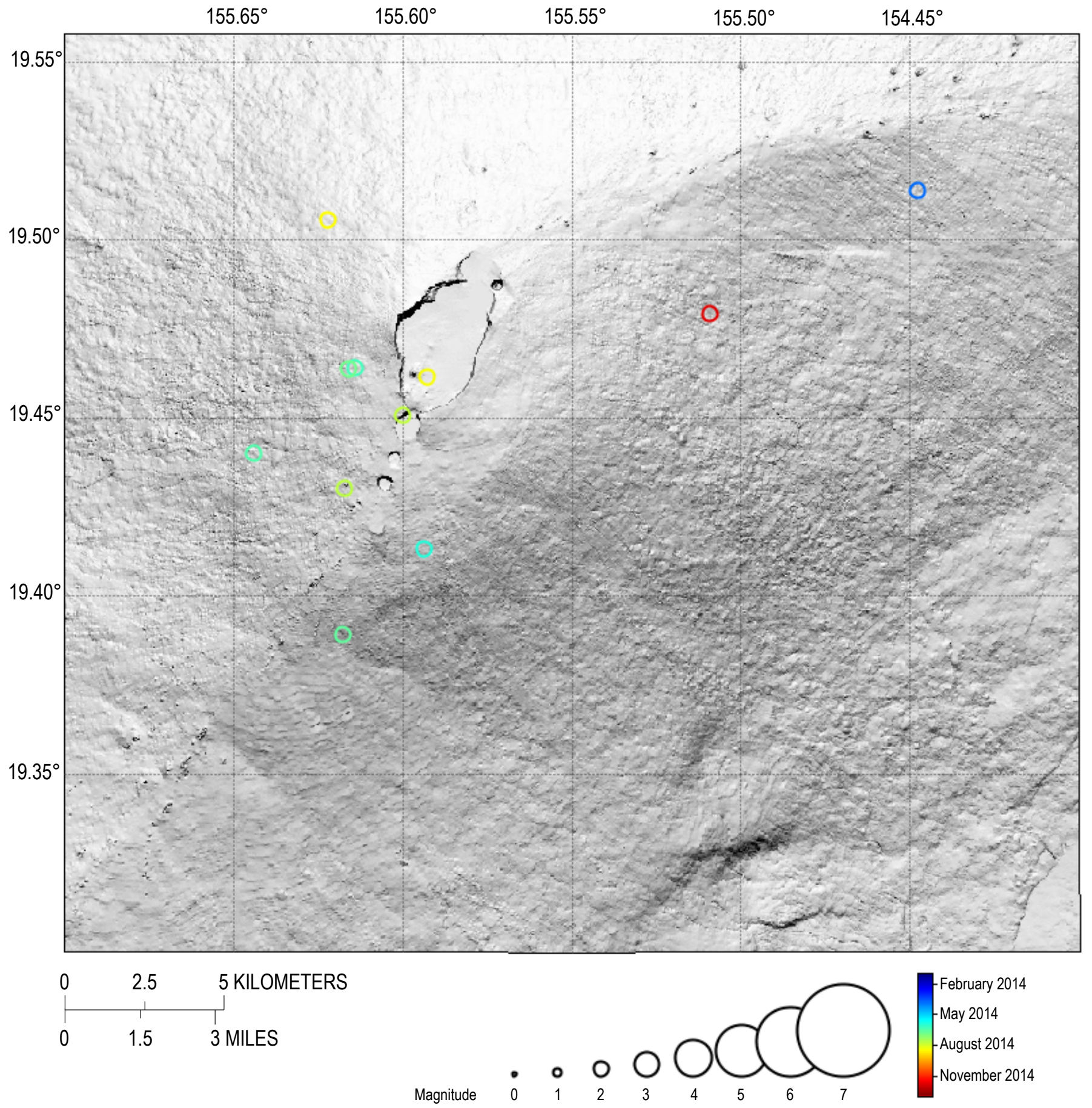

Figure 26. Map of earthquake locations near the Mauna Loa summit during 2014 showing deep earthquakes (13.1-60.0 km) having $M \geq 2$.0. Symbol color reflects date of event. Symbol size depicts preferred magnitude. Plotted events include both reviewed and automatically determined locations that have horizontal errors $<2 \mathrm{~km}$ and vertical errors $<4 \mathrm{~km}$. 


\section{References Cited}

Klein, F.W., 1981, A linear gradient crustal model for south Hawaii: Bulletin of the Seismological Society of America, v. 71, no. 5, p. 1503-1510.

Klein, F.W., 2002, User's guide to HYPOINVERSE-2000, a Fortran Program to solve for earthquake locations and magnitudes: U.S. Geological Survey Open-File Report 02-171, 116 p.
Klein, F.W., and Wright, T.L., 2000, Catalog of Hawaiian Earthquakes, 1823-1959, U.S. Geological Survey

Professional Paper 1623, $90 \mathrm{p}$.

Okubo, P., Nakata, J., and Koyanagi, R., 2014, The evolution of seismic monitoring systems at the Hawaiian Volcano Observatory, chap. 2 of Poland, M.P., Takahashi, T.J., and Landowski, C.M., eds., Characteristics of Hawaiian Volcanoes: U.S. Geological Survey Professional Paper 1801, p. 67-94. 


\section{Appendix C-1. Table of M3+ Earthquakes in 2014}

Reviewed earthquakes $M>2.95$, Hawaiian Islands east of Kaua'i.

[Date is given in the format month/day/year. Gap is the largest angle in degrees between stations used in the earthquake solution. Delta is the distance to the closest station from the epicenter. Mag, magnitude; RMS, root mean square error in seconds]

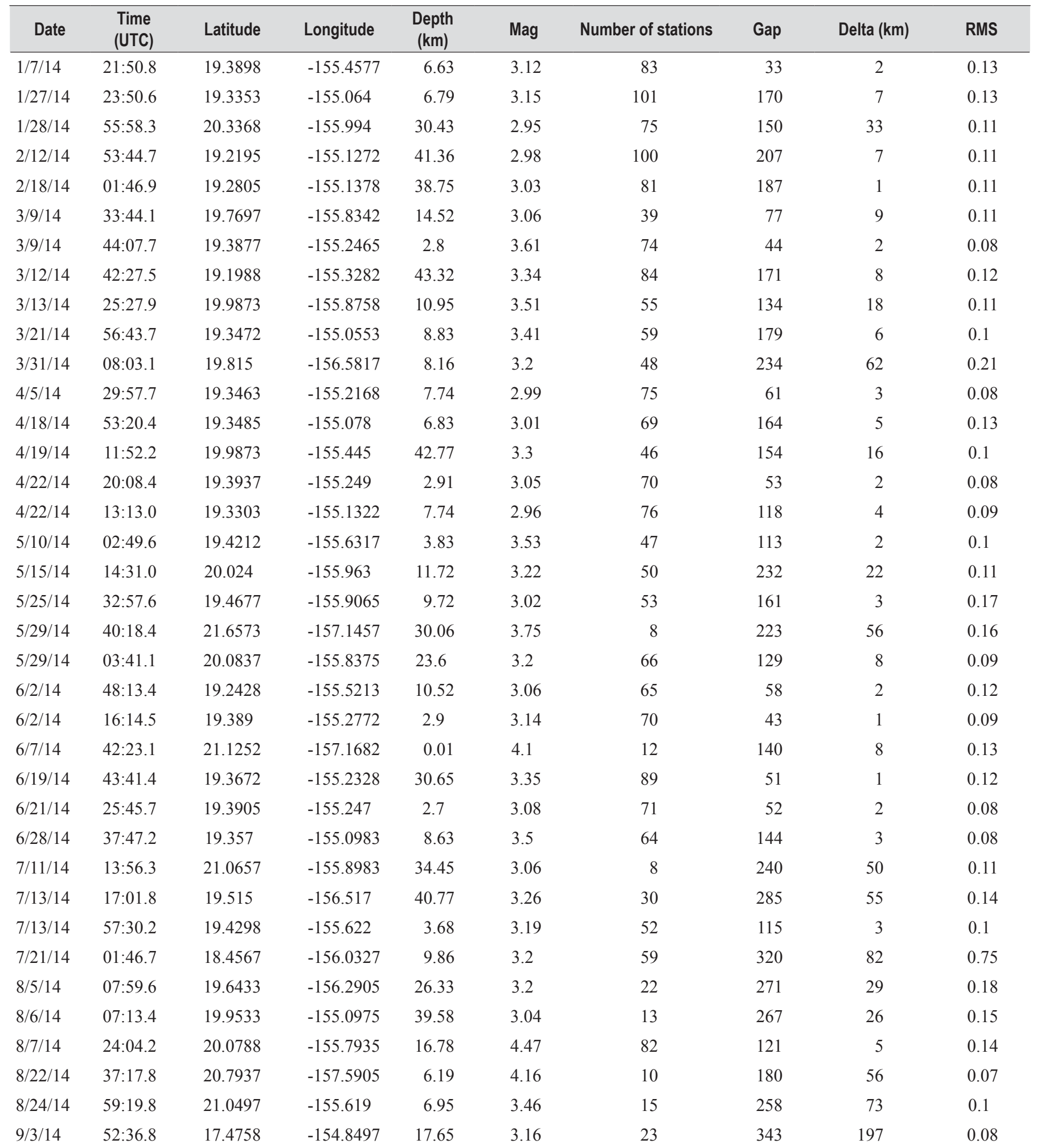


44 The 2014 Annual Report for the Hawaiian Volcano Observatory

Reviewed earthquakes $M>2.95$, Hawaiian Islands east of Kaua'i.-Continued

\begin{tabular}{cccccccccc}
\hline Date & $\begin{array}{c}\text { Time } \\
(\text { UTC) }\end{array}$ & Latitude & Longitude & $\begin{array}{c}\text { Depth } \\
(\mathbf{k m})\end{array}$ & Mag & Number of stations & Gap & Delta $(\mathbf{k m})$ & RMS \\
\hline $10 / 3 / 14$ & $34: 58.1$ & 19.3562 & -155.3235 & 28.03 & 2.97 & 86 & 46 & 3 & 0.12 \\
$10 / 13 / 14$ & $43: 51.2$ & 19.1608 & -155.5965 & 5.42 & 4 & 82 & 102 & 14 & 0.19 \\
$11 / 10 / 14$ & $39: 08.1$ & 19.7448 & -156.0647 & 10.89 & 3.77 & 26 & 237 & 11 & 0.2 \\
$11 / 15 / 14$ & $06: 15.7$ & 19.314 & -155.2183 & 8.2 & 3.63 & 80 & 83 & 4 & 0.09 \\
$11 / 22 / 14$ & $58: 05.5$ & 19.8225 & -156.2077 & 5.9 & 3.34 & 27 & 263 & 42 & 0.24 \\
$11 / 23 / 14$ & $35: 39.9$ & 19.4265 & -155.26 & 1.84 & 3.34 & 70 & 45 & 0 & 0.08 \\
$11 / 24 / 14$ & $48: 53.4$ & 19.5418 & -156.3588 & 38.14 & 3.12 & 21 & 273 & 47 & 0.14 \\
$11 / 30 / 14$ & $46: 30.2$ & 19.5247 & -156.4638 & 38.04 & 3.46 & 27 & 244 & 49 & 0.17 \\
$12 / 13 / 14$ & $42: 49.2$ & 19.7535 & -156.5263 & 11.59 & 4.19 & 36 & 241 & 55 & 0.21 \\
\hline
\end{tabular}




\title{
Chapter D
}

\section{Deformation}

\author{
By Asta Miklius, Michael Poland, Kyle Anderson, and Loren Antolik
}

\section{Kīlauea}

The largest deformation signals on Kîlauea in 2014 were associated with the June 27 th flow from $\mathrm{Pu}^{\prime} \mathrm{u}$ ' $\mathrm{O}^{`}$ ō. As fissures opened on the northeast flank of the cone, dramatic tilt and motion towards the crater occurred (figs. 1, 2). The deflationary tilt and horizontal motion continued, at a lower rate than the initial deformation, until August. From then to the end of the year, exceptionally little deformation was recorded at $\mathrm{Pu}^{6} \mathrm{u}{ }^{`} \overline{\mathrm{O}}^{`} \overline{\mathrm{o}}$.

Stations at the summit showed no immediate reaction to the start of the June 27th flow, but the variable-rate inflation of Kîlauea that had been ongoing since 2010 ceased shortly afterward. From July to August, there was no net change in extension across the caldera or vertical signal at GPS sites in the summit area, although the tiltmeter at Uēkahuna still showed tilt away from the caldera (figs. 1, 3, 4). Slight subsidence and contraction were recorded by GPS data from August to mid-September. From then to the end of the year, there was no net change at the summit, but approximately month-long cycles of inflation and deflation were recorded that appear to be originating at a shallow source beneath the southeastern edge of Halema'uma' $u$. These cycles are not unusual - they have been frequent, but not regular, in at least the past couple of years at the summit — but the process that causes them is not yet clear. The cycles are not evident at $\mathrm{Pu}^{\prime} \mathrm{u}$ 'ত̄'o.

The very common, short time-scale, moderate magnitude deflation-inflation (DI) events that we observe mainly in the tilt data continued in 2014. The larger events were recorded at $\mathrm{Pu}^{\prime} \mathrm{u}$ ' $\overline{\mathrm{O}}^{`} \mathrm{o}$ in the first half of the year, but were not apparent after the start of the June 27 th flow.

\section{Mauna Loa}

After 5 years of quiescence, Mauna Loa once again started inflating in 2014. Extension and uplift may have started as early as April or May, but magma accumulation at fairly shallow levels began in earnest in June. Inflation rate was highly variable through the rest of the year, with a distinct slowing in September and an apparently complete cessation of inflation in December (fig. 5). The pattern of displacements is consistent with inflation of multiple magma bodies beneath the summit area: a spherically

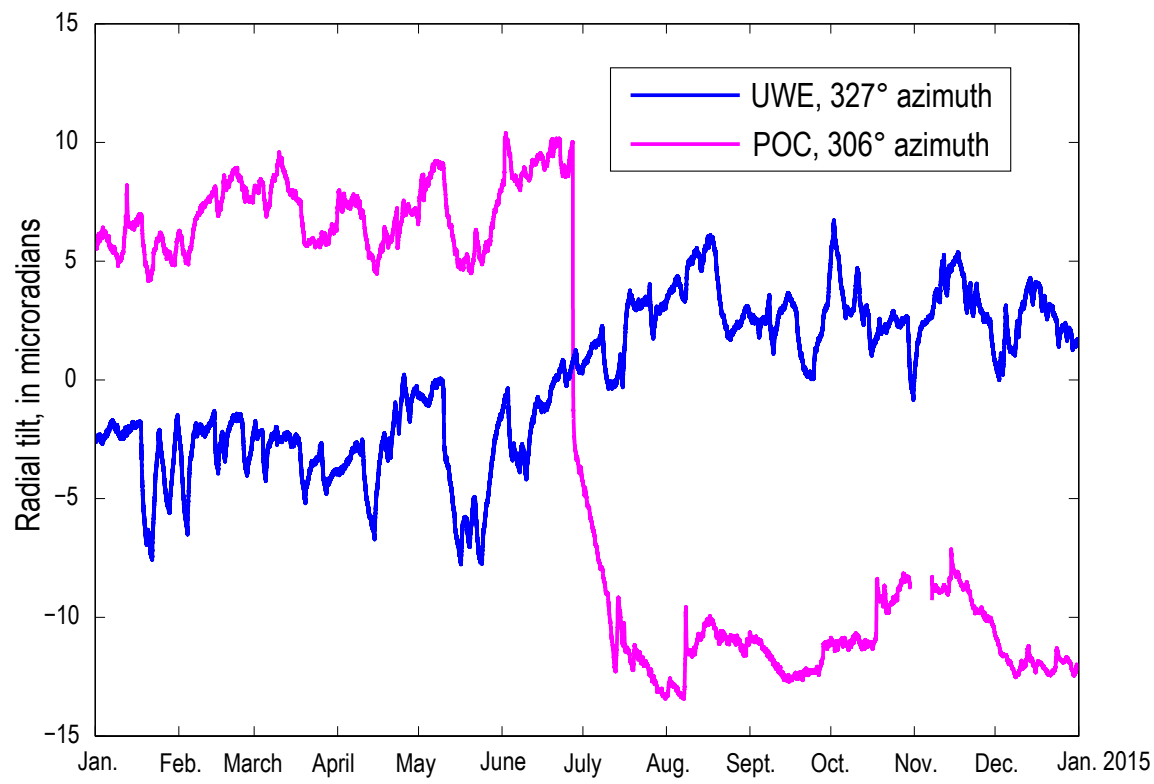

Figure 1. Radial tilt measured by borehole instruments at the summit (station code UWE) and at Pu'u 'Ō'ō (POC) during 2014. Positive change represents tilt away from the most common magmatic sources, usually indicating inflation, and negative change represents tilt towards those sources, usually indicating deflation.

Month in 2014 
Figure 2. Changes in position of the GPS site near the north rim of Pu'u 'Ō'ō crater in 2014.
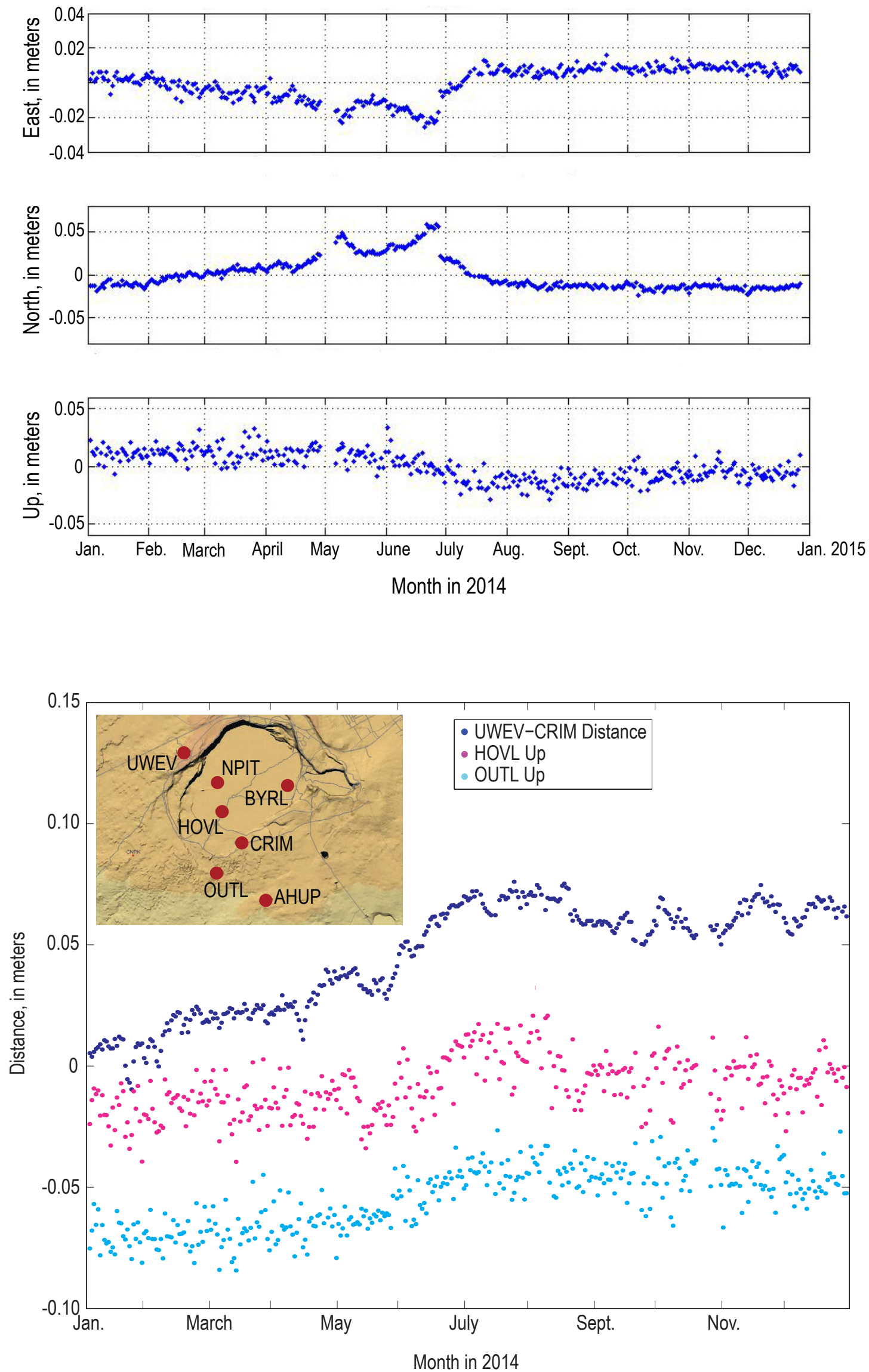

Figure 3. Changes in distance across Halema'uma'u and elevation of selected Kīlauea summit GPS stations in 2014. Inset shows station locations and codes. 


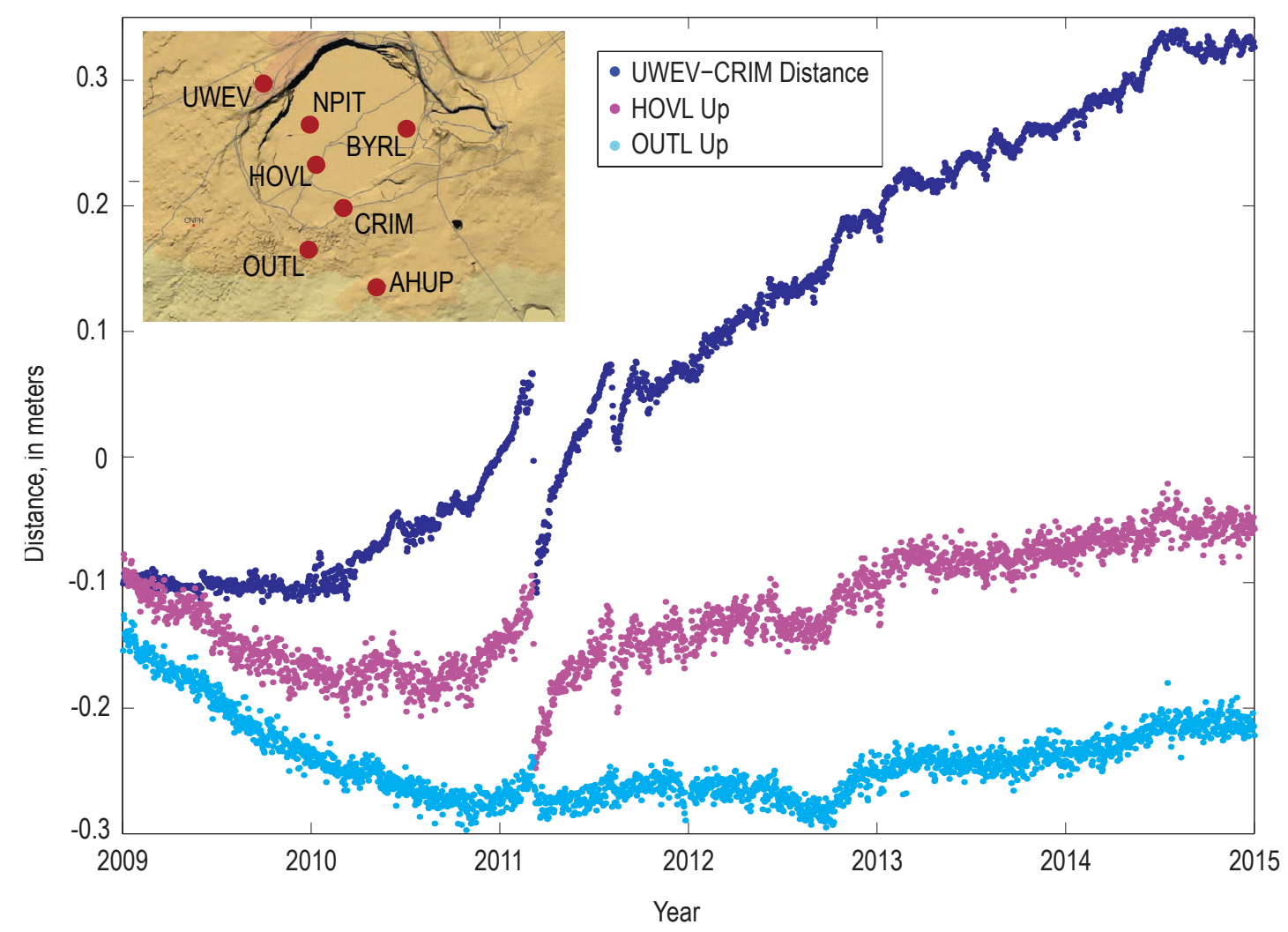

Figure 4. Changes in distance across Halema'uma'u and elevation of selected Kīlauea summit GPS stations from 2009 through 2014.

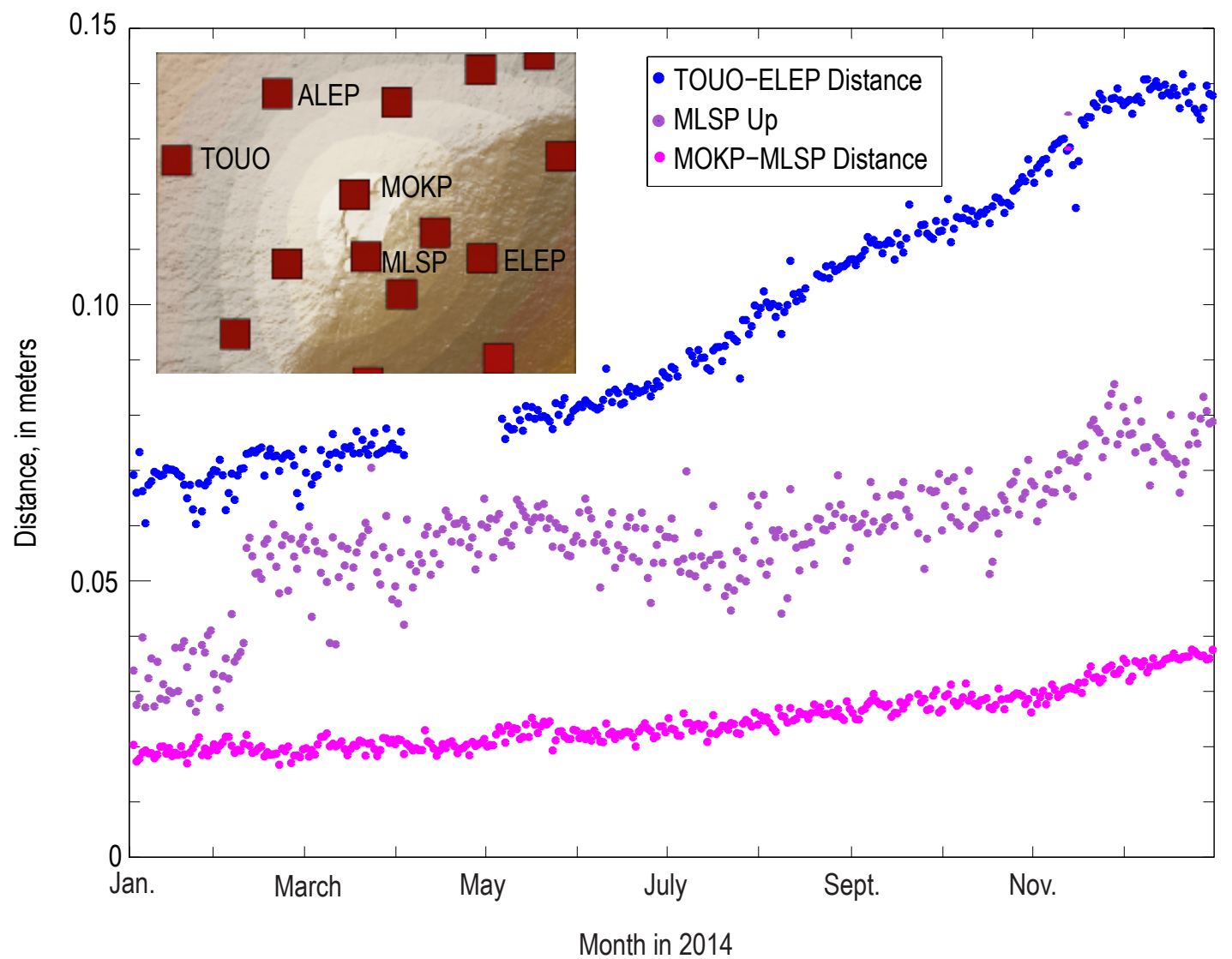

Figure 5. GPS data from selected continuously recording GPS sites on Mauna Loa Volcano.

Month in 2014 
expanding reservoir beneath the east edge of the caldera and a dike-like source beneath the caldera and uppermost Southwest Rift Zone (figs. 6-8). Both of these sources are about 3.5-4 km beneath the surface. The vast majority of the volume accumulation is in the dike-like structure.

\section{Haleakalā}

A GPS survey in late July showed no significant deformation of Haleakalā volcano, Maui, since the previous survey in 2008.

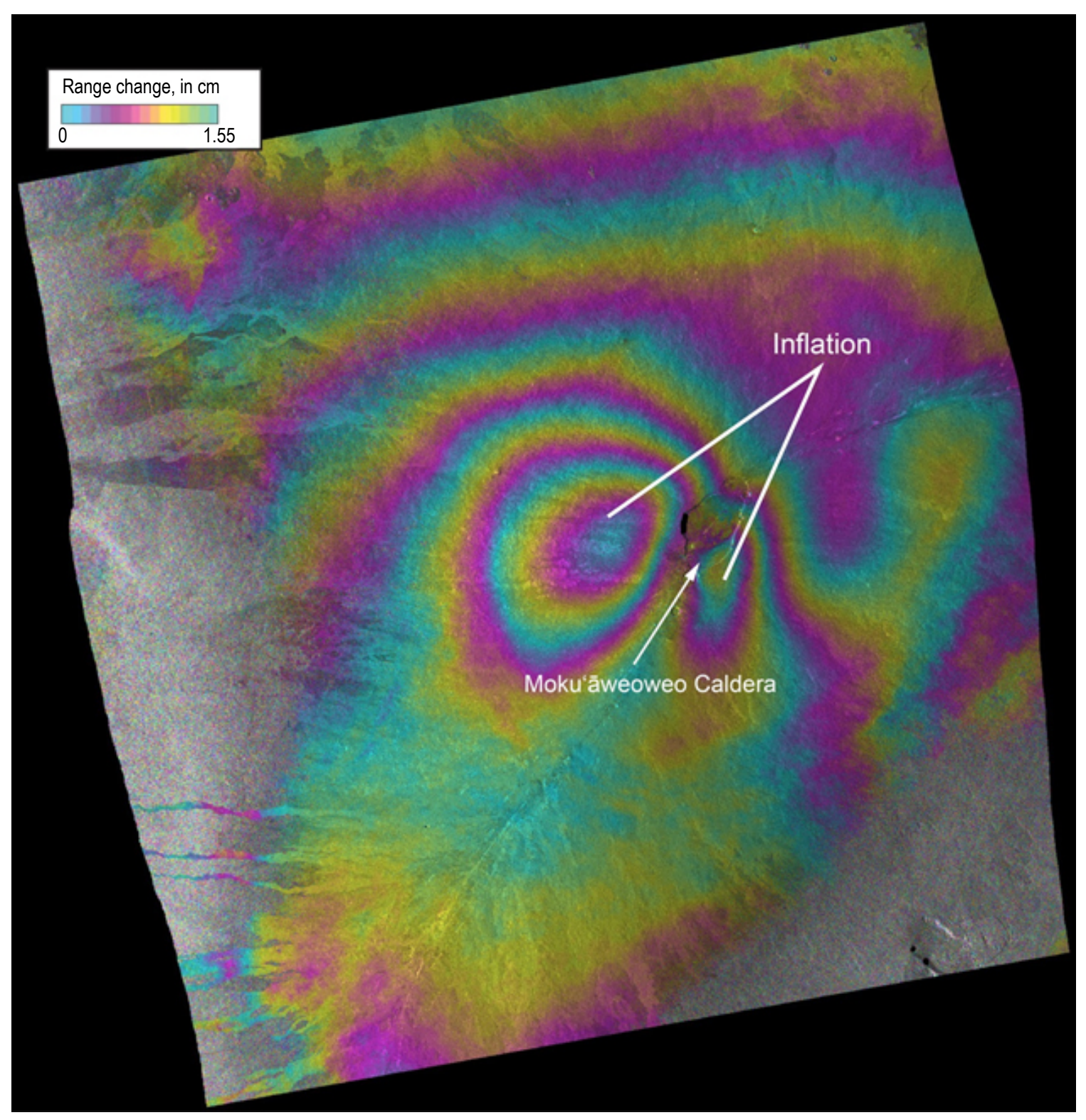

Figure 6. COSMO-SkyMed (COnstellation of small Satellites for the Mediterranean basin Observation) ascending-mode interferogram of Mauna Loa spanning January 26-December 28, 2014. Lobes of line-of-sight uplift straddle Moku'āweoweo Caldera and are consistent with inflation of a dike-like reservoir that runs the length of the caldera. The larger magnitude of the western lobe is a function of the satellite's line of sight. 


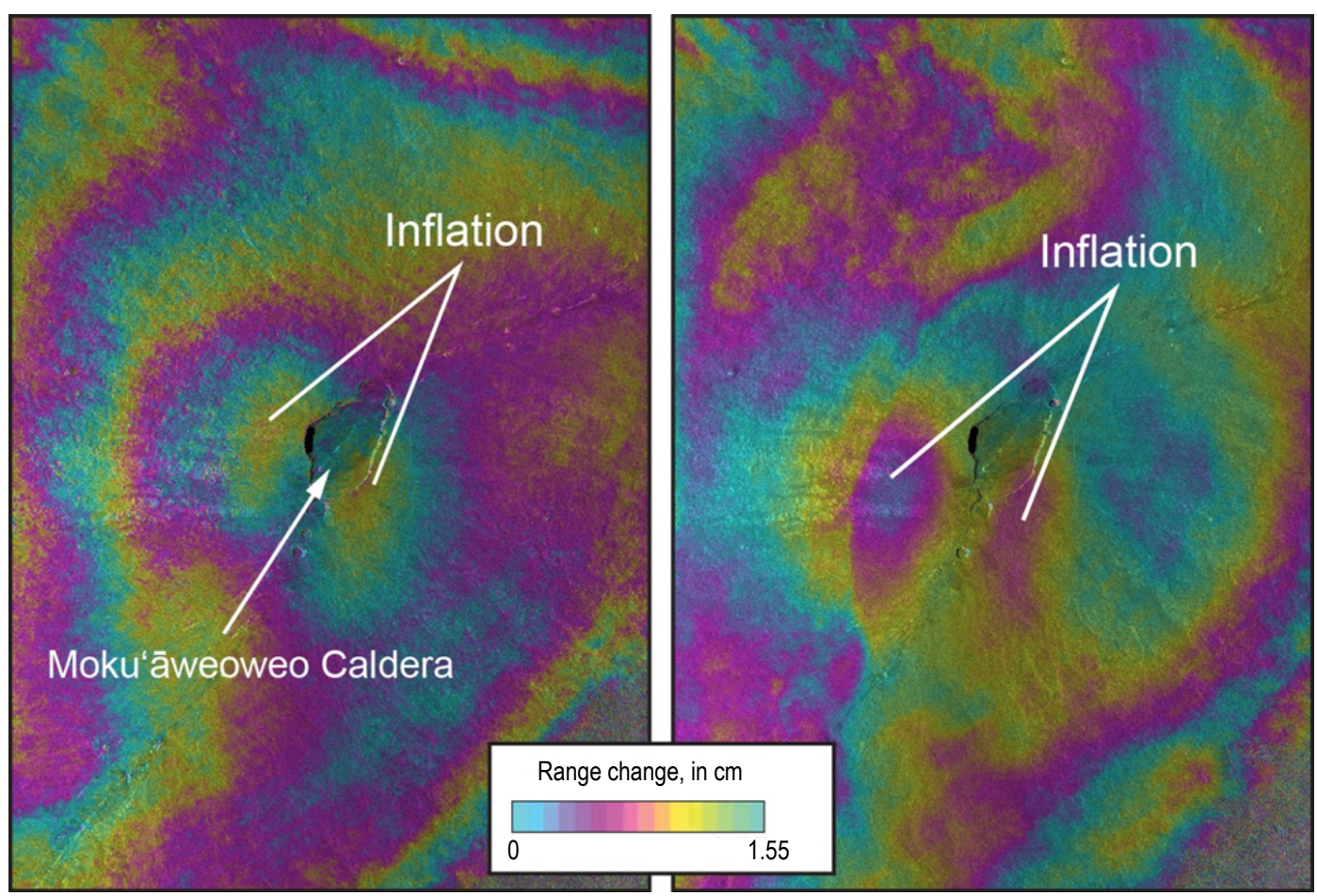

Figure 7. COSMO-SkyMed (COnstellation of small Satellites for the Mediterranean basin Observation) ascending-mode interferograms of Mauna Loa's summit region showing two periods of inflation. Left interferogram spans June 19-September 23, 2014. Right interferogram spans October 25-December 12, 2014. The lobes uprift are located farther south in the later interferogram, although it is not clear if this shift is significant, given the small magnitude of the signal.

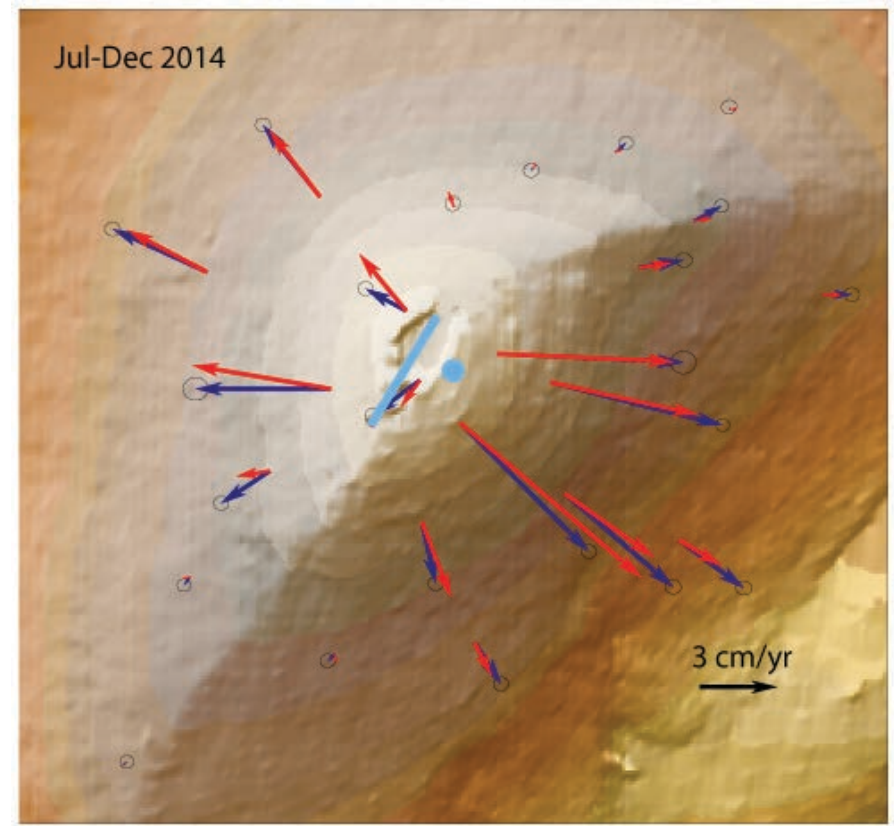

Figure 8. Preliminary modeling of deformation sources on Mauna Loa. Observed displacements (blue) are compared to displacements predicted by a model of an inflating reservoir beneath the south caldera (light blue circle) and an expanding dike beneath the summit and upper southwest rift zone (light blue line). 



\title{
Chapter E
}

\section{Gas Geochemistry}

\author{
By Tamar Elias, Jeff Sutton, Christoph Kern, and Cindy Werner
}

\section{Introduction}

In 2014, HVO continued to monitor gas emission rates, chemistry, and concentrations to track the eruptions at Kîlauea, improve our understanding of eruptive processes, and address hazards and environmental impacts.

\section{Kīlauea Summit Gas Emission Rate Measurements}

Refining the measurement of large, dense $\mathrm{SO}_{2}$ plumes emitted from the Kîlauea summit was a featured activity in 2014. The multiple scattering effects of gases and particles on incoming radiation have contributed to significant errors in calculated Kîlauea summit $\mathrm{SO}_{2}$ emission rates since 2008. Since that time, our analysis methods have evolved significantly and the improved methods have been incorporated into our operational procedures. We pursued several approaches that resulted in constraining a more accurate summit emission rate.

For campaign road-based measurements, we have incorporated a more flexible $\mathrm{SO}_{2}$ column path calculation algorithm by upgrading our FLYSPEC hardware and software, and, since April, have used the new dual fit window (DFW) FLYSPEC software. This allows more accurate quantification of low $\mathrm{SO}_{2}$ column pathlengths (such as for the east rift plume) and very high column pathlengths (such as for the dense, opaque summit plume). Although the transition to the FLYSPEC version 3 hardware and version 5 software represents an improvement over the FLYSPEC 2 configuration, we suspect that the absolute accuracy of the road measurements may still be compromised due to the proximity to the summit vent and the high plume column density. Changes in lava lake activity continue to be reflected in these near-vent road-based measurements. Beginning in 2014, we discontinued the single, short-fit window data collection/processing.

We have continued to reprocess our road-traverse data, using Christoph Kern's (of the Cascades Volcano Observatory, or CVO) Simulated Radiative Transfer (SRT)-DOAS code (Kern and others, 2012). We use a refined SRT-DOAS algorithm that incorporates several improvements over previous versions, including a faster table-search algorithm, which makes it feasible to use the code operationally. In addition, a higher resolution look-up table, more spectral data in the look-up table (300-340 $\mathrm{nm}$ rather than 300-325 nm), an optimized wavelength fitting range (312-338 nm rather than 309-324 nm), and a better high pass filter for measured optical densities were included.

By year's end we had reprocessed select $\mathrm{SO}_{2}$ summit data from 2008-2014 using the DFW and SRT-DOAS algorithms. The subset of reprocessed data includes only spectra that are unsaturated with light and have a plume location along the road so that a reasonably perpendicular cross section could be measured (fig. 1). During periods of low $\mathrm{SO}_{2}$ emissions $(<1,000 \mathrm{t} / \mathrm{d})$ the SRT and DFW data consistently agree within the error of the measurement; the scatter in the data increases with emission rate (fig. 2). These data are subject to revision, as some refinement of the data will occur over the coming year.

The SRT-DOAS-modeled and DFW-calculated $\mathrm{SO}_{2}$ emission rate data from 2008-2009 are in much better agreement with recent estimates from space-based platforms (Beirle and others, 2014) than our original emission rate estimates from that period.

\section{FLYSPEC Array: Measuring a More Dispersed and Optically Thin Plume}

Data capture from the upward-looking FLYSPEC array, located $\sim 2.8 \mathrm{~km}$ from the summit Overlook crater emission source, improved greatly this year thanks to power system and communications upgrades made over the past two years. By February 2014, the FLYSPEC array software had incorporated the DFW algorithm for calculating column path values, which should improve the accuracy of the reported emission rates. Although we are measuring nearly $3 \mathrm{~km}$ from the source, where the plume is more dispersed and optically thin, the column amounts are still thousands of ppm-m - beyond the threshold associated with accurate fitting using the traditional $305-315 \mathrm{~nm}$ range. The $319.5-338 \mathrm{~nm}$ fit window used in the DFW software results in better signal-to-noise ratio and more accurate spectral fits. The calculated array emission rates are significantly higher than those calculated from the road-based measurements (fig. 3), and we continue to explore the source of this discrepancy. 


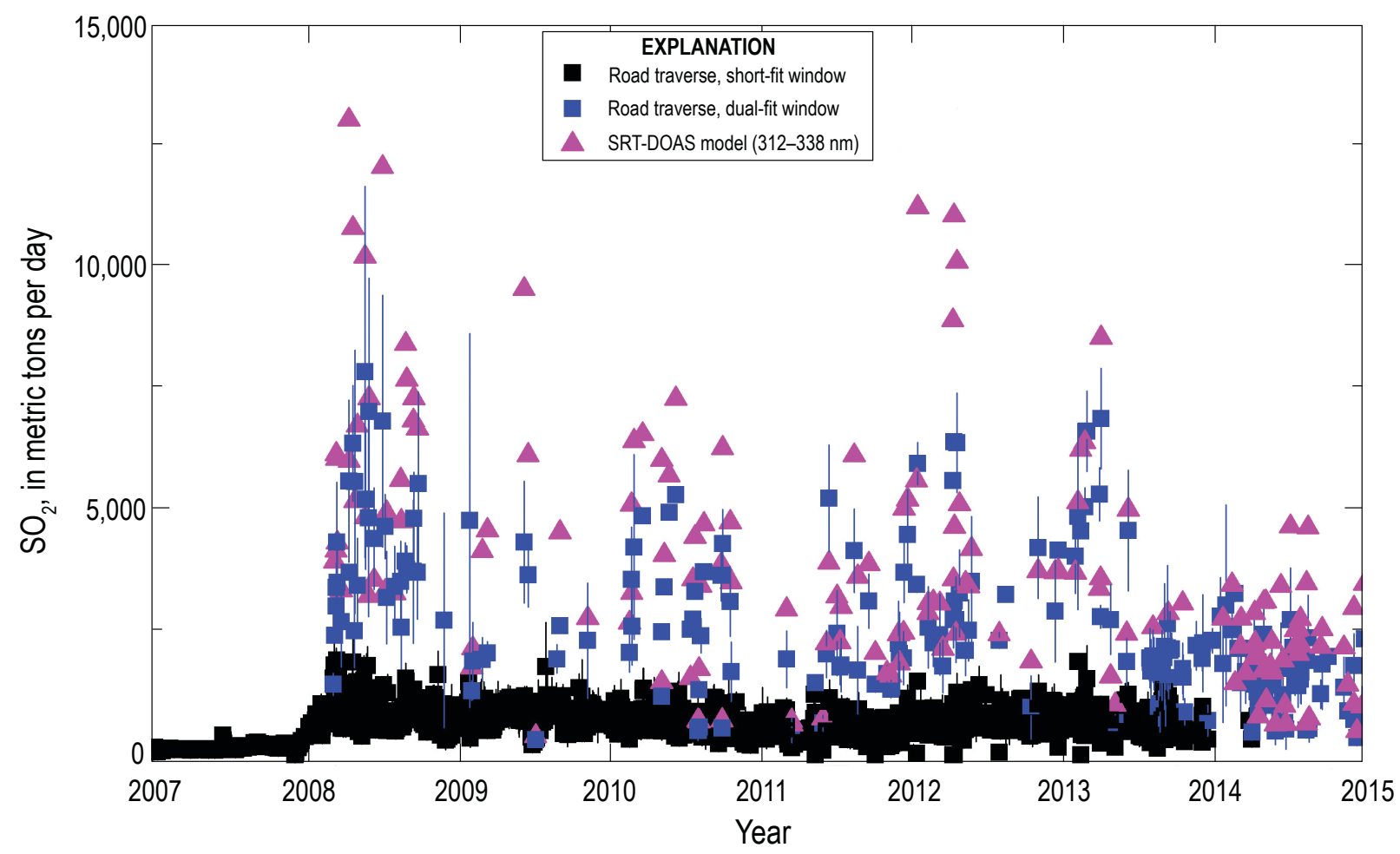

Figure 1. Daily average $\mathrm{SO}_{2}$ emissions from the summit of Kïlauea, 2007-2014, as measured by road-based traverse campaigns, using the single-fit 305-315 nm window (black squares), dual-fit window (blue squares), and the SRTmodeled values (pink triangles). Vertical bars represent the standard deviation of individual measurements recorded on a single day.

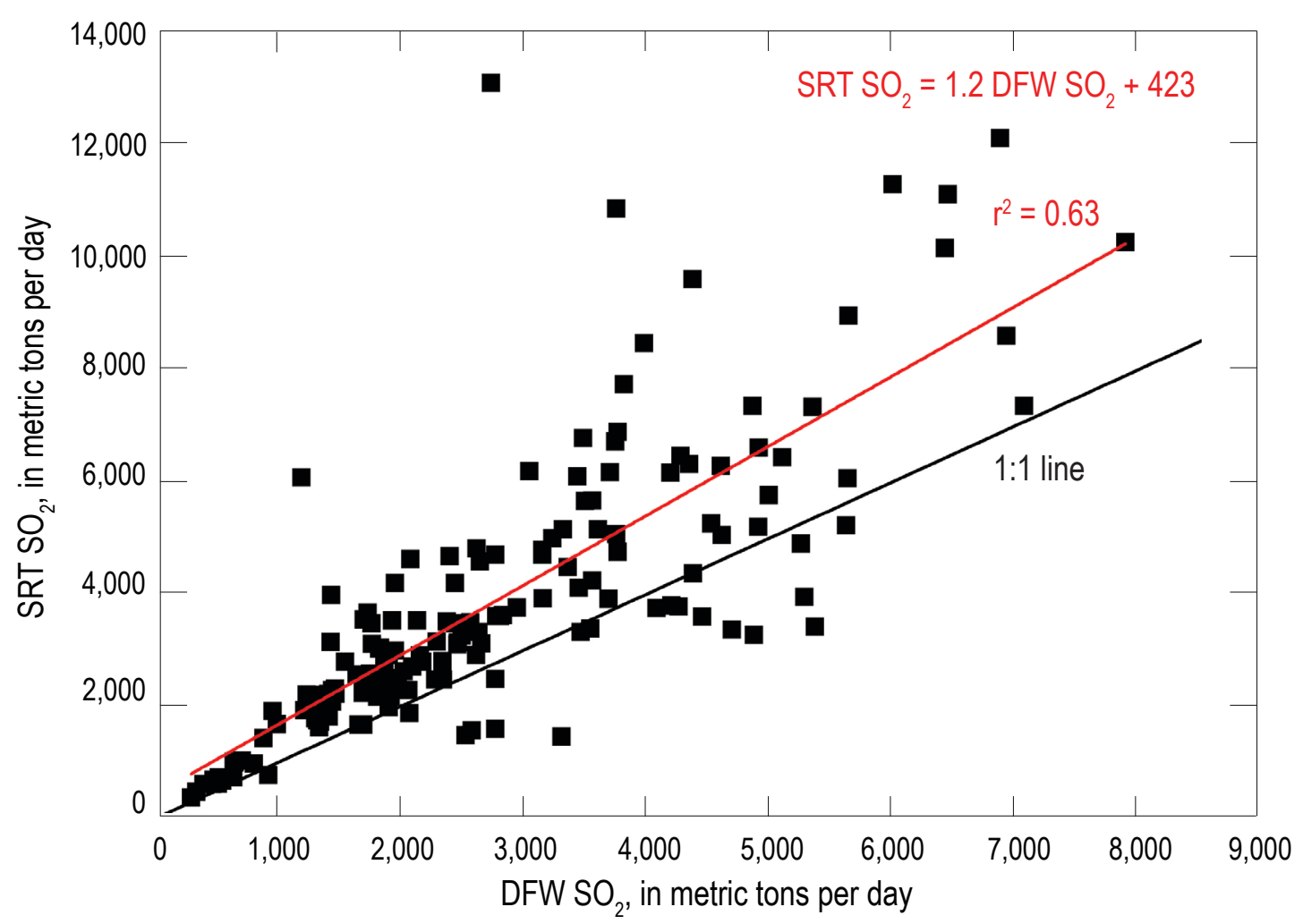

Figure 2. Modeled $\mathrm{SO}_{2}$ emission-rate data (using the SRT-DOAS algorithm) versus FLYSPEC dual fit window (DFW) SO emission-rate data for the period 2008-2014. 


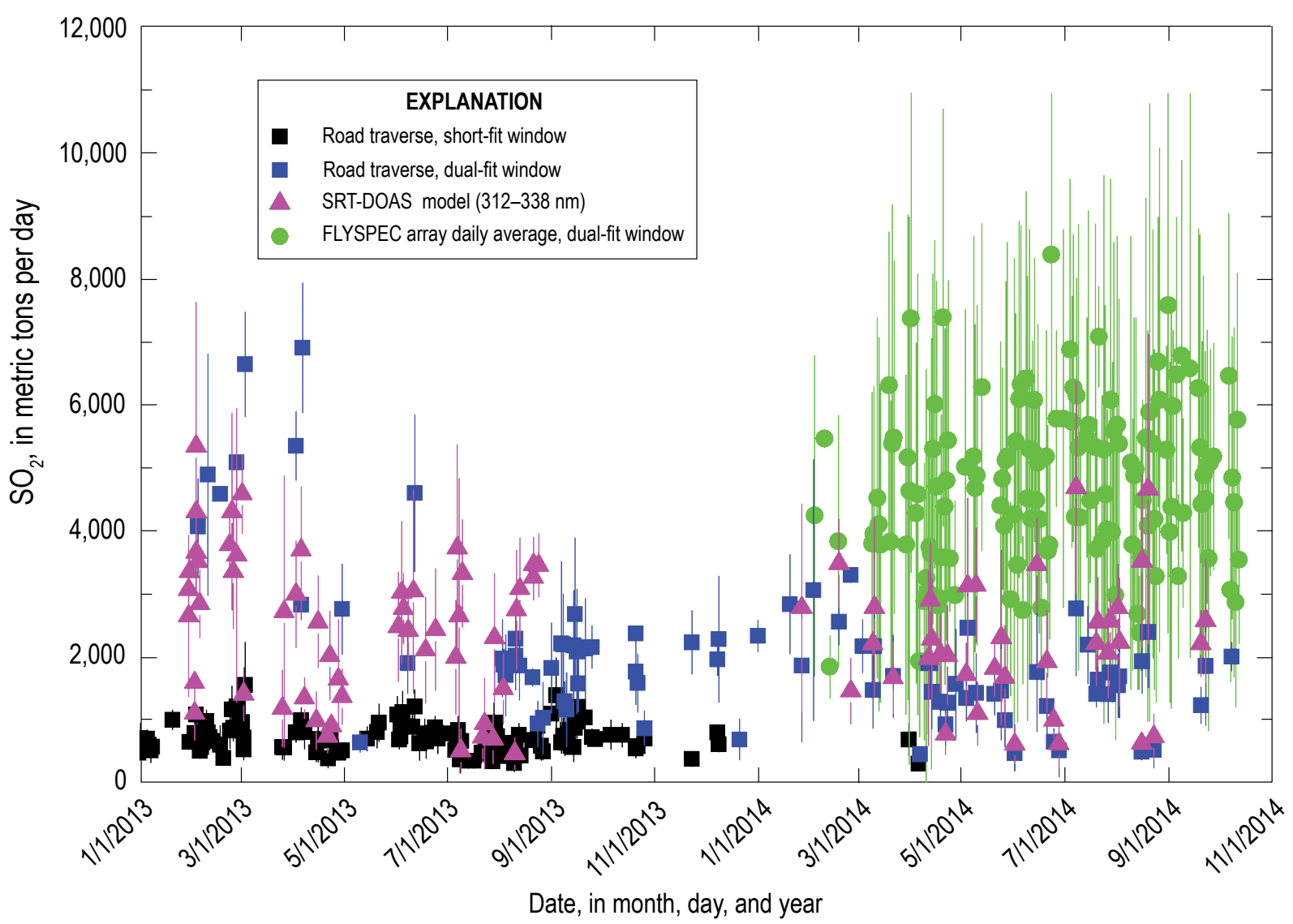

Figure 3. Daily average $\mathrm{SO}_{2}$ emissions from the summit of Kīlauea for 2013-2014, as measured by road-based traverse campaigns, using the traditional short fit window (black squares), the long or dual fit window (blue squares), and the SRT-modeled values (pink triangles), as well as the upward-looking FLYSPEC array, using the dual fit window (green circles). Vertical bars represent the standard deviation of individual measurement values recorded on a single day.

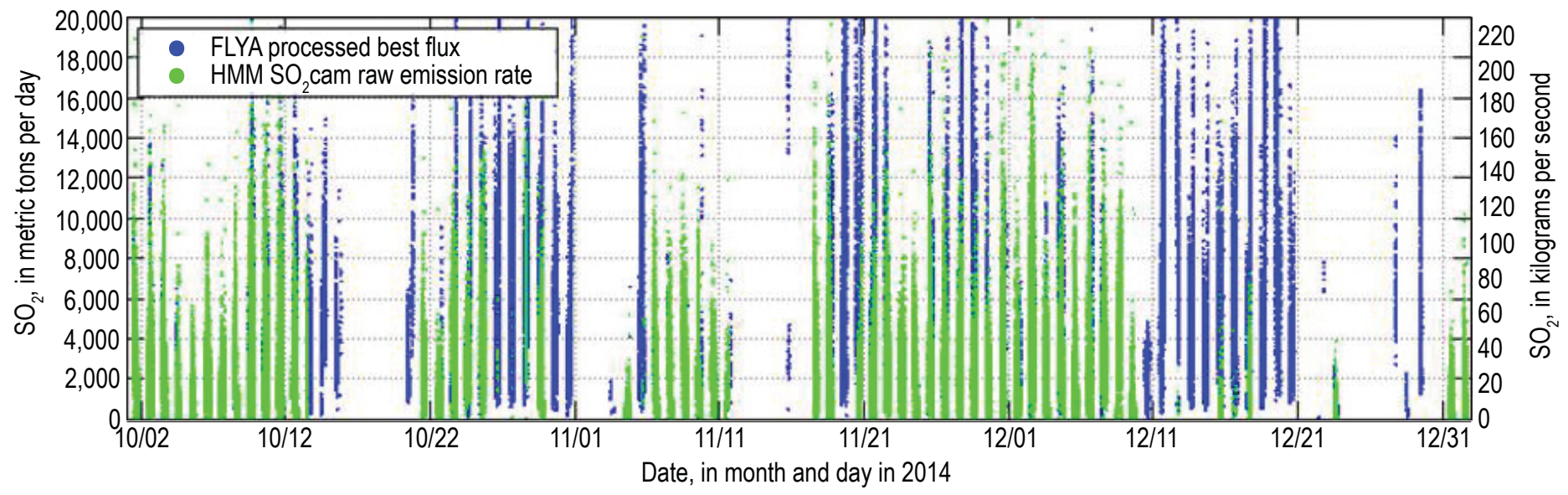

Figure 4. $\mathrm{SO}_{2}$ emissions from the summit of Killauea for October-December 2014 as measured by the $\mathrm{SO}_{2}$ camera (green) and the FLYSPEC array (blue). 


\section{$\mathrm{SO}_{2}$ Camera}

During 2014, the ultraviolet (UV) $\mathrm{SO}_{2}$ camera, located $\sim 1.4$ $\mathrm{km}$ from the Overlook crater, underwent significant software advances. Working with Christoph Kern, Cindy Werner (of the Cascades and Alaska Volcano Observatories, respectively), and the HVO technical and Information Technology groups, this system was originally installed in August 2013 and was funded through the Richard Lounsbery Foundation.

Although a relative calibration is still being used to calculate $\mathrm{SO}_{2}$ column amounts for the $\mathrm{SO}_{2}$ camera measurements, Christoph Kern converted the in-situ UV spectrometer processing algorithm to run on a 64-bit computer, so that both the UV camera and the Ocean Optics spectrometer can acquire and process data on a single 64-bit virtual machine. Operationally, these are significant advances. Figure 4 shows a comparison of the $\mathrm{SO}_{2}$ camera and FLYSPEC array $\mathrm{SO}_{2}$ emission rate data for the last quarter of 2014.

\section{RSAM and $\mathrm{SO}_{2}$ Emissions Relations}

During the years since the Halema'uma'u lava lake reappeared, multiple datasets (emission rates via $\mathrm{SO}_{2}$ camera, FLYSPEC array, road traverses, as well as ambient $\mathrm{SO}_{2}$ concentration data) have reflected the sympathetic changes in $\mathrm{SO}_{2}$ and real-time seismic amplitude measurement (RSAM) and lava lake activity (fig. 5). A preliminary look at several active/inactive lava lake transitions using the FLYSPEC array data suggests that while emissions and seismic energy increase and decrease in concert, there is significant scatter in emission rates with a given RSAM value (figs. 6, 7).

\section{$\mathrm{SO}_{2}$-Summing it All Up at the Summit}

Using the $\mathrm{SO}_{2}$ emission rate data for 2014 from the FLYSPEC array yields a rough estimate of $\sim 1.8 \mathrm{MT}$ for total annual $\mathrm{SO}_{2}$ released from the summit of Kilauea. Because of the change to the dual-fit algorithm in 2014, the 2014 discharge estimate is not directly comparable to the 2013 FLYSPEC array total of $\sim 1.2 \mathrm{MT}$, which was calculated using the traditional short-fit window. The vehicle-based data yield a 2014 total of 0.6 MT and 0.8 MT using the DFW and SRTDOAS data, respectively.

\section{Summit $\mathrm{CO}_{2}$ Emission Rates}

Challenges in measuring $\mathrm{CO}_{2}$ emission rates increased with the onset of the 2008 eruption and enlargement of the Overlook crater over time. In order to calculate an accurate $\mathrm{CO}_{2}$ emission rate, one must be able to constrain the $\mathrm{SO}_{2}$ emission rate, as well as a representative $\mathrm{CO}_{2} / \mathrm{SO}_{2}$ ratio for the degassing area of the caldera:

$$
\begin{array}{r}
\mathrm{CO}_{2} \text { emission rate }=\left(\mathrm{CO}_{2} / \mathrm{SO}_{2}\right) \times\left(\mathrm{SO}_{2} \text { emission rate }\right) \times \\
\left(\mathrm{CO}_{2} \text { molecular weight } / \mathrm{SO}_{2} \text { molecular weight }\right)
\end{array}
$$

To calculate $\mathrm{CO}_{2} / \mathrm{SO}_{2}$ we measure ambient concentrations (in parts per million, ppm) of each species as we drive through the grounded plume along Crater Rim Drive. Calculating the area beneath the curve for plots of $\mathrm{CO}_{2}$ and $\mathrm{SO}_{2}$ gas concentration with distance along the traverse provides the respective plume crosssectional areas (in ppm $\times \mathrm{m}$ ), which are then used to calculate the ratio, $\mathrm{CO}_{2} / \mathrm{SO}_{2}$, in the above formula. The lofting summit plume from the Overlook crater is the main source of $\mathrm{SO}_{2}$, so accurately quantifying $\mathrm{SO}_{2}$ concentration and a representative $\mathrm{SO}_{2}$ plume cross-sectional area is difficult from the earth-bound vehicle. In contrast, the majority of the $\mathrm{CO}_{2}$ is released quiescently from an area to the east of the eruptive vent; the configuration along the road for this ground-hugging plume has been consistent since $\mathrm{CO}_{2}$ monitoring began in 1995. While the calculated $\mathrm{CO}_{2}$ emission rate is dependent on accurately quantifying both $\mathrm{CO}_{2}$ and the challenging $\mathrm{SO}_{2}$ cross-sectional plume areas, the $\mathrm{CO}_{2}$ area by itself provides an independent measure of relative $\mathrm{CO}_{2}$ release.

For 2014, road-based $\mathrm{CO}_{2}$ data were collected on October 10 and analyzed using the average dual-fit window $\mathrm{SO}_{2}$ emission rate and the maximum $\mathrm{SO}_{2}$ cross-sectional area for the day's collection to calculate $\mathrm{CO}_{2}$ emission rates for each traverse through the plume (fig. 8). As noted above, the plotted raw $\mathrm{CO}_{2}$ areas (black symbols) provide an independent measure of $\mathrm{CO}_{2}$ release. The decrease in observed $\mathrm{CO}_{2}$, beginning in 2005 , has been followed by a leveling-out of $\mathrm{CO}_{2}$ emissions that continued through 2014.

In 2014, we examined $\mathrm{CO}_{2}$ release using an alternate method. In collaboration with Cindy Werner and Christoph Kern, $\mathrm{CO}_{2}$ was measured from the summit of Killauea using an eddy covariance technique as well as a multi-gas sensor system designed by staff at CVO (figs. 9, 10). In July, eddy covariance measurements were made at 14 locations in the area of diffuse emissions, and we recorded elevated fluxes that generally ranged from 500 to $>5,000 \mathrm{~g} / \mathrm{m}^{2} / \mathrm{d}$. The eddy covariance instrument was then deployed until mid-October, when the threat of high winds associated with Hurricane Ana necessitated the retrieval of the sensitive instrument. These data help us better understand the spatial distribution and temporal variability of $\mathrm{CO}_{2}$ release from the summit caldera. Multi-gas measurements of the $\mathrm{CO}_{2}$ and $\mathrm{SO}_{2}$ concentration in air at $1 \mathrm{~m}$ above the ground identified approximately seven areas of elevated area of $\mathrm{CO}_{2}$ degassing in the caldera. Areas of highest $\mathrm{CO}_{2}$ concentration correlated with the areas of highest flux using the eddy covariance method were found near the middle of the caldera approximately $1 \mathrm{~km}$ northeast of the active vent (Werner and others, 2014). 

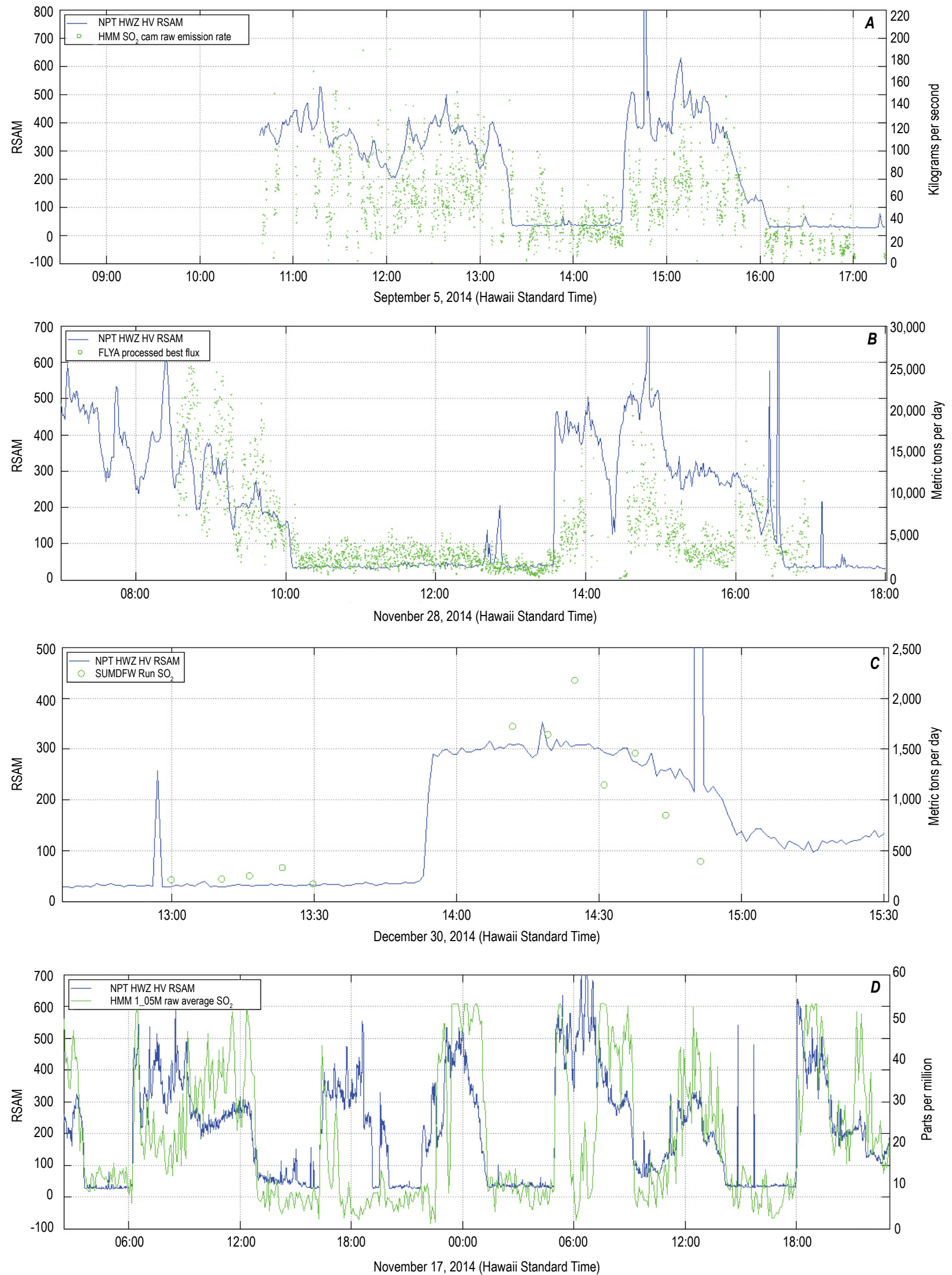

Figure 5. Killauea summit real-time seismic amplitude measurement (RSAM) (blue) and $\mathrm{SO}_{2}$ (green) during transitions in lava lake activity. $A, \mathrm{SO}_{2}$ emission rate detected by the untraviolet camera. $B, \mathrm{SO}_{2}$ emission rate detected by the $\mathrm{FLYSPEC}$ array. $C$, $\mathrm{SO}_{2}$ emission rates measured during road-based traverses along Highway 11 during Kona (southerly) wind conditions. $D$, Ambient $\mathrm{SO}_{2}$ concentrations measured on the rim of Halema'uma'u; each measurement is a five-minute average. 

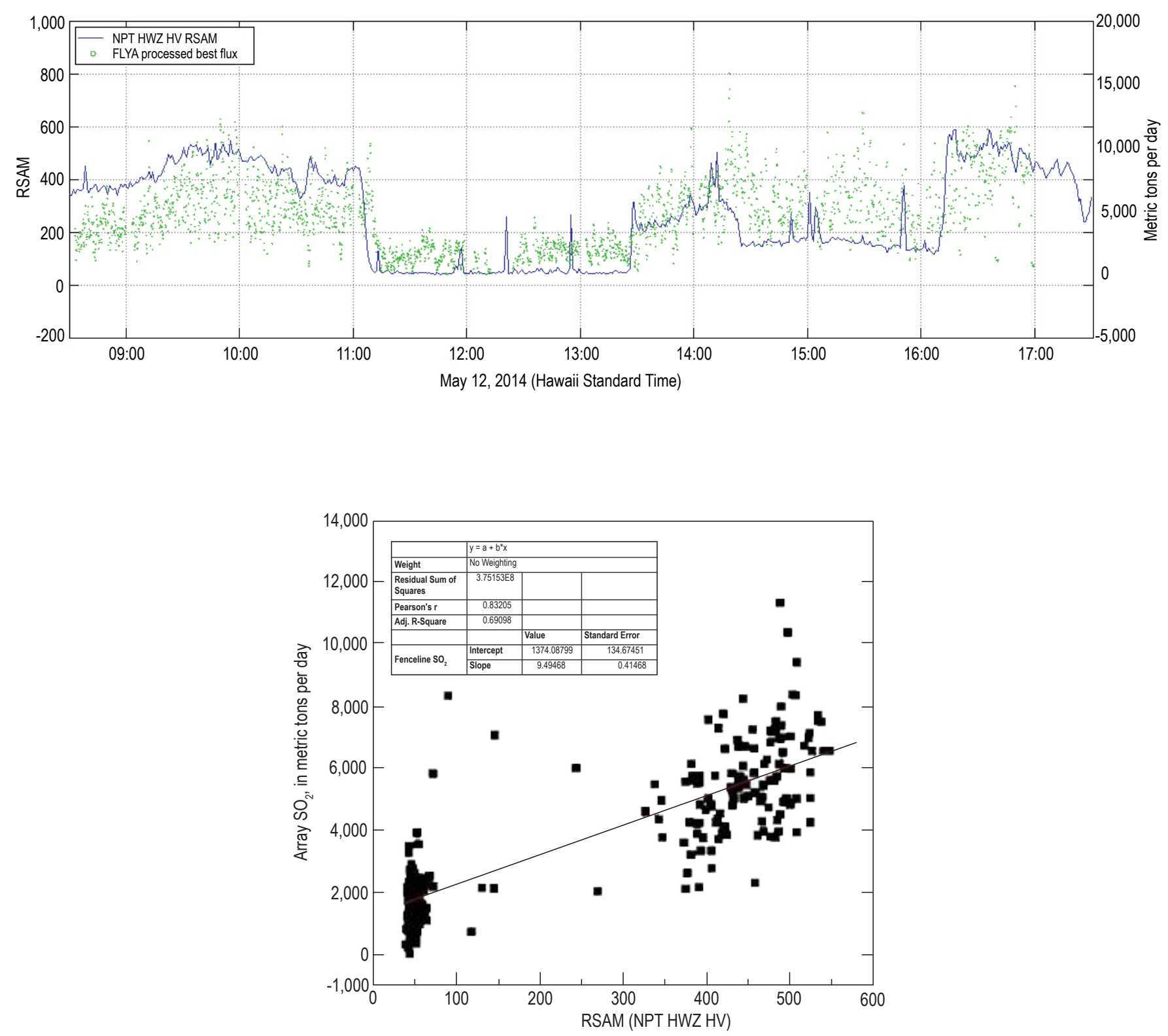

Figure 6. The upper time-series plot shows summit $\mathrm{SO}_{2}$ emissions estimated using the FLYSPEC array in green and the real-time seismic amplitude measurement (RSAM) in blue on May 12, 2014. The lower graph shows correlation between $\mathrm{SO}_{2}$ emission rate measurements and RSAM. At a typical wind speed of $7 \mathrm{~m} / \mathrm{s}$, it takes the plume $\sim 6.5$ minutes to travel the $2.8 \mathrm{~km}$ from the vent to the FLYSPEC fence-line array. A 6.5-minute time shift in the $\mathrm{SO}_{2}$-to-RSAM correlation increases the $\mathrm{R}^{2}$ value from 0.69 to 0.75 . 

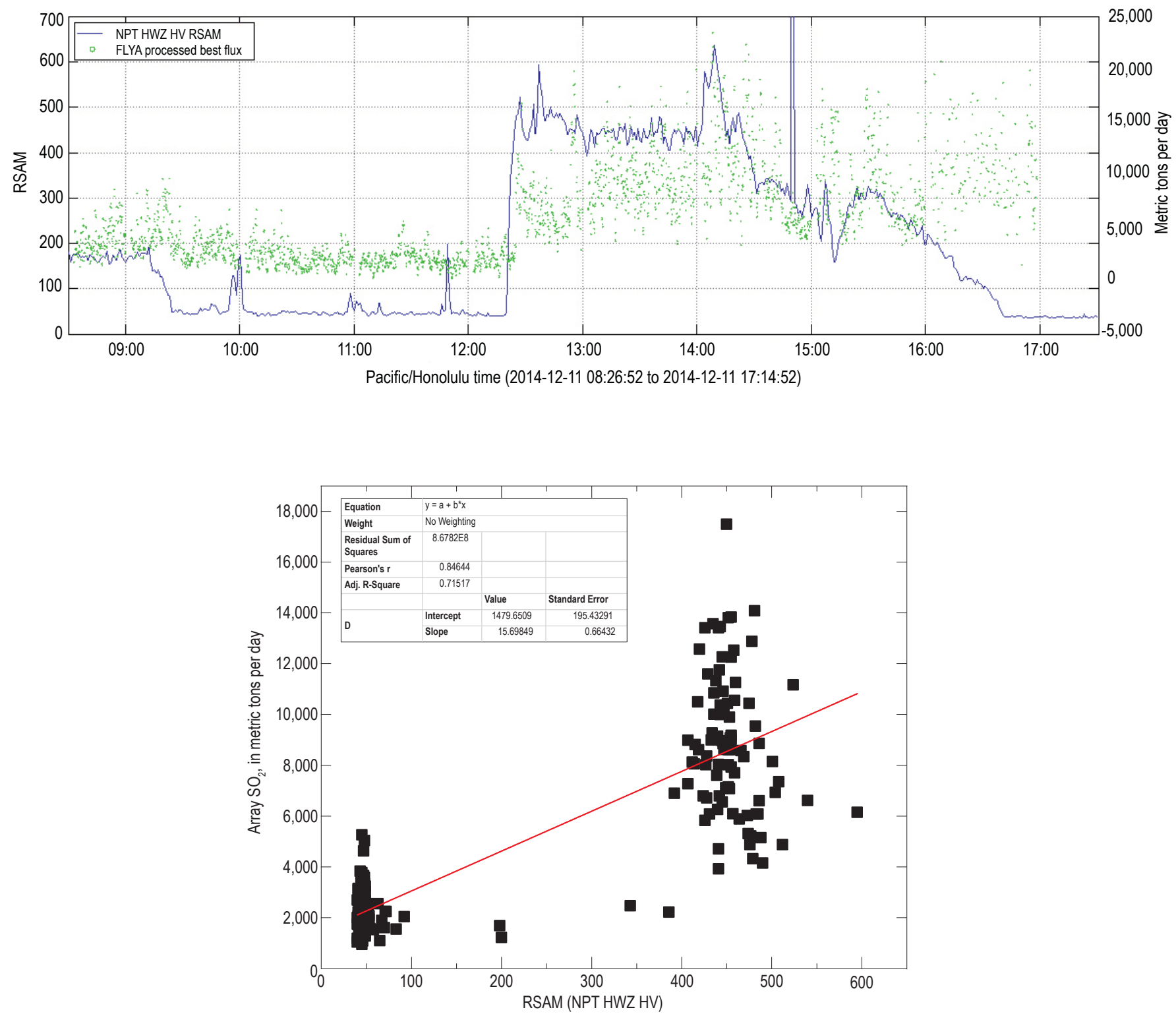

Figure 7. The upper time-series plot shows summit $\mathrm{SO}_{2}$ emissions estimated using the FLYSPEC array in green and the real-time seismic amplitude measurement (RSAM) in blue on December 11, 2014. The lower graph shows correlation between $\mathrm{SO}_{2}$ emission rate measurements and RSAM. 


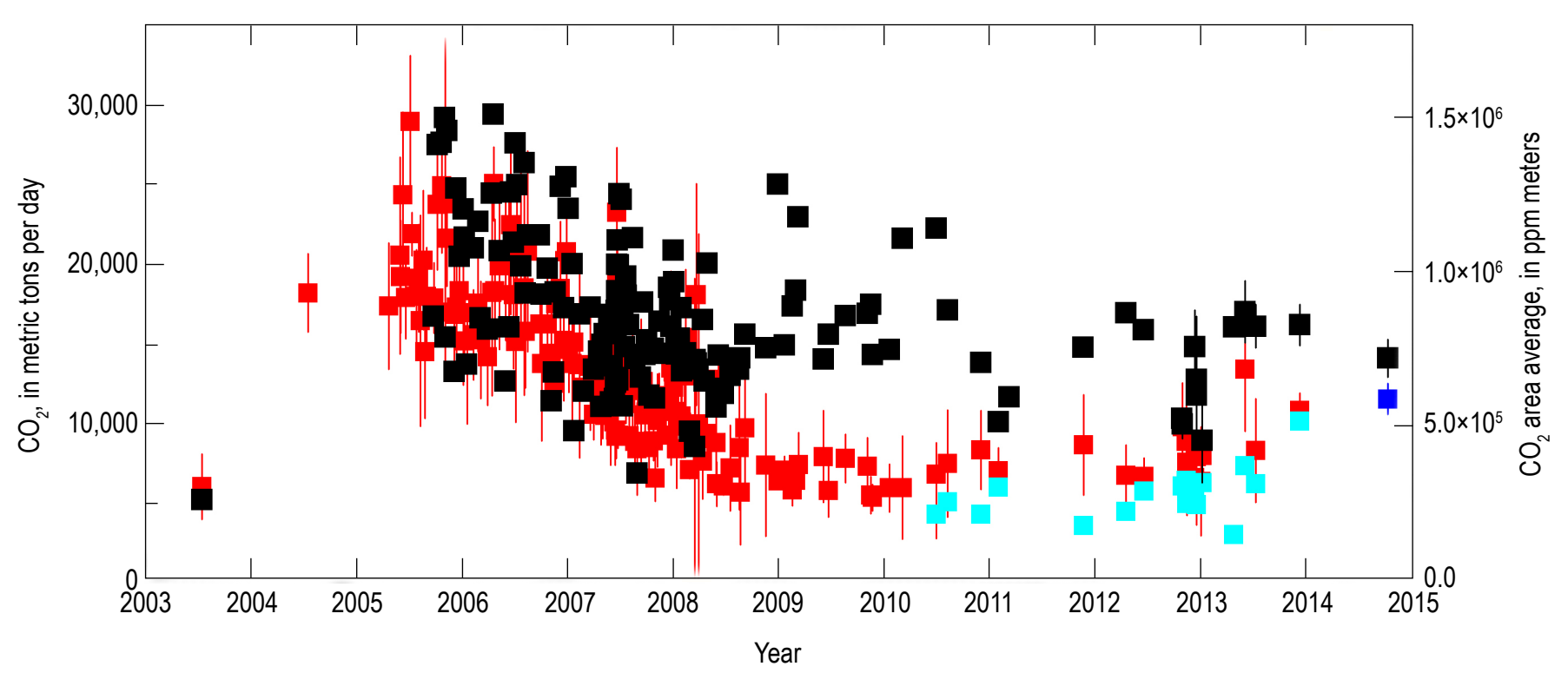

Figure 8. $\mathrm{CO}_{2}$ emission rates in metric tons per day from the summit of Killauea for 2003 to 2014 . The cyan symbols show $\mathrm{CO}_{2}$ calculated using the most grounded $\mathrm{SO}_{2}$ plumes, and may be more representative of relative $\mathrm{CO}_{2}$ emission rates. The dark blue symbol represents the measurements made on October 10 and calculated using the average dual-fit window $\mathrm{SO}_{2}$ emission rate and the maximum $\mathrm{SO}_{2}$ cross-sectional area for the day's collection to calculate $\mathrm{CO}_{2}$ emission rates for each traverse through the plume. The red symbols incorporate all measured data, excluding outliers, and the black symbols show the average crosssectional area of the integrated $\mathrm{CO}_{2}$ plume traversed along Crater Rim Drive.
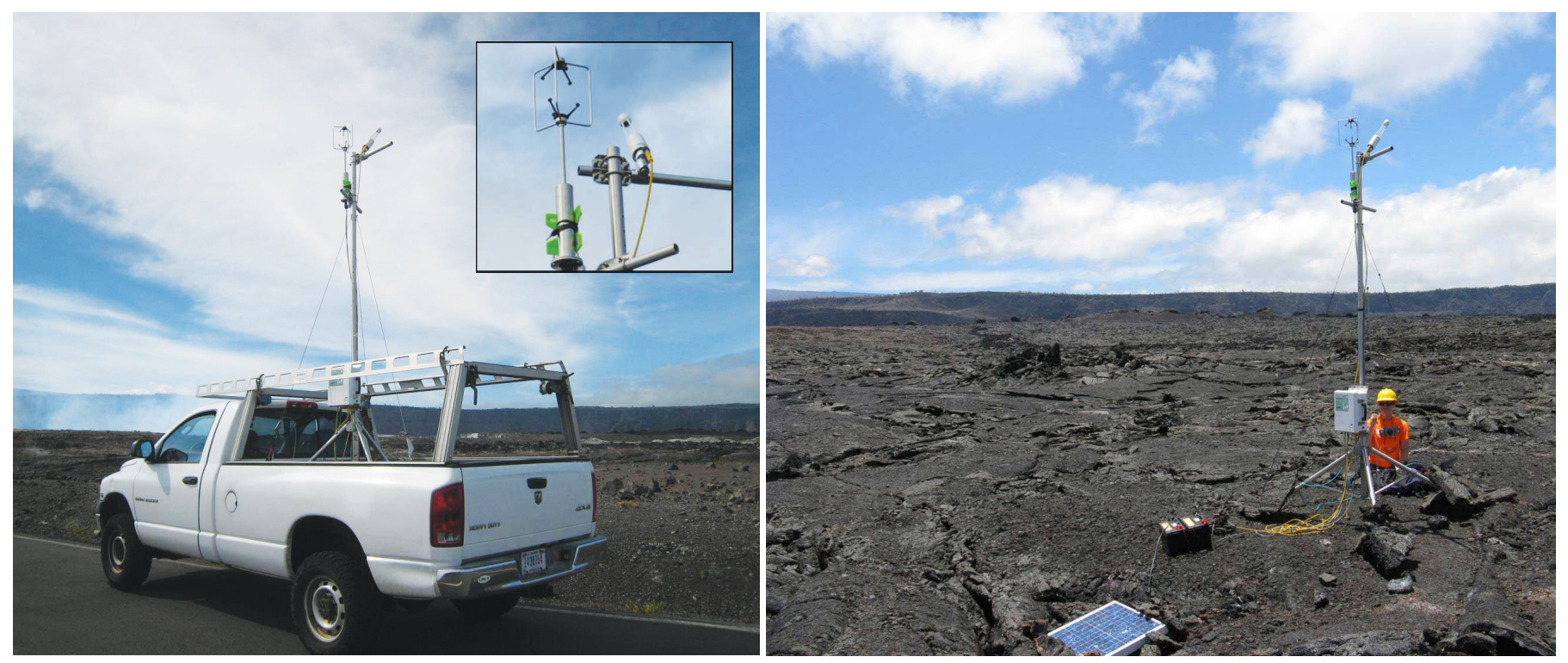

Figure 9. Eddy correlation instrument in mobile mode (left). Multi-hour surveys were conducted where the $\mathrm{CO}_{2}$ plume crosses the road. Instrument in continuous operation mode (right) near center of Kïlauea Caldera. 


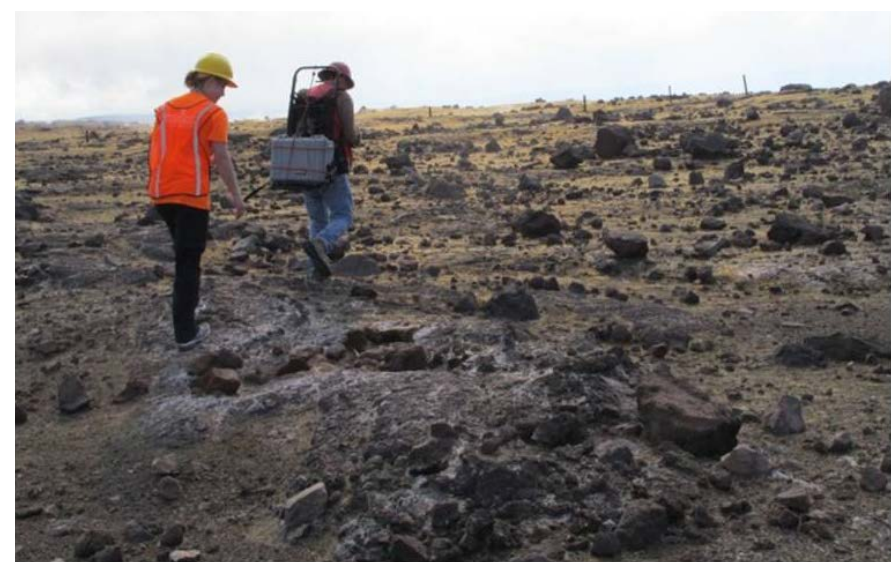

Figure 10. Jeff Sutton and Cindy Werner measuring ambient gas concentrations using the multi-gas system designed and fabricated at the Cascades Volcano Observatory.

\section{Quantifying Summit Plume Characteristics}

Throughout 2014 we continued to monitor the summit plume using a variety of techniques, including multi-species sensorbased time-series measurements and open-path Fourier-transform infrared (FTIR) spectroscopy.

FTIR measurements of the summit plume continued to show the shallow nature of the degassing source, with plume chemistry characterized by low $\mathrm{CO}_{2}$, high $\mathrm{SO}_{2}$, high water, and significant $\mathrm{HCl}$ and $\mathrm{HF}$. The 2014 data were collected using a liquid nitrogencooled mercury-cadmium-telluride (MCT) detector, because the Indium-Antimonide ( $\mathrm{InSb}$ ) detector has been broken since August 2013 (fig. 11).
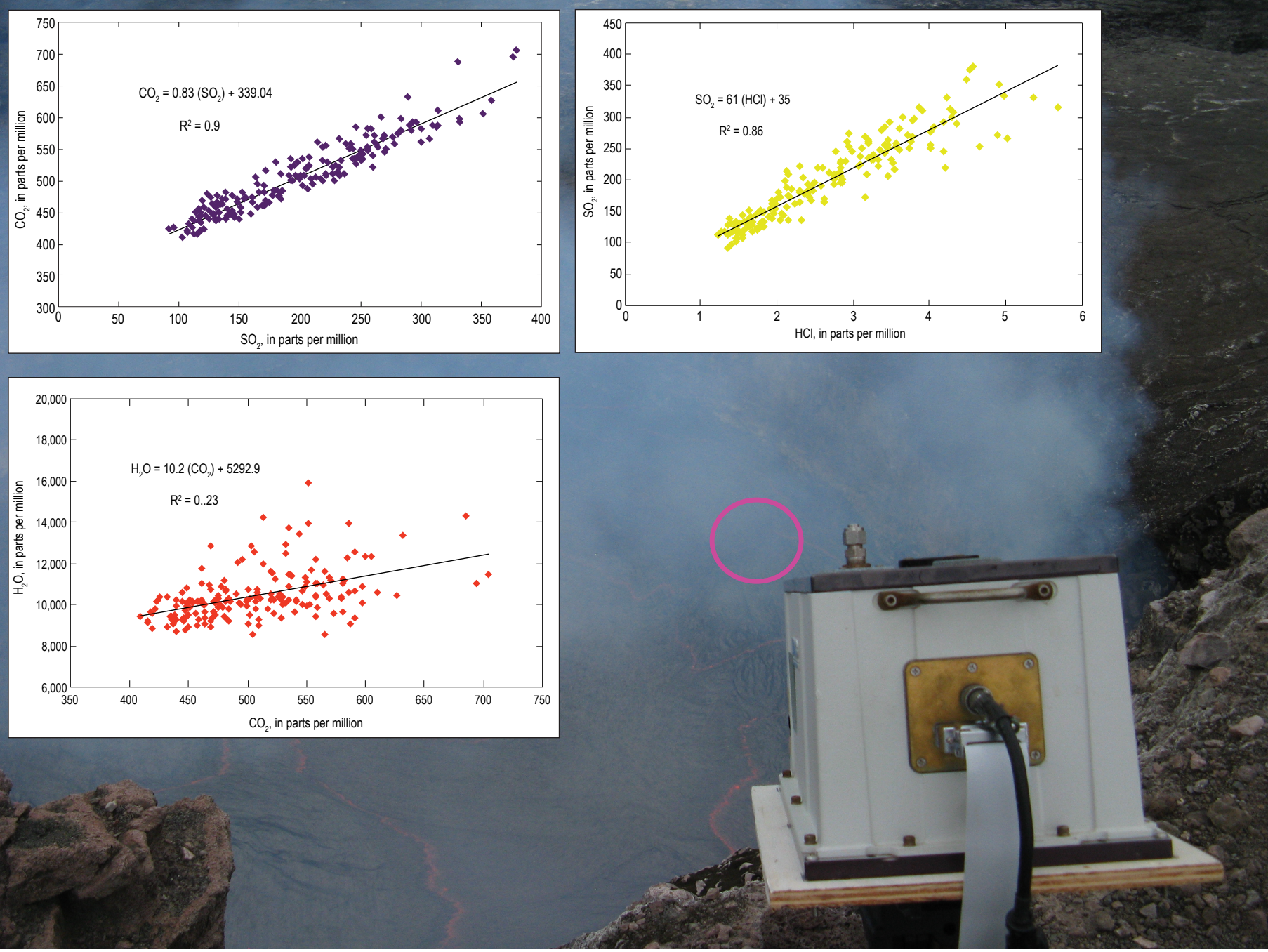

Figure 11. Preliminary FTIR (Fourier-transform infrared spectrometer) results for measurements of the summit gas plume at Kilauea, June 22, 2014. These data were acquired using a liquid-nitrogen-cooled mercury-cadmium-telluride detector on loan from Midac Corporation. These data were collected without a telescope during active lava lake conditions, using the lava surface (within the pink circle) within the Halema'uma'u Overlook crater as a passive infrared source. 
An overview of eruptive gas composition through the years is presented in figure 12 incorporating the 2014 FTIR summit data. These data are consistent with our conceptual model for the current eruptions: pre-eruptive summit degassing, then transport and final gas release on the rift. The summit eruptive gas chemistry in 2014 is similar to that measured in 2013, when summit values were last obtained (table 1).
Figure 12. An overview of eruptive gas composition (during 2008-2014, along with two earlier samples from 1968 and 1983) for rift and summit degassing sources. Preliminary results from the Kīlauea summit on June 22, 2014 (red circle) are similar to 2013 samples. Sample HMM 2008 (pink square), of the Kîlauea summit plume on April 8, 2008, was depleted in $\mathrm{SO}_{2}$ and $\mathrm{CO}_{2}$, which suggests that this event involved magma that had lost much of its $\mathrm{SO}_{2}$ and $\mathrm{CO}_{2}$ prior to eruption. Sample G\&G Pu'u 'O'o (1983 bottle sample results in Gerlach and Graeber,1985, shown by black square) plots notably higher in $\mathrm{SO}_{2}$ than current pre-degassed east rift samples.

\section{Kilauea eruptive gas emissions chemistry}

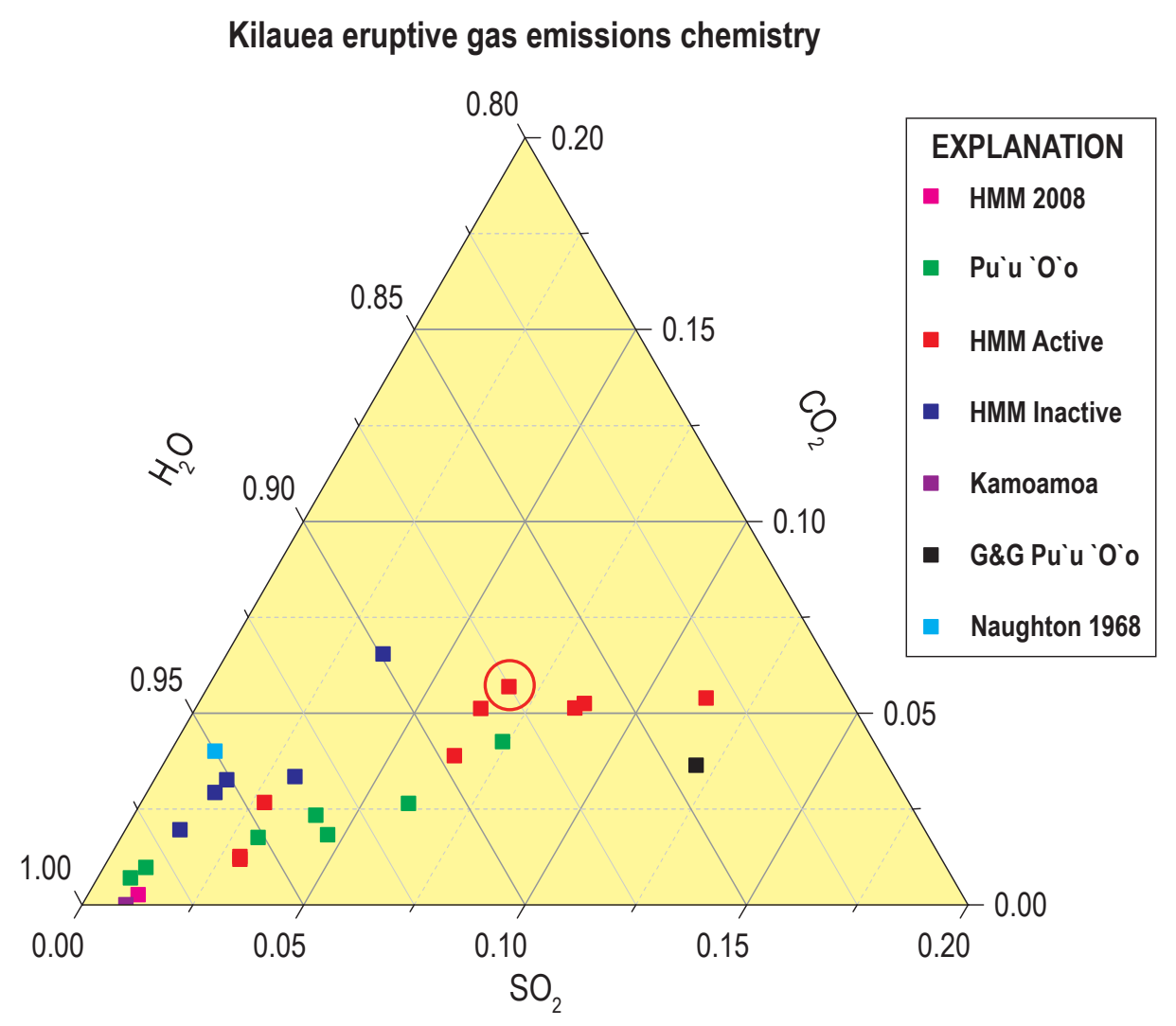

Table 1. Carbon-Sulfur (C/S) ratios from the summit and Pu'u 'Ō'ō vent, Kīlauea Volcano.

\begin{tabular}{|c|c|c|}
\hline Date (month/day/year) & Location & $\mathrm{C} / \mathrm{S}$ \\
\hline $05 / 21 / 2012$ & Summit & 0.5 \\
\hline 09/19/2012 & Summit & $0.9-1.0$ \\
\hline $10 / 24 / 2012$ & Summit & 0.4 \\
\hline $1 / 17 / 2013$ & Summit & 1.1 \\
\hline $1 / 31 / 2013$ & Summit & 0.8 \\
\hline $3 / 5 / 2013$ & Summit & 1.9 \\
\hline $6 / 22 / 2014$ & Summit & 0.8 \\
\hline $05 / 21 / 2012$ & $\mathrm{Pu}^{\prime} \mathrm{u}^{`} \overline{\mathrm{O}}^{`} \overline{\mathrm{o}}$ & 0.5 \\
\hline 09/19/2012 & $\mathrm{Pu} u^{\prime} \mathrm{u}^{`} \overline{\mathrm{O}}^{\prime} \overline{\mathrm{o}}$ & 0.2 \\
\hline $11 / 1 / 2012$ & $\mathrm{Pu}^{\prime} \mathrm{u}^{`} \mathrm{O}^{\prime} \overline{\mathrm{o}}$ & 1.1 \\
\hline $1 / 31 / 2013$ & $\mathrm{Pu}^{\prime} \mathrm{u}^{`} \mathrm{O}^{\prime} \overline{\mathrm{o}}$ & 0.5 \\
\hline
\end{tabular}




\section{East Rift Zone $\mathrm{SO}_{2}$ Emissions: Summit Pre-Eruptive Degassing Produces Lower Emissions from East Rift Zone Vents}

Rift emissions for 2014 decreased very slightly during the first half of the year, increased with the onset of the June 27 lava flow, and then declined through the remainder of the year. Rift emissions were consistently less than summit emissions during 2014 , totaling $\sim 120,000$ metric tons. This is roughly equivalent to emissions reported in 2013, and among the lowest recorded since the East Rift Zone eruption began in 1983 (fig. 13). The low $\mathrm{SO}_{2}$ emissions from the rift are due at least partially to pre-eruptive degassing at the summit.

\section{Gas-Derived East Rift Zone Lava Effusion Rates}

Using existing data to estimate the gas-derived lava effusion rate on the East Rift Zone provides important supplemental information on eruption rates. Lava effusion rate can be calculated from gas data using the ratios of weight fractions of $\mathrm{CO}_{2}$ and $\mathrm{SO}_{2}$ dissolved in the melt $\left(\mathrm{WCO}_{2} / \mathrm{WSO}_{2}\right)$, the ratios of the measured number of moles of $\mathrm{CO}_{2}$ and $\mathrm{SO}_{2}\left(\left[\mathrm{CO}_{2}\right] /\left[\mathrm{SO}_{2}\right]\right)$ and the ratio of the formula weights for $\mathrm{CO}_{2}$ and $\mathrm{SO}_{2}\left(\mathrm{fwCO}_{2} / \mathrm{fwSO}_{2}\right)$.

$$
\frac{\mathrm{WCO}_{2}}{\mathrm{WSO}_{2}}=\frac{\left[\mathrm{CO}_{2}\right]}{\left[\mathrm{SO}_{2}\right]} \times \frac{f \mathrm{wCO}}{\mathrm{fwSO}_{2}}
$$

The calculated weight fraction of $\mathrm{SO}_{2}$ along with the $\mathrm{SO}_{2}$ emission rate can then be used to quantify the amount of magma that has degassed. Using C/S ratios measured on the East Rift Zone from 2011-2013 that take into account summit pre-eruptive degassing, and current $\mathrm{SO}_{2}$ emissions data produced effusion rates similar to concurrent estimates using very low frequency (VLF) electromagnetic geophysical techniques and other methods. Time series dating back to 2011 show that changes in effusion rates estimated from gas emission measurements coincide with effusive events such as the Kamoamoa fissure eruption, the August 2011 breakout flow, the Peace Day fissure eruption, and the June 27th flow (fig. 14). Effusion rate estimates were calculated using a range of $\mathrm{C} / \mathrm{S}$ ratios because access to the east rift degassing siteand thus contemporary data — was limited during 2014 (fig. 15).

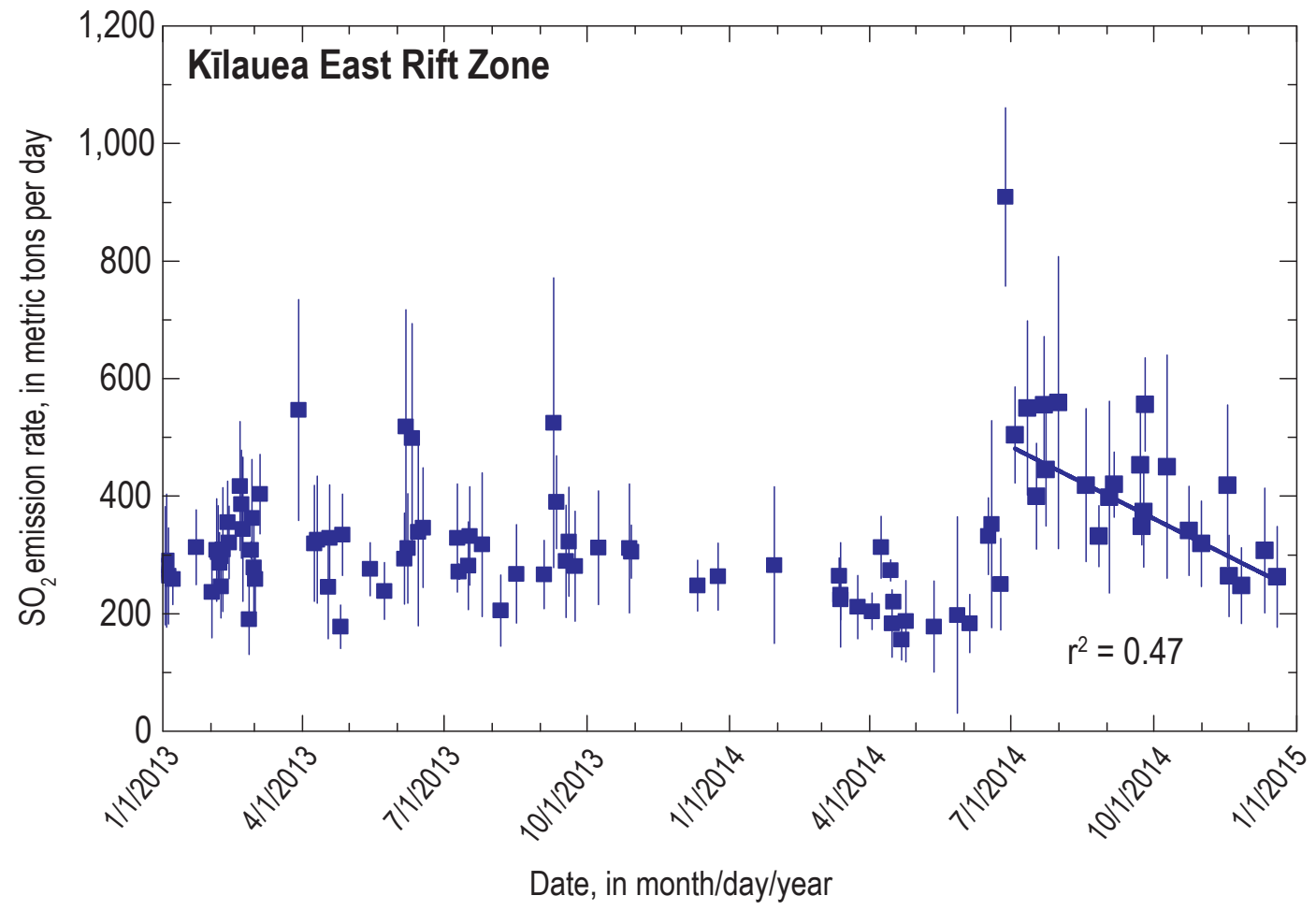

Figure 13. Daily average $\mathrm{SO}_{2}$ emissions for the years 2013 and 2014 as measured along Chain of Craters Road under trade-wind conditions. Vertical lines are standard deviations of all traverses on a single day. Blue line is linear fit to data following the onset of the June 27 lava flow. 
Figure 14. Lava effusion rates for 2011-2014 calculated using estimated $\mathrm{CO}_{2}$ weight fraction dissolved in melt, historical $\mathrm{C} / \mathrm{S}$ ratio data, and $\mathrm{SO}_{2}$ emission rates. Effusion rates, based on recent verylow-frequency (VLF) electromagnetic data, are plotted as black squares.

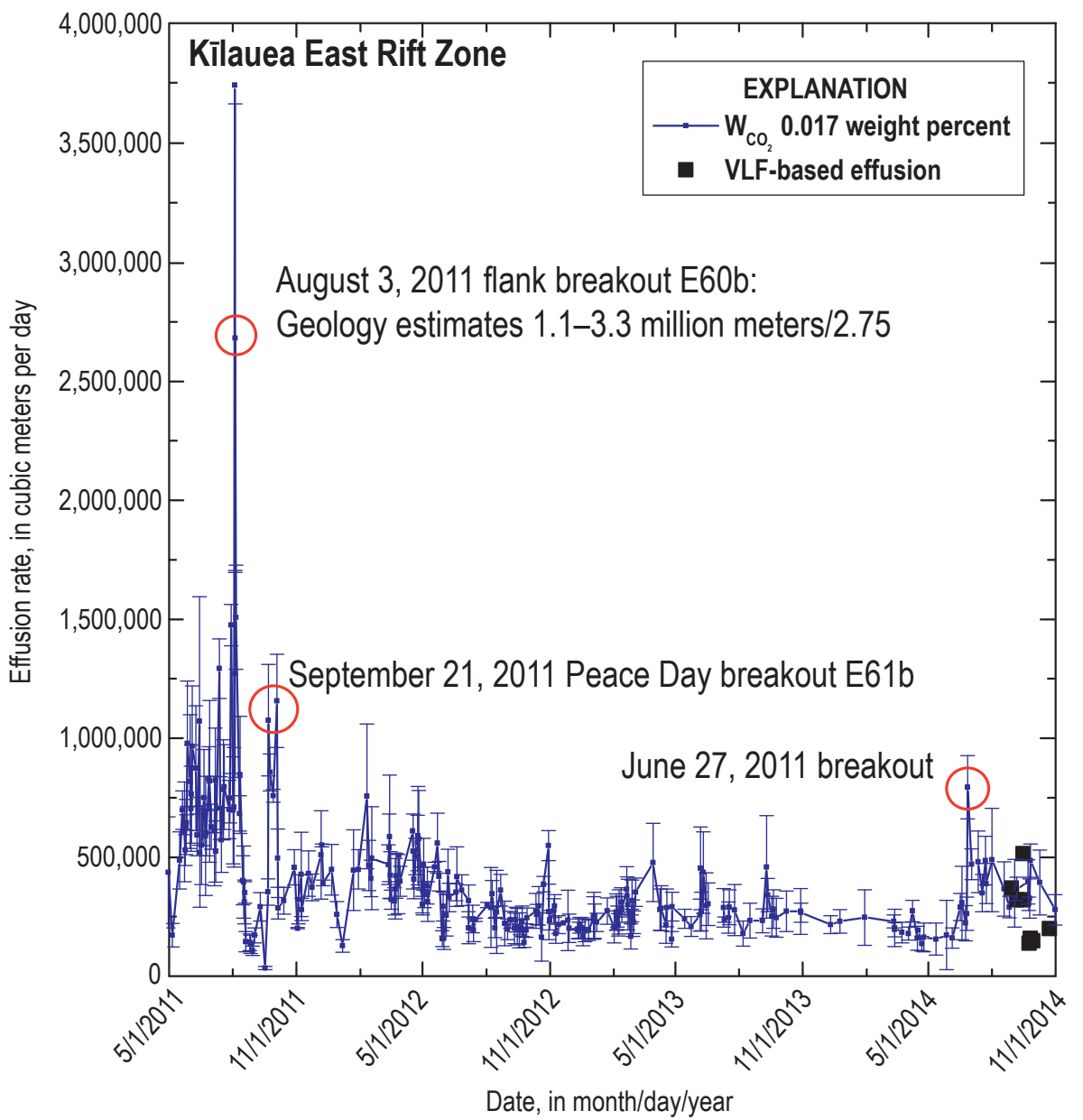

Figure 15. Lava effusion rate calculated using an estimated $\mathrm{CO}_{2}$ weight fraction of 0.017 percent dissolved in melt, a range of $\mathrm{C} / \mathrm{S}$ ratio data, and $\mathrm{SO}_{2}$ emission rate for 2014. Constraining the $\mathrm{C} / \mathrm{S}$ ratio will improve gas-derived effusion rate estimates.

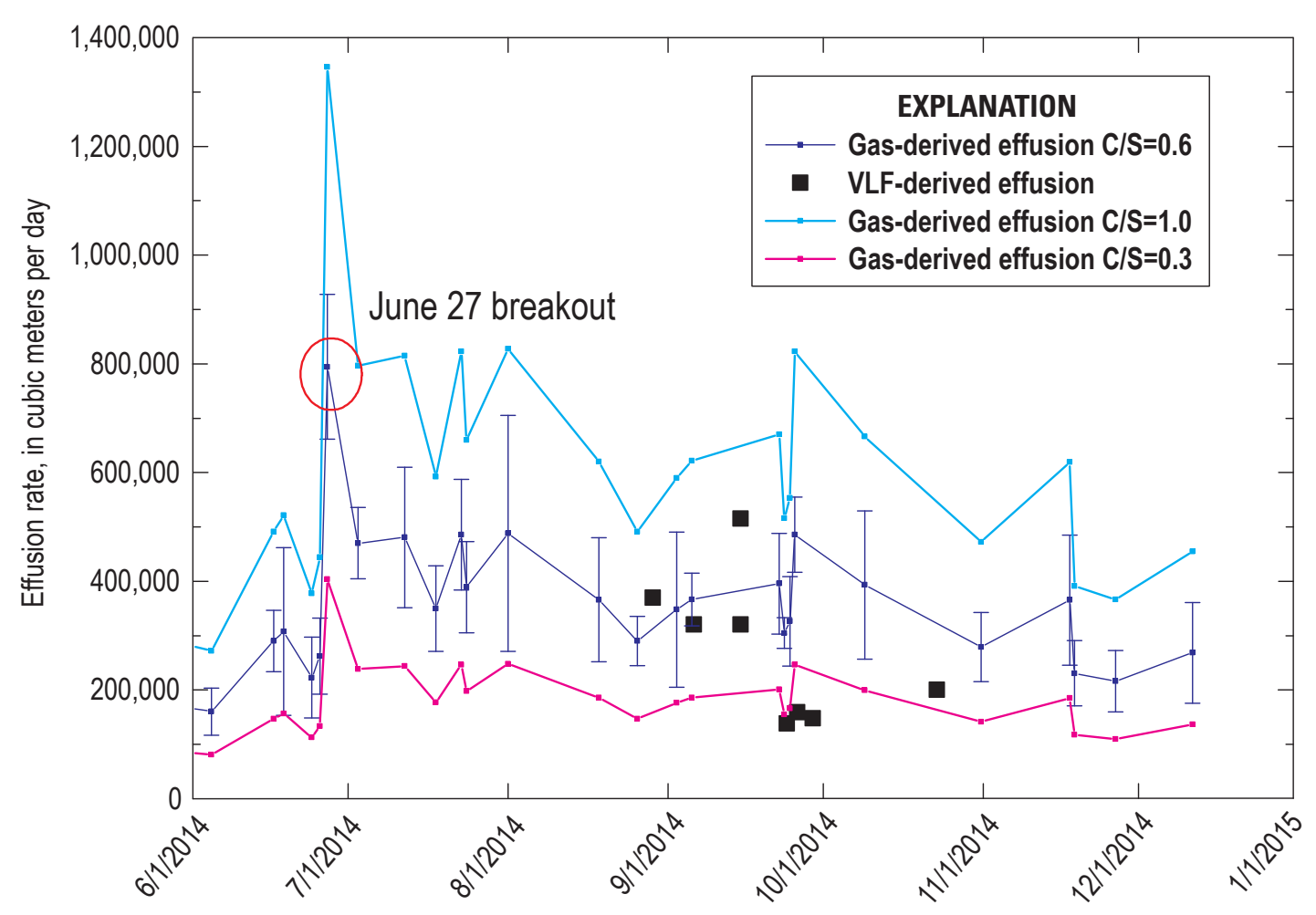

Date, in month/day/year 


\section{Gas Hazards in 2014}

\section{Kapāpala Ranch}

We continued to operate the low-resolution $\mathrm{SO}_{2}$ sensor and rain collector network on Kapāpala Ranch this year. During the early years of activity at the Halema'uma' $u$ Overlook vent, the ranch's livestock exhibited runny eyes, respiratory issues, weight loss, and tooth mottling and degradation (possibly indicating fluorosis). Additionally, fences and other metal infrastructure on the ranch were deteriorating more rapidly than before the summit eruption began. Data show $\mathrm{SO}_{2}$ concentrations up to $5 \mathrm{ppm}$ measured during 2014. These data represent a one-second measurement taken every minute. Hazard monitoring and communication with the ranch managers, veterinarians, and public health officials is ongoing.

\section{ARRA-Funded Networks}

The low- and high-resolution $\mathrm{SO}_{2}$ monitoring sites, originally established with funding through the American Recovery and Reinvestment Act (ARRA), have been incorporated into our regular gas monitoring network. The original network comprised 33 low-resolution $\mathrm{SO}_{2}$ sites, 11 high-resolution $\mathrm{SO}_{2}$ sites, $3 \mathrm{PM}_{2.5}$ sites, and 10 fixed-view UV spectrometer systems (the FLYSPEC array) for measuring $\mathrm{SO}_{2}$ column amounts and calculating nearreal-time emission rates. Downsizing of the network was carried out in 2013, and by the end of 2014, we had 12 low-resolution $\mathrm{SO}_{2}$ sites, 7 high-resolution $\mathrm{SO}_{2}$ sites, and 10 upward-looking spectrometer systems operating (the FLYSPEC array). The HVO ARRA ambient air and routine emission-rate data are used for model input and validation for the Vog Measurement and Prediction Project (VMAP) $\mathrm{SO}_{2}$ and particle forecast model (http://weather.hawaii.edu/vmap/).

\section{Highlights from Air-Quality-Related Activities in Hawai'i Volcanoes National Park}

- Ambient $\mathrm{SO}_{2}$ concentrations measured downwind of Halema'uma'u continued to reach very high levels (>100 ppm) along Crater Rim Drive near the Halema'uma'u parking lot, warranting continued caution along Crater Rim Drive in 2014 (fig. 16). We continued to brief community groups and County, State, and Federal agencies on the changing gas hazard conditions associated with the ongoing eruptions.

- The National Park Service's ambient air quality stations, located at HVO behind the Kîlauea Visitor Center, continued to record periods of hazardous air quality due to the ongoing eruptions. Days when $\mathrm{SO}_{2}$ exceeded the 24-hour health standard for 2001-2014 are shown in figure 17. The National Park Service (NPS) continued their closure of highly impacted areas of the park during poor air-quality episodes. The Kinlauea Visitor Center and the Jaggar Museum closed to the public when $\mathrm{SO}_{2}$ concentrations exceeded $1 \mathrm{ppm}$ for 6 consecutive 15-minute periods ( 1.5 hours), $3 \mathrm{ppm}$ for 3 consecutive 15-minute averages (45 minutes), or $5 \mathrm{ppm}$ for one 15 -minute average. NPS highresolution $\mathrm{SO}_{2}$ analyzers located at the visitor centers operated in the extended 0-10 ppm range. While the U.S. Environmental Protection Agency (EPA) replaced the 24-hour standard with a 1-hour health standard in 2010 , the 24-hour exceedances continue to be relevant for historical perspective.

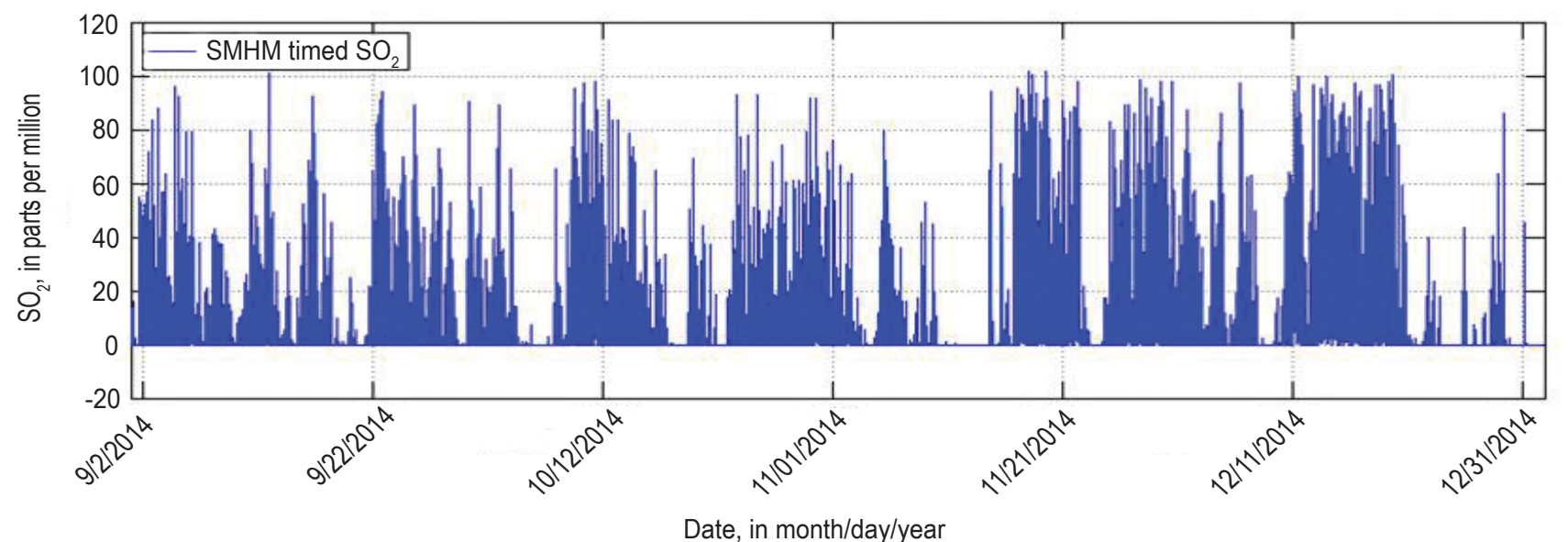

Figure 16. Ambient $\mathrm{SO}_{2}$ concentrations measured on the west edge of the Halema'uma'u parking lot during the final quarter of 2014. The IDLH (immediately dangerous to life or health) threshold for $\mathrm{SO}_{2}$ is set by the National Institute for Occupational Safety and Health at $100 \mathrm{ppm}$. The IDLH is defined as "an atmospheric concentration that poses an immediate threat to life or would cause irreversible or delayed adverse health effects or would interfere with an individual's ability to escape from a dangerous atmosphere" (29 CFR 1910.120). 

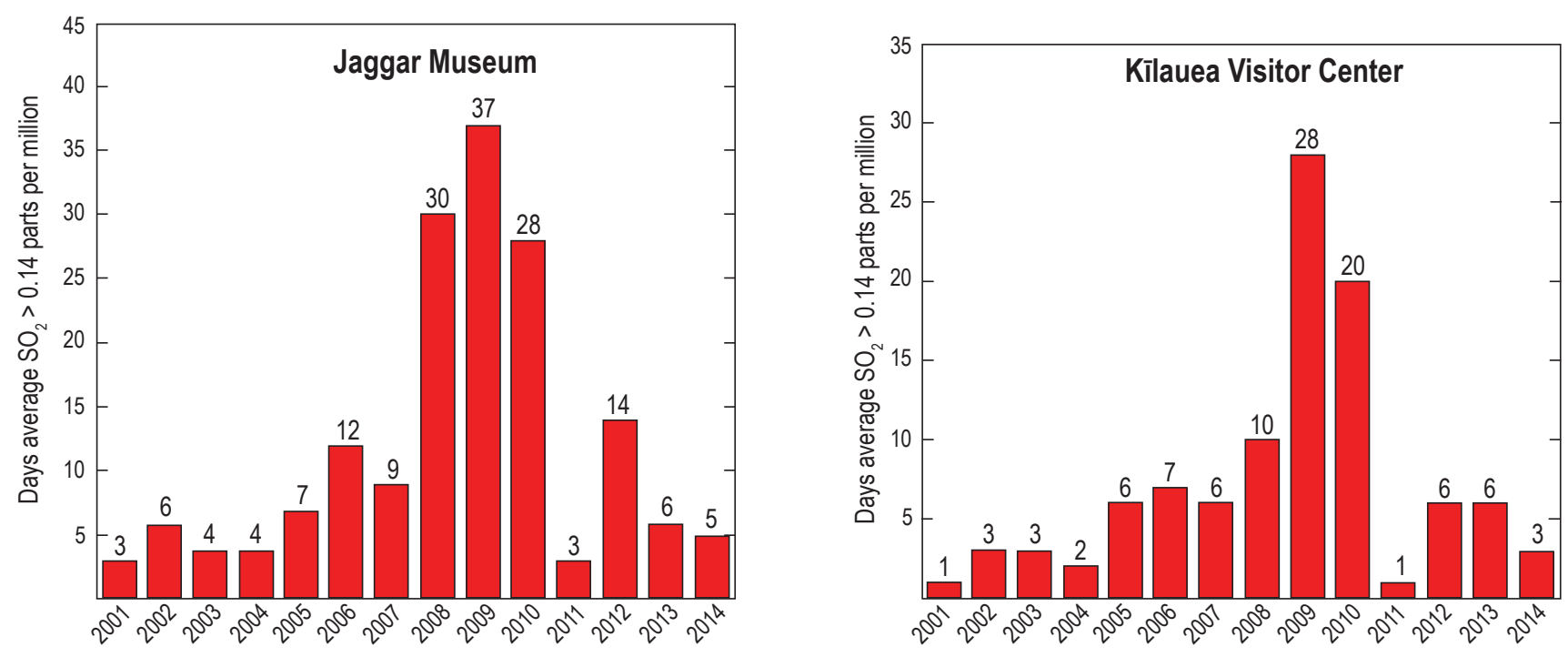

Figure 17. Number of days each year that the 24-hour ambient air quality standard was exceeded at the Jaggar Museum (left) and Kïlauea Visitor Center (right) monitoring stations, both located at the Kïlauea summit.

- The SHARP analyzer (Synchronous Hybrid Ambient Real-time Particle Monitor) installed at HVO continued to have problems in 2014, and little valid particle data were captured. Limited data available for January-February 2014 shows that the national ambient air quality standard for particles less than 2.5 microns in average diameter $\left(\mathrm{PM}_{2.5}\right)$ was not exceeded during this period. The $\mathrm{PM}_{2.5}$ standard of $35 \mu \mathrm{g} / \mathrm{m}^{3}$ is based on a 24-hour average. Hourly averages reached $66 \mu \mathrm{g} / \mathrm{m}^{3}$ during periods of the poorest air quality, but the maximum 24-hour average observed was $31 \mu \mathrm{g} / \mathrm{m}^{3}$. The EPA considers 24-hour average concentrations of $36-65 \mu \mathrm{g} / \mathrm{m}^{3}$ to be unhealthy for sensitive groups, $66-150 \mu \mathrm{g} / \mathrm{m}^{3}$ is unhealthy, $151-250 \mu \mathrm{g} / \mathrm{m}^{3}$ is very unhealthy, and $251-500 \mu \mathrm{g} / \mathrm{m}^{3}$ is considered hazardous.

\section{Mauna Loa Continuous Gas Monitor}

No notable changes in $\mathrm{SO}_{2}$ or $\mathrm{CO}_{2}$ gas concentrations were recorded by the Moku'āweoweo gas monitor. There was a small fumarole temperature excursion between early October and late November 2014 in which temperatures increased from $\sim 72{ }^{\circ} \mathrm{C}$ to $\sim 79^{\circ} \mathrm{C}$. This is in contrast to the typical seasonal changes that are observed at this sitefumarole temperature typically decreases slightly during the winter months. As 2014 came to a close, fumarole temperature was decreasing and was recorded at $77^{\circ} \mathrm{C}$. No maintenance was performed on the station this year.

\section{Ongoing and Benchmark Activities in 2014}

- We continued to guide and assist instrument repair and provided calibration gases and technical support to research assistants with University of Hawai ${ }^{\circ}$ i, Mānoa John A. Burns School of Medicine (JABSOM) in support of community-based health studies.

- We continued to participate in interagency discussions regarding vog. Year 2014 was notable in our increased organizational role for the multi-agency group that includes EPA, Centers for Disease Control (CDC), Hawaii Department of Health, NPS, University of Hawai' $i$, and USGS. We facilitated the inclusion of Claire Horwell, of Durham University in the United Kingdom, who will be working on a project to examine vog intervention strategies, and the relevance of official vog advice and messaging.

- We participated in organizing and teaching the 2014 International Training Program course for the Center for the Study of Active Volcanoes.

- We continued to work under the CDC grant (project title: Hawaii Island Lung Assessment and Scientific Studies, or HICLASS) to further study the relationship between volcanic emissions and community health. As study cooperators working with primary investigator Dr. Elizabeth Tam (University of Hawai'i, Mānoa, 
John A. Burns School of Medicine), we were able to make significant headway on re-evaluating the 2008-2013 summit FLYSPEC data. Working with colleagues Keith Horton and Harold Garbeil (University of Hawai'i, Mānoa), who developed an algorithm to reanalyze previously collected spectra, we have provided improved $\mathrm{SO}_{2}$ column path values and emission rates. These data are being used by health researchers to model human exposures.

- HVO gas studies were presented at the Plume Imaging and IAVCEI-CCVG (International Association of Volcanology and Chemistry of the Earth's Interior Commission on Chemistry of Volcanic Gases) workshops in Chile, and at the fall meeting of the American Geophysical Union.

- We helped organize and support field measurements of $\mathrm{CO}_{2}$ release at Horseshoe Lake and Mammoth Mountain, Calif.

\section{Acknowledgments} volunteers:

We are particularly grateful to the 2014 gas geochemistry

- Mary Barr, recently retired chemist from Los Alamos National Laboratory

- Lora Beatty, recent geology graduate of Western Washington University (B.S.)

- Mike Cappos, recent earth science graduate of Pennsylvania State University (B.S.)

- Isabelle Taylor, recent graduate of Bristol University's volcanology program (M.Sc.)

\section{References Cited}

Beirle, S., Hörmann, C., Penning de Vries, M., Dörner, S., Kern, C., and Wagner, T., 2014, Estimating the volcanic emission rate and atmospheric lifetime of $\mathrm{SO}_{2}$ from spacea case study for Kīlauea volcano, Hawai 'i: Atmospheric Chemistry and Physics, v. 14, p. 8,309-8,322, doi:10.5194/ acp-14-8309-2014, 2014.

Gerlach, T., and Graeber, E., 1985, Volatile budget of Kilauea volcano, Nature, v. 313, p. 273-277.

Kern C., Deutschmann T., Werner C., Sutton A.J., Elias T., Kelly P.J., 2012, Improving the accuracy of $\mathrm{SO}_{2}$ column densities and emission rates obtained from upwardlooking UV-spectroscopic measurements of volcanic plumes by taking realistic radiative transfer into account: Journal of Geophysical Research, v. 117, D20302, doi:10.1029/2012JD017936.

Werner, C., Kern, C., Sutton, A.J., Elias, T., Hauri, E., Kelly, P., 2014, Mapping the spatial distribution of $\mathrm{CO}_{2}$ release from Kīlauea Volcano, Hawaii, USA [abs.]: American Geophysical Union, fall meeting abstract no. V41D-04, accessed July 6, 2015, at https://agu.confex.com/agu/fm14/ meetingapp.cgi\#Paper/31107. 
Menlo Park Publishing Service Center, California Approved for publication on December 28, 2015 Edited by Claire M. Landowski

Layout by Cory Hurd 


\section{אוe \\ א}

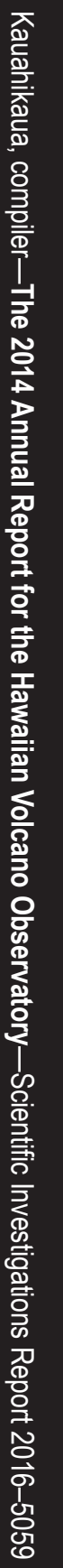

